\title{
The use of Internet resources by midwives in
}

\section{New Zealand}

by

\section{Sarah Stewart}

\author{
A thesis \\ submitted to the Victoria University of Wellington \\ in partial fulfilment of the requirements for the degree of \\ Master of Arts (Applied) \\ in Midwifery
}

Victoria University of Wellington 


\begin{abstract}
The Internet is growing every day as a source of knowledge and medium for exchange of information. Midwives are beginning to recognise its potential for networking and collaboration, as well as a research tool for accessing evidence-based information that can be utilised in practice. This thesis explores the use of the Internet by midwives in New Zealand. It describes a pilot study, which took the opportunity to trial the use of the Internet as a research tool. The pilot study also tested a survey designed to discover how midwives regard and utilise the potential of the Internet to revolutionise the provision of maternity care. The sample for this study was a convenience sample of 54 midwives working in New Zealand. The midwives were invited by personal e-mail to access the web site and complete the questionnaire. The data were then transferred by electronic transmission into the research database, and analysed by SPSS computer software. The data generated were nominal and descriptive statistics were used.
\end{abstract}

This pilot study has shown that there is a population of midwives in New Zealand who regularly use the Internet for searching information, which they utilise in their professional practice, and pass onto colleagues and midwifery clients. Respondents were recruited to the study by way of 'snowballing.' One hundred and ten e-mails were sent out inviting midwives to participate in the study. They were also asked to pass on the invitation e-mail to as many colleagues as possible. 54 midwives completed and submitted the questionnaire. 
Major findings were that respondents were utilising the Internet to find information for themselves and women in their care, as well as for communication and collaboration. Respondents utilised Internet resources such as e-mail discussion lists, personal web sites and online newsletters. They were also very enthusiastic for as many resources as possible to be made available on the Internet such as electronic claiming, midwifery education programs and online mentoring. The main barriers to use of the Internet were insufficient time and training.

This pilot study has provided valuable lessons for the shaping of a national survey of midwives in New Zealand and their use of the Internet. It has also generated important information about the use of the Internet as a tool for research. In order to gather more detailed information, a national study should include midwives who do not use the Internet. This will require reverting to more traditional methods of data collection such as paper survey, to increase response rates. 


\section{Acknowledgements}

To husband Mark, who has followed me around the world. Thank you for all your support during the ten years that it has taken me to get to this point, and letting me buy a new computer!

To Ellen and Andrew, my children who were good enough to leave home for seven weeks so I could write this thesis in peace!

To Maralyn Foureur, my supervisor who has always encouraged and motivated me, as well as help me to see the issues with much more clarity. I hope that one day I will have the same inspiring effect on my students. To Kathy Nelson, who supported me in the final stages.

To Sheridan Massey, who has shown me endless patience in helping me to use SPSS, and analyse statistics. How you have maintained a sense of humour while trying to explain 'probability' to me, I'll never know.

To Gareth Bowden (Bowen Web Design), who saved my life. What more can I say!

A big 'thank you' to the members of the AOIR and Midwifery research discussion lists, who responded to my many pleas for help. 
Lastly but most important, the midwives who participated in this study. Without you there would be no thesis. Thank you all for your generosity and enthusiasm shown in taking part in this research.

The development work of this study was supported by the Research and Development Committee, Otago Polytechnic. 


\section{Table of Contents}

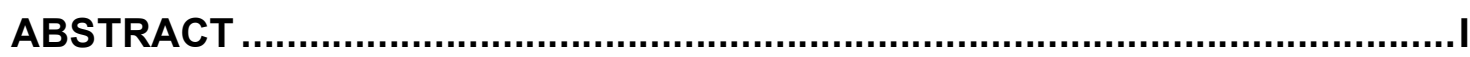

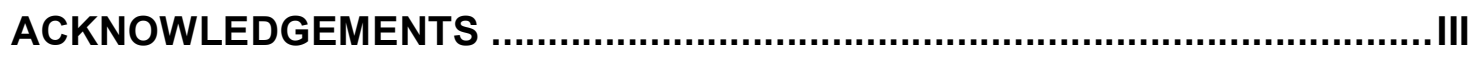

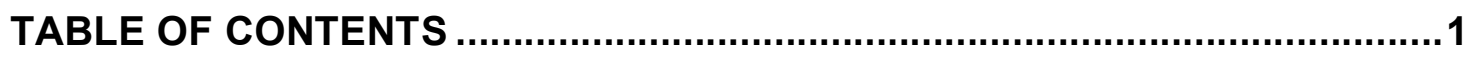

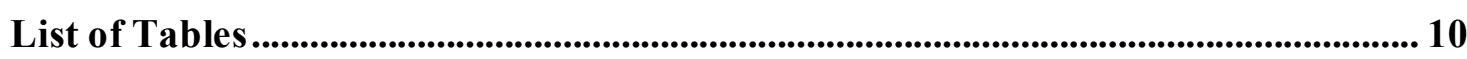

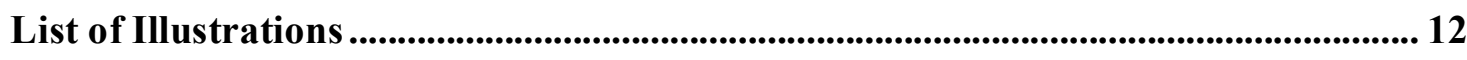

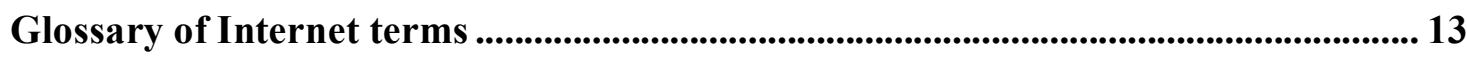

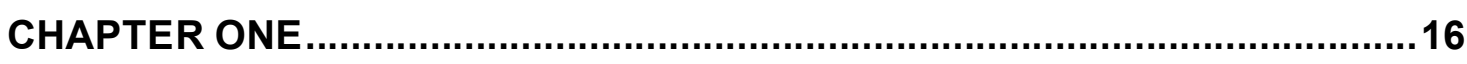

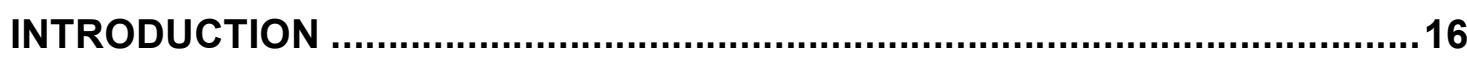

$1.0 \mathrm{My}$ interest in the Internet.................................................................................. 16

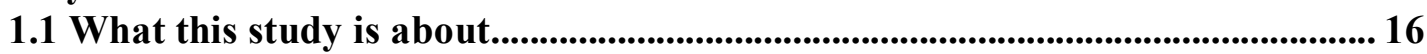

1.2 The Internet as source and tool for research ......................................................... 16

1.3 Discovery of the Internet........................................................................................................ 16

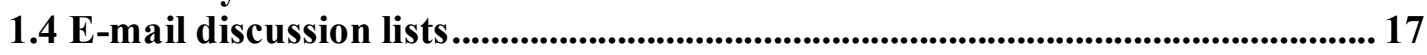

1.5 Membership of discussion lists........................................................................................ 18

1.6 New Zealand Midwives' List............................................................................... 19

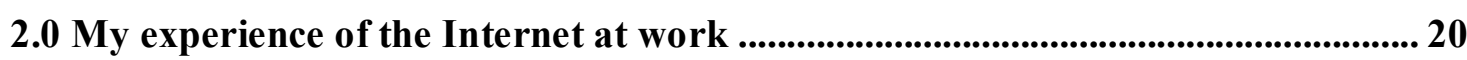

2.1 Use of Internet in the role of midwifery lecturer ........................................................ 20

2.2 Use of Internet in the role of midwifery practitioner ............................................... 21

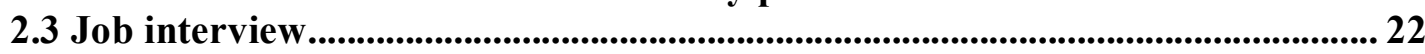

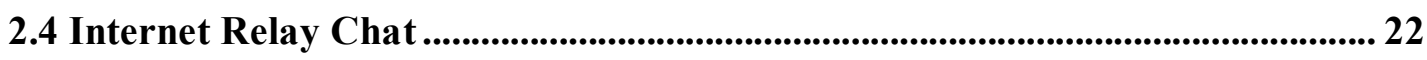

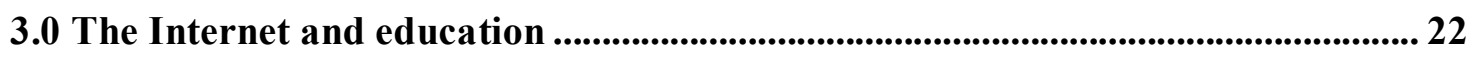

3.1 Cost of accessing resources............................................................................................. 22

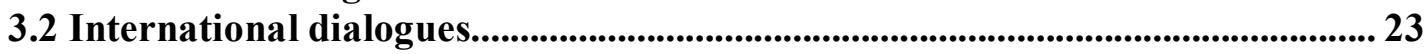

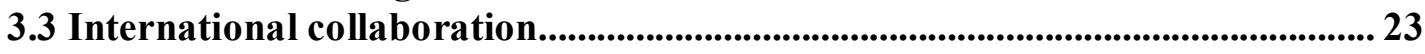

4.0 New Zealand midwives and their use of Internet resources...................................24

4.1 Questions about midwives and their use of the Internet ................................... 24

4.2 Significance of this study ........................................................................................24

4.3 Pilot for national study ............................................................................................................. 25

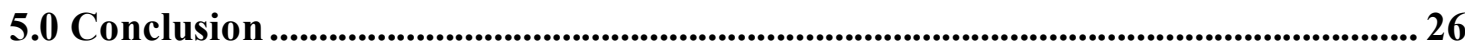

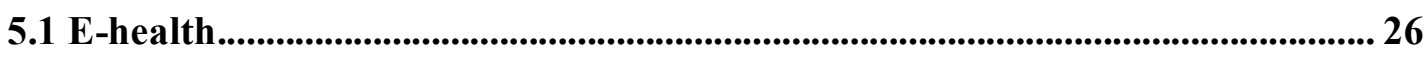




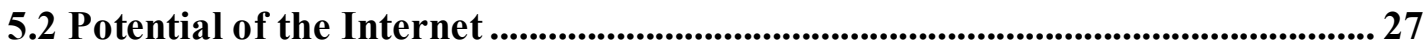

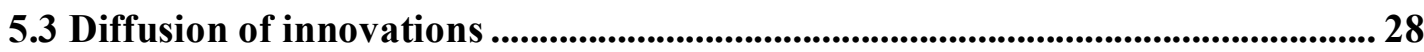

5.4 Structure of the thesis.............................................................................................. 29

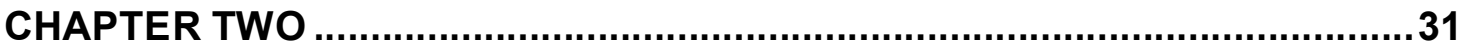

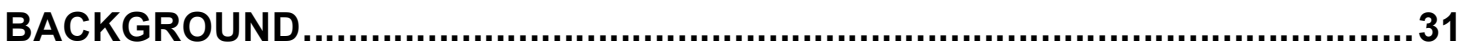

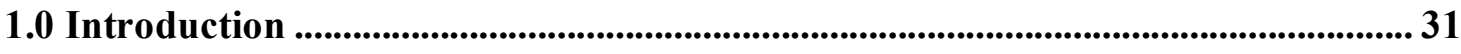

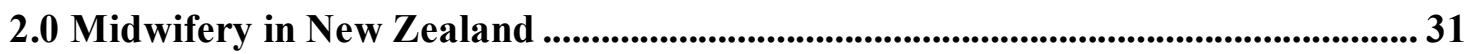

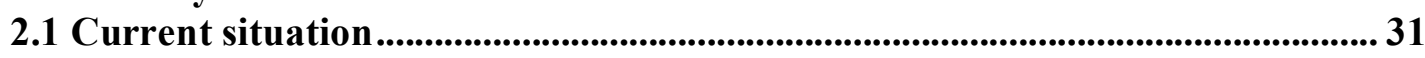

2.2 Lead Maternity Carer ........................................................................................ 32

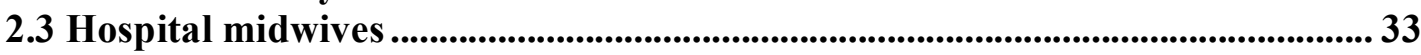

2.4 Midwifery education................................................................................................................... 33

2.5 Potential of the Internet for midwives ............................................................... 33

3.0 The development of the Internet........................................................................................... 35

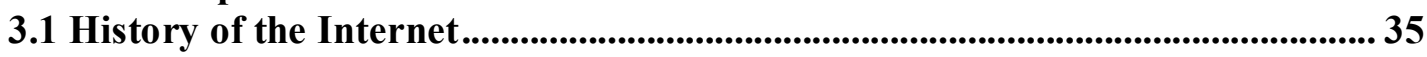

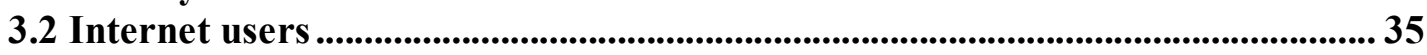

3.3 Access to the Internet ........................................................................................................ 36

4.0 Possibilities of e-health ................................................................................................................37

4.1 Health consumers and the Internet ........................................................................... 37

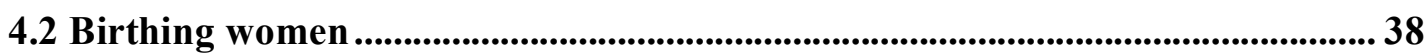

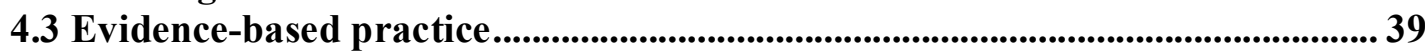

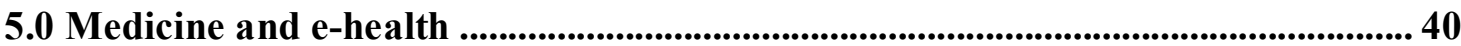

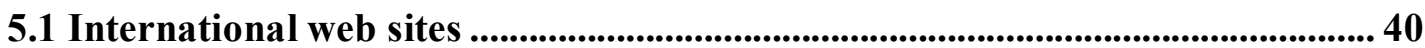

5.2 Medicine and the Internet in New Zealand .........................................................42 42

5.3 Effect of the Internet on relationship of consumers and health professionals $\mathbf{4 3}$

5.4 Guidelines for dealing with Internet-literate patients............................................. 44

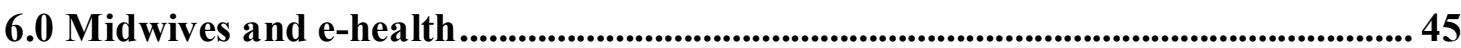

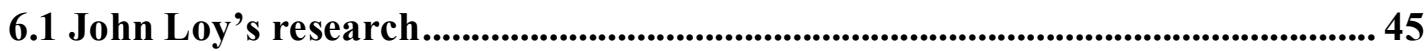

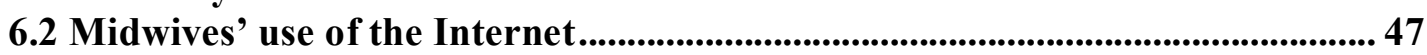

6.4 Midwifery education on the Net .........................................................................4 47

7.0 Internet resources that are available to midwives and support.............................49

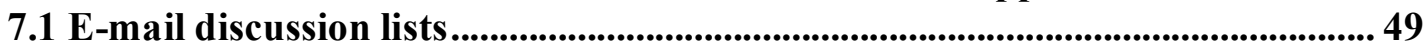

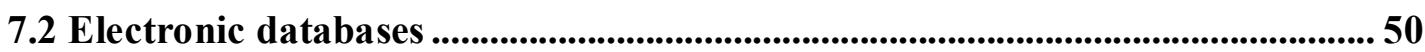

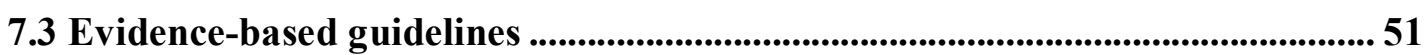

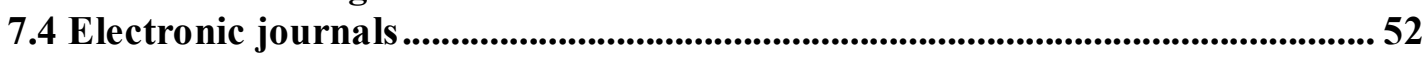

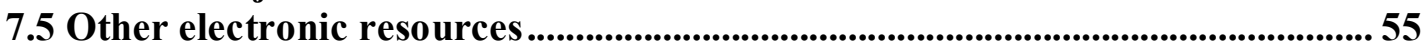

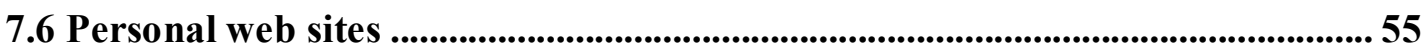

8.0 Midwives and the Internet in New Zealand ..............................................................5 57 


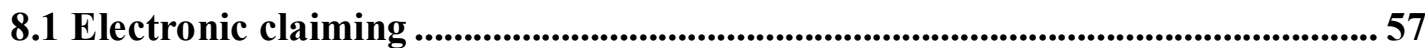

8.2 New Zealand College of Midwives' web site.......................................................5 57

8.3 Home pages ............................................................................................................................................ 58

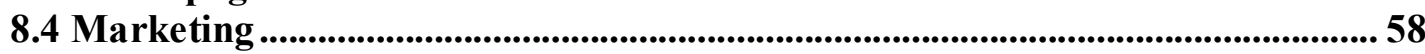

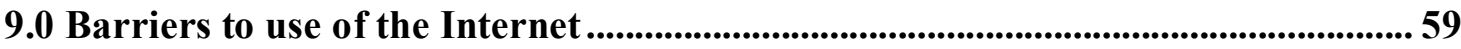

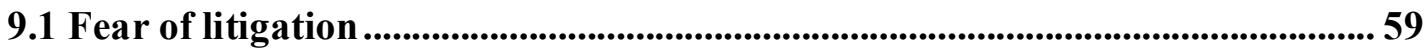

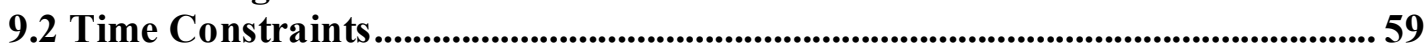

9.3 Face to face versus electronic interactions........................................................59

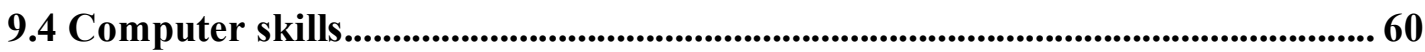

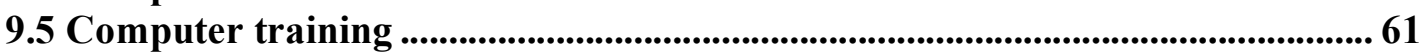

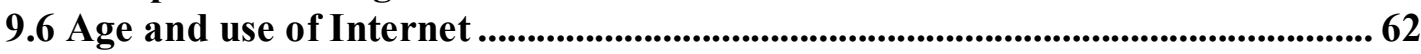

9.7 Critiquing information found on the Internet.................................................62

9.8 Guidelines for evaluating the Internet............................................................................ 64

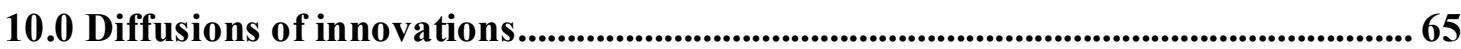

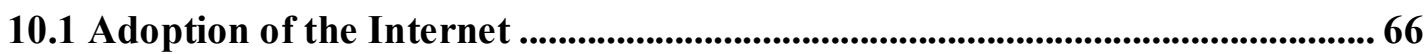

10.2 The innovation-decision process ...........................................................................6 67

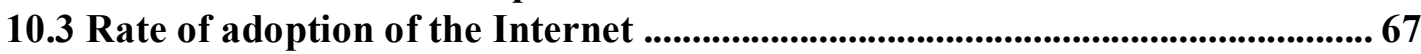

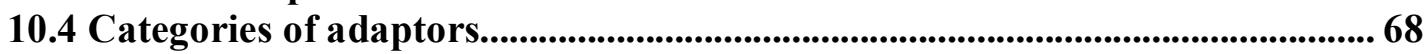

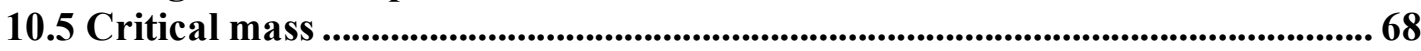

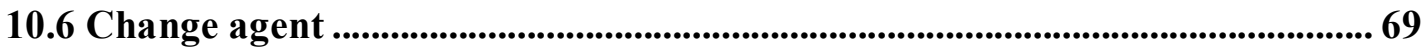

10.7 Consequences of innovations............................................................................................. 69

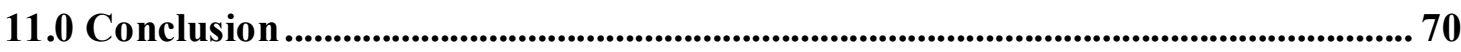

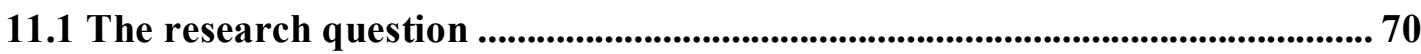

11.2 Pilot study ............................................................................................................................... 71

11.3 Internet as a tool for research .......................................................................................... 71

11.4 Summary .................................................................................................................................. 72

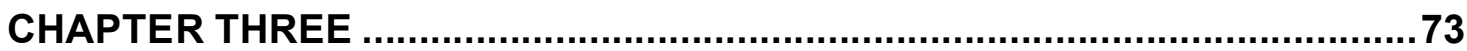

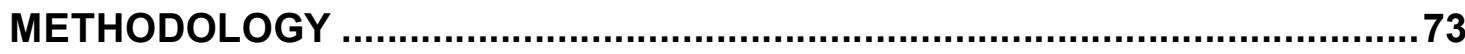

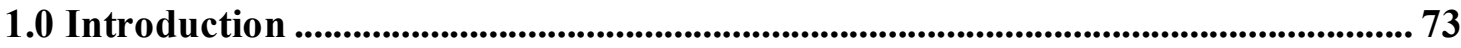

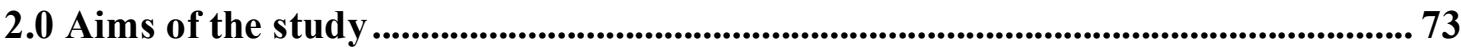

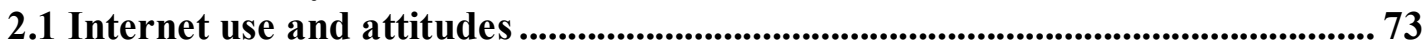

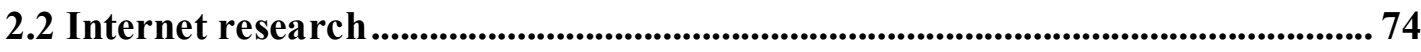

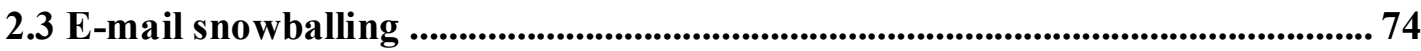

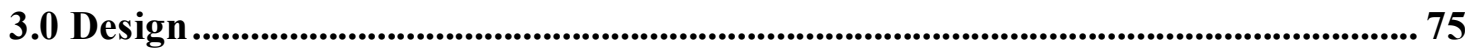

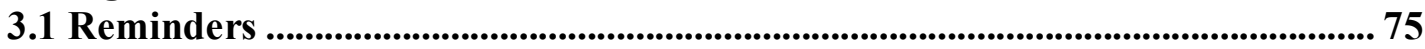

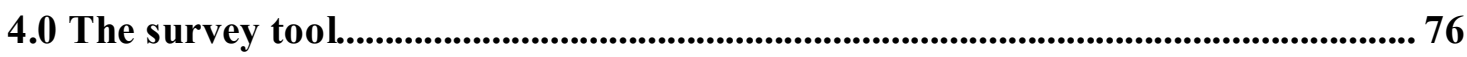

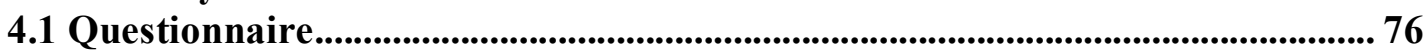

4.2 Survey length .................................................................................................................................... 81 


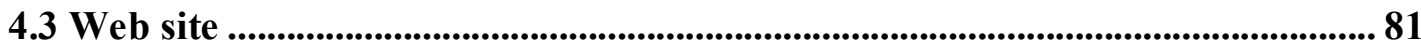

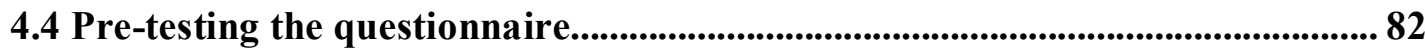

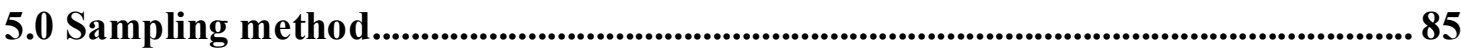

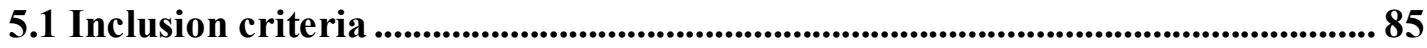

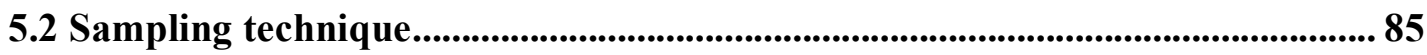

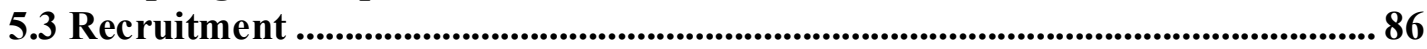

5.5 E-mail snowballing ............................................................................................................... 88

6.0 Considerations specific to Internet survey .......................................................................89

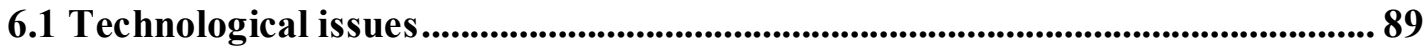

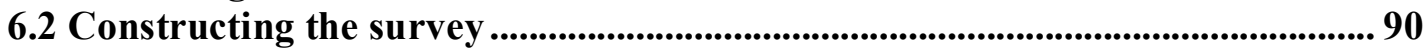

6.3 Principles for design of Internet questionnaire ...............................................91

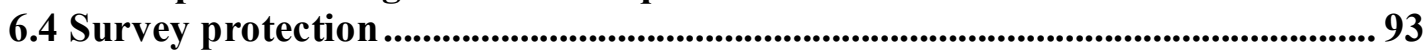

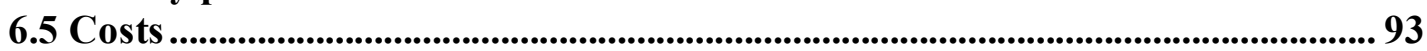

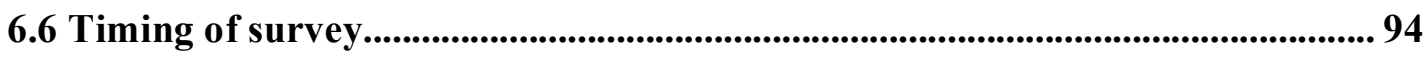

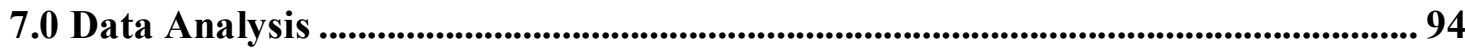

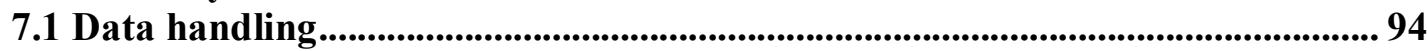

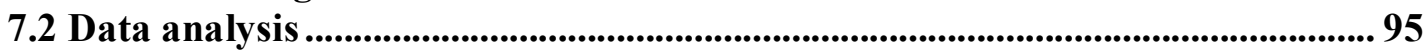

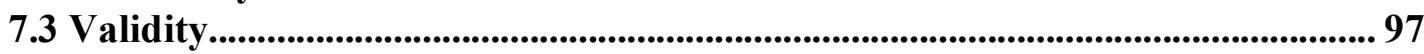

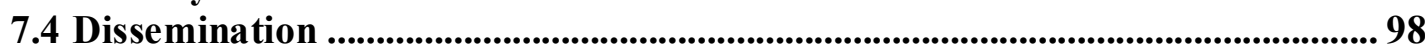

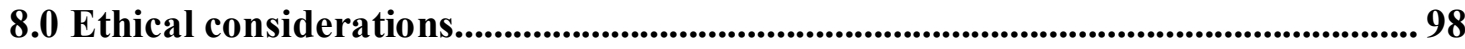

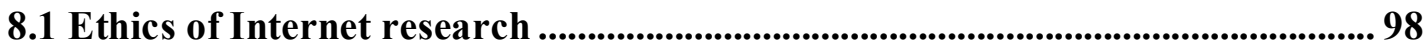

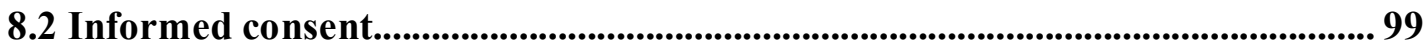

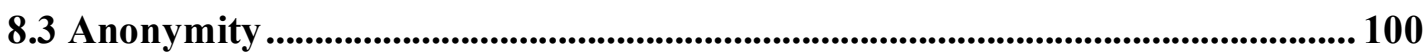

9.0 Treaty of Waitangi issues......................................................................................................... 101

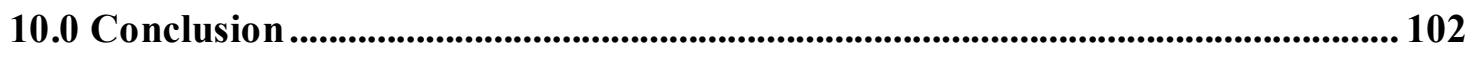

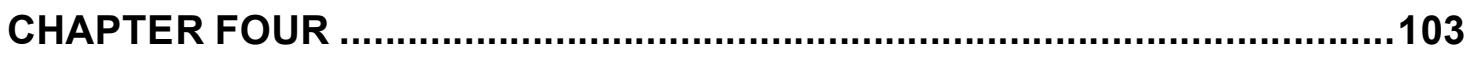

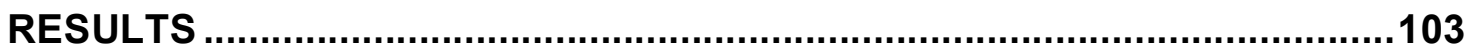

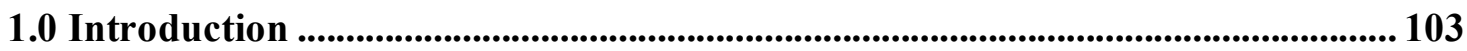

2.0 Response rate ..................................................................................................................................... 103

2.1 Content of e-mail responses........................................................................................... 105

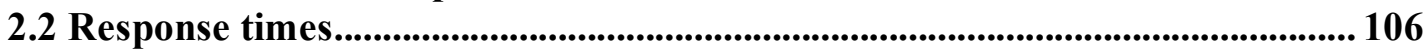

3.0 Demographics .................................................................................................................................... 107

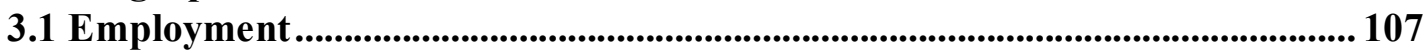

3.2 Age, employment status and years qualified as registered midwife ................ 108

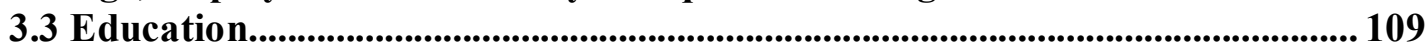




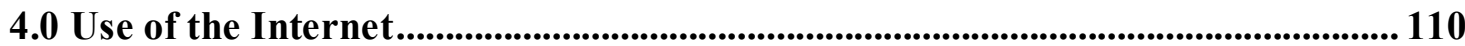

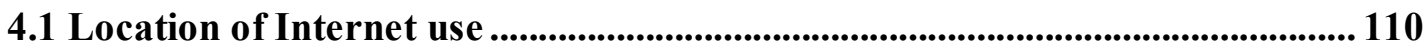

4.2 Frequency of access to the Internet...............................................................111

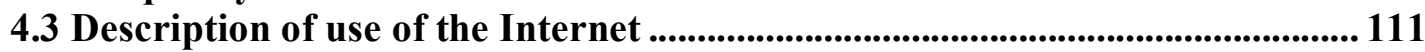

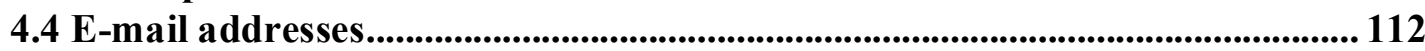

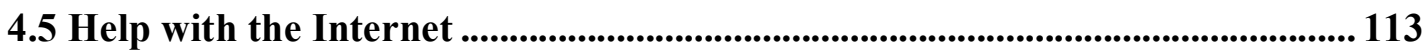

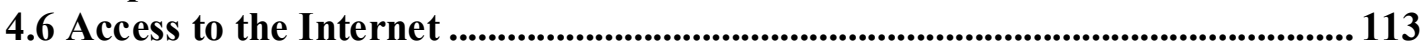

4.7 Searching for midwifery information ...........................................................114

4.8 Ease of access to the Internet ............................................................................................ 114

4.9 Experience of searching for information....................................................................... 115

4.10 Main reasons for using the Internet..................................................................116

4.11 Barriers to use of the Internet......................................................................... 117

4.12 Incorporation of midwifery information found on the Internet into

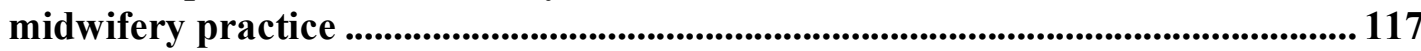

4.13 Internet training .................................................................................................................. 118

4.14 The use of the Internet to deliver lecturers, tutorials or counselling............. 118

4.15 Enrolment in a program of study delivered via the Internet......................... 118

4.16 Information found on the Internet....................................................................119

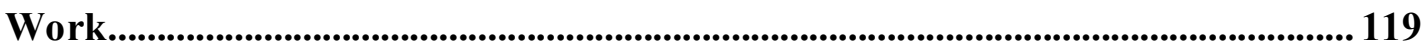

5.0 Use of the Internet by consumers ....................................................................................... 121

5.1 Respondents' impressions of use of the Internet by women receiving

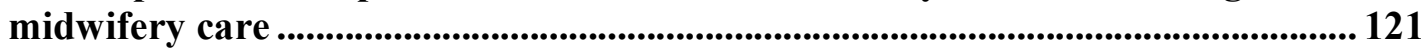

5.2 Quality of information found on the Internet ..................................................122

5.3 Ability to critique information found on the Internet.......................................122

5.4 Impact on midwifery practice of consumers accessing information on the

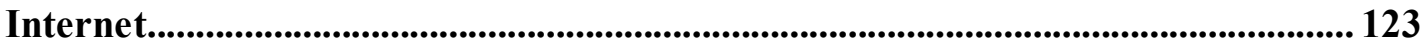

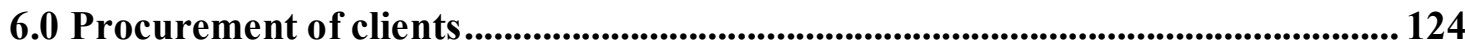

7.0 Midwifery care delivered via the Internet........................................................ 125

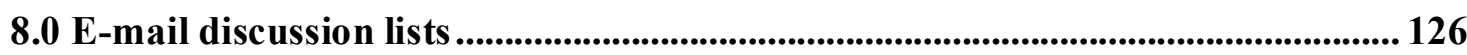

E-mail lists experienced.............................................................................................................. 127

9.0 Internet resources available to midwives ......................................................................... 127

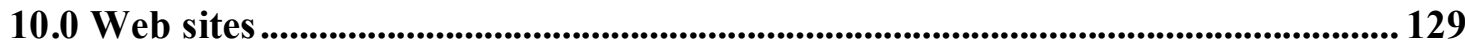

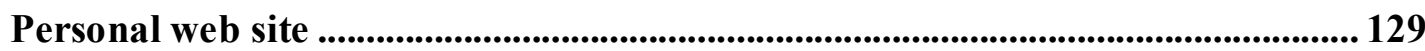

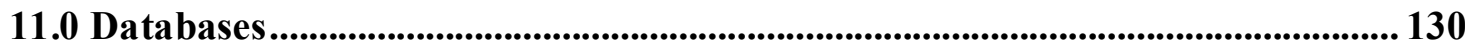

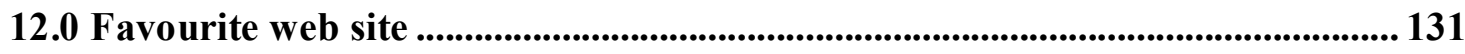

13.0 Desired resources for the future ......................................................................... 131

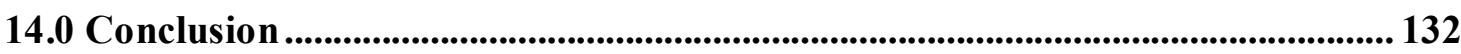




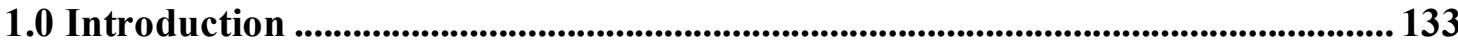

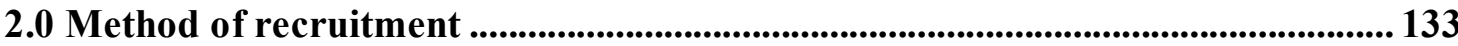

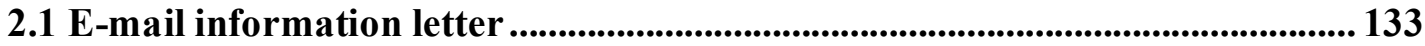

2.2 Snowballing ..................................................................................................................... 134

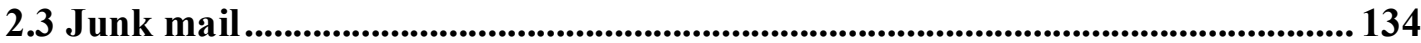

2.4 Electronic network of midwives in New Zealand ............................................134

2.5 Promotion of survey...................................................................................................................... 135

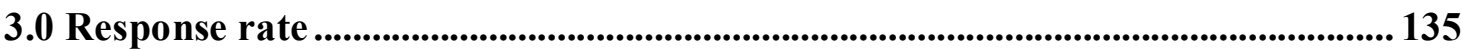

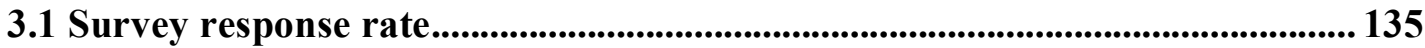

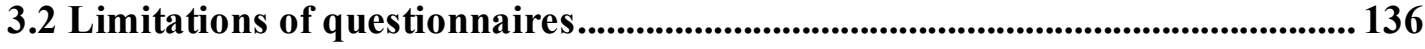

3.3 Increasing response rates......................................................................................... 137

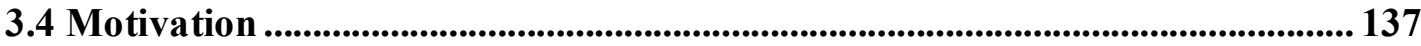

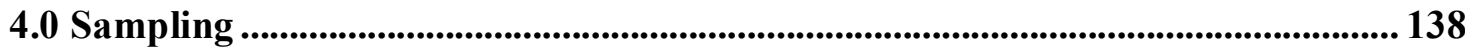

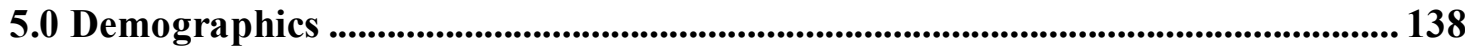

5.1 Employment ................................................................................................................................ 138

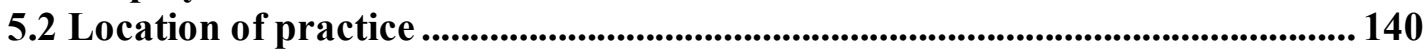

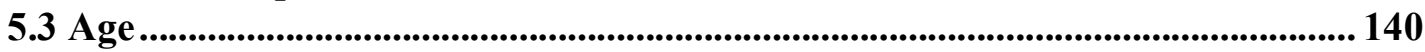

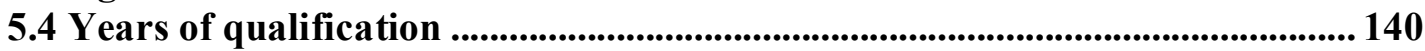

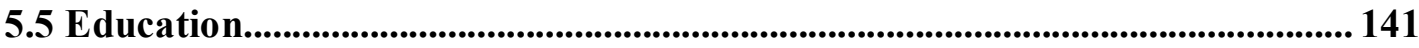

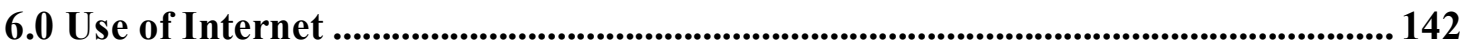

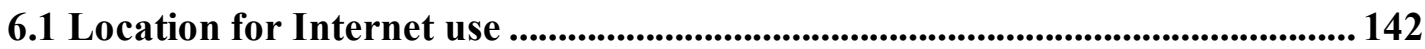

6.2 Definition of 'place of work' .................................................................................... 143

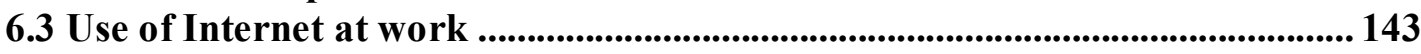

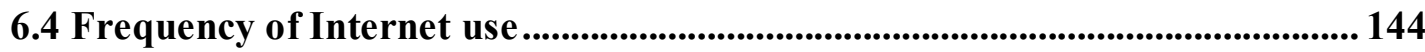

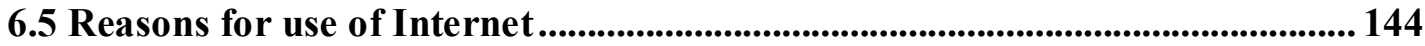

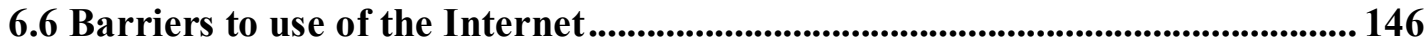

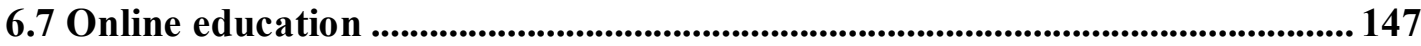

6.8 Information found on the Internet......................................................................... 147

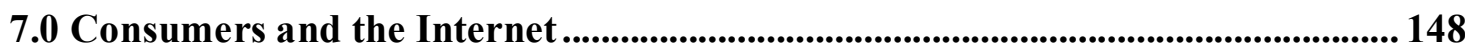

7.1 Use of the Internet by consumers ........................................................................... 148

7.2 Quality of information found on the Internet .................................................... 148

7.3 Impact of consumers accessing information on the Internet ............................. 149

7.4 Advertising services on the Internet .......................................................................... 151

7.5 Midwifery care delivered through the Internet ...................................................... 151

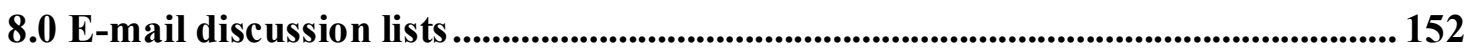




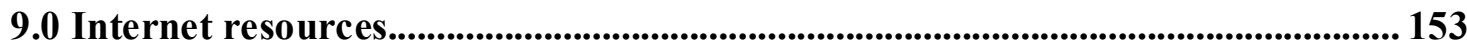

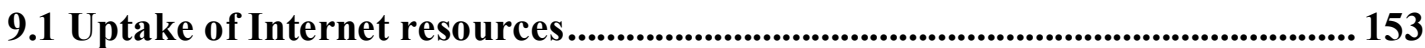

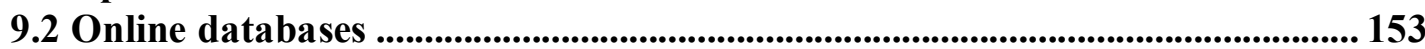

9.3 Suggestions for future online resources........................................................... 154

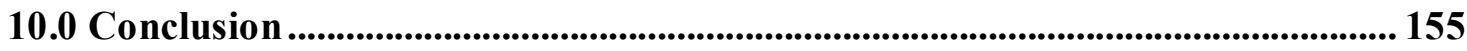

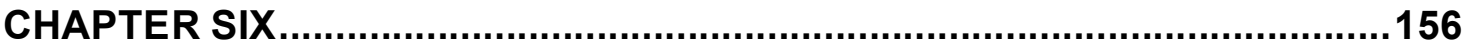

ISSUES FOR FURTHER CONSIDERATION ............................................ 156

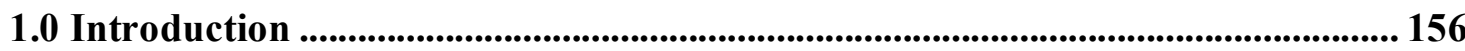

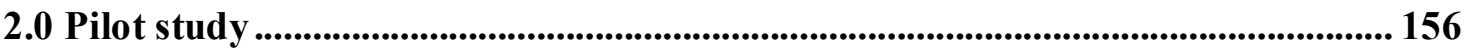

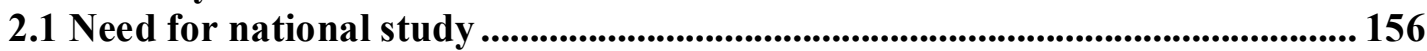

2.2 Level of education and the use of the Internet ................................................... 157

3.0 Topics of information found on the Internet by midwives .................................... 158

4.0 Time-saving strategies .................................................................................................................. 159

5.0 Provision of evidence-based information ......................................................................... 160

5.1 Recognition of the importance of evidence-based practice ................................. 160

5.2 Access to sources of evidence-based information...................................................... 161

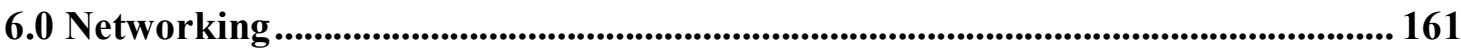

6.1 Communication and collaboration.................................................................... 161

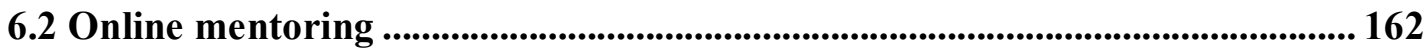

6.3 E-mail discussion lists........................................................................................................ 163

6.4 NZCOM Newsletter and Journal .................................................................................. 163

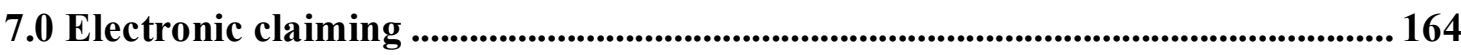

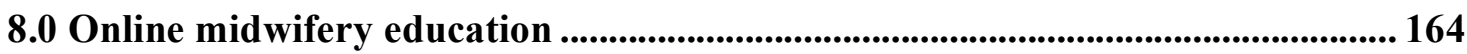

9.0 Critiquing information found on the Internet....................................................... 165

10.0 Consumers and the Internet................................................................................................ 165

10.1 Midwives' feelings about consumers accessing information on the Internet

10.2 Growth of e-health and midwives' response................................................. 165

10.3 Online midwifery care....................................................................................... 166

10.4 Online question/answer service ....................................................................... 166

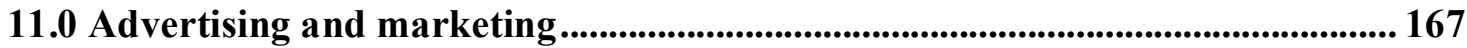

11.1 NZCOM 'Search for a midwife' ......................................................................... 167

12.0 Midwives who do not use the Internet ......................................................................... 168 
PART TWO

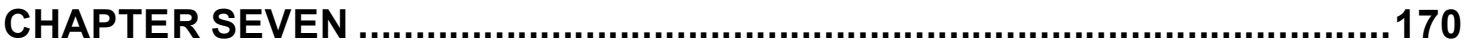

REFLECTIONS........................................................................................ 170

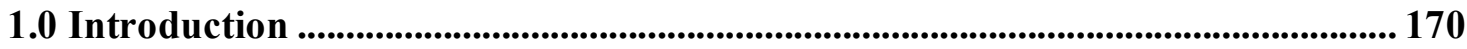

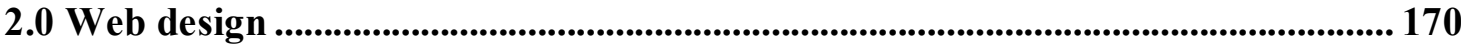

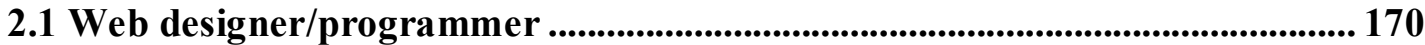

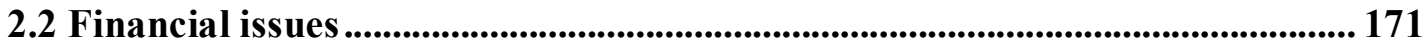

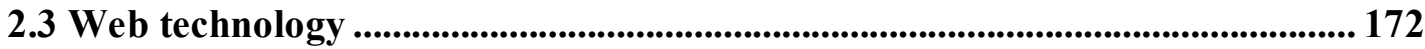

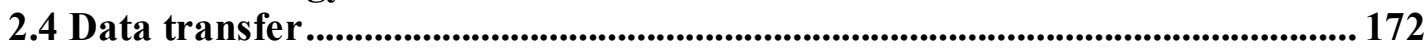

2.5 Technological problems ............................................................................ 172

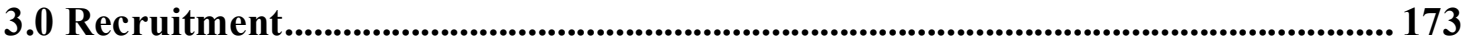

3.1 Response rate ..................................................................................................................... 173

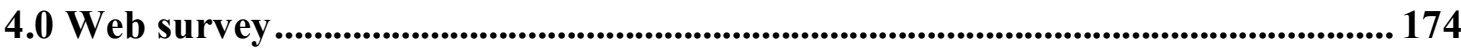

5.0 Questionnaire development .................................................................................................. 175

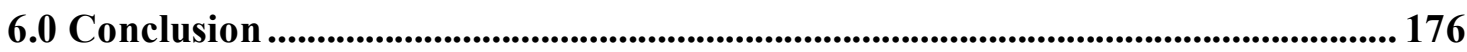

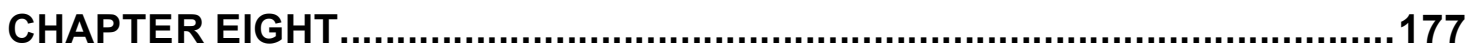

RECOMMENDATIONS FOR FUTURE RESEARCH .................................177

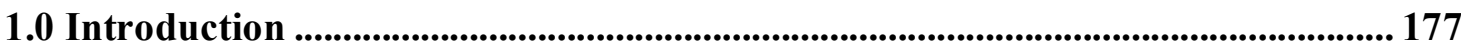

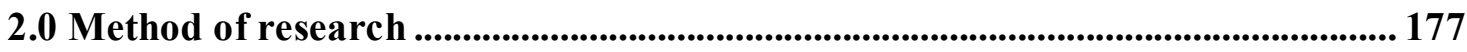

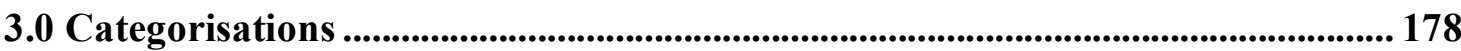

3.1 Categorisation of midwifery roles .................................................................. 178

3.2 Categorisation of location of employment......................................................... 179

3.3 Categorisation of information found on the Internet and how that information was used ...................................................................................................................................... 179

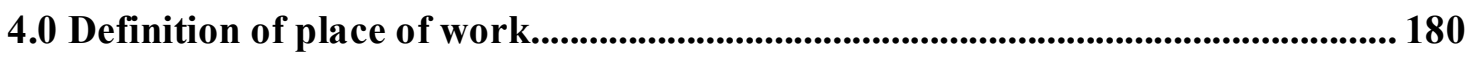

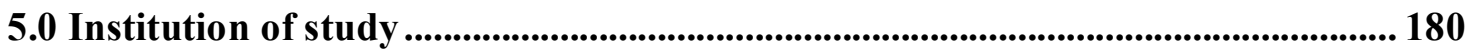

6.0 Teaching via the Internet ............................................................................................. 181

7.0 Conclusion ........................................................................................................................................ 181 


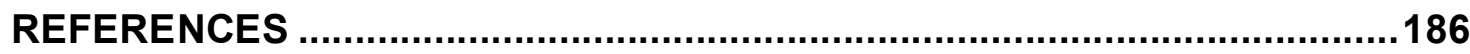

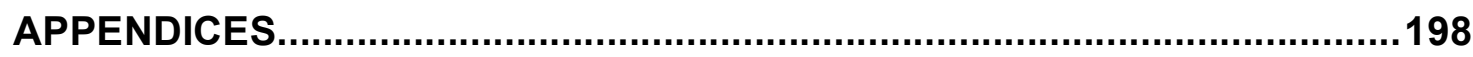

Appendix One .............................................................................................................................. 198

Appendix Two ............................................................................................................................... 199

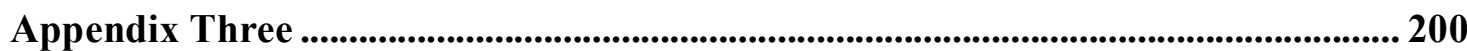

New Zealand College of Midwives' web site ................................................................. 200

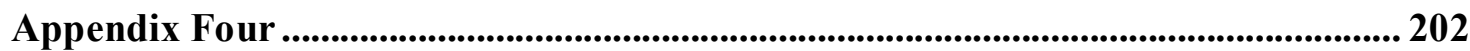

Questionnaire that was developed into web survey ................................................... 202

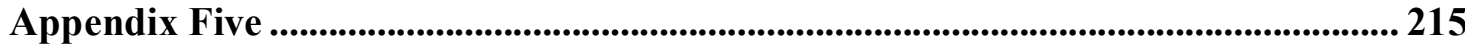

Web survey ............................................................................................................................................... 215

Appendix Six ............................................................................................................................. 216

Web site....................................................................................................................................................... 216

Appendix Seven ...................................................................................................................................... 221

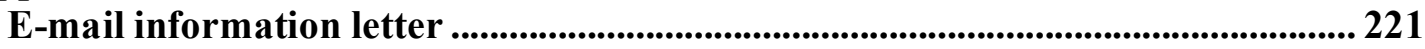

Appendix Eight ........................................................................................................................ 223

Consent forms for computer programmer and statistician...................................... 223 


\section{List of Tables}

Table 1.

Table 2.

Table 3.

Table 4.

Table 5.

Table 6.

Table 7.

Table 8.

Table 9.

Table 10.

Table 11.

Table 12.

Table 13.

Table 14.

Table 15.

Table 16.

Table 17.

Table 18.

Table 19.

Table 20.
Content of e-mail responses. 105

Time that responses were received. .106

Employment of respondents. 107

Characteristics of respondents. 108

Level of professional education. 109

Location of Internet use. .110

Frequency of access to the Internet. 111

Description of use of the Internet. 111

Location of personal e-mail addresses. .112

Help with the Internet .113

Access to the Internet. .114

Searching for midwifery information. 114

Ease of access. .114

Experience of searching for information .115

Main reasons for using the Internet. 116

Barriers to the use of the Internet. 117

Incorporation of midwifery information found on the Internet into midwifery practice.

Internet training. .118

Instances of information found on the Internet. 119

Explanations of how information found on the Internet was used... 120 
Table 21. Respondents' impressions of use of the Internet by women receiving midwifery care......................121

Table 22. Quality of information found on the Internet .122

Table 23.

Ability to critique of information found on the Internet.

Table 24. Impact on midwifery practice of consumers accessing information on the Internet .............................123

Table 25.

Gaining a client through the Internet.

Table 26.

Delivering midwifery care via the Internet

Table 27.

E-mail discussion Lists

Table 28.

Internet resources available to midwives... .128

Table 29.

Personal web sites

Table 30.

Online databases available to midwives .130

Table 31.

Comparison of level of education between the general population of midwives and the respondents of this survey 


\section{List of Illustrations}

Figure 1.

Figure 2.

Figure 3.
Design of Internet questionnaire..........................81

Process of pre-testing Internet information and Questionnaire.. .84

Principles for questionnaire design..................................................92 


\section{Glossary of Internet terms}

Asynchronous communication

Browser

Bulletin board

CGI script

Cyberspace

Domain

Download

E-mail

Hardware

Html

Http

IRC

ISP

Java script communication that takes place at a different time

program that allows user to view, download, upload, surf and access web pages

an Internet forum where messages can be posted. Users can leave messages and reply to those of other users

Common Gateway Interface: a form of computer language

term used to describe digital worlds created by Internet networks

the basis for an Internet address. The domain is like a piece of real estate in cyberspace.

taking information from the Internet and 'loading' it onto your personal computer

basic form of asynchronous communication that allows text messages to be sent to a specific address

machinery that makes up computer systems

Hypertext Markup Language: Language in which web pages are written

Hypertext Transfer Protocol: Protocol that tells the server what to send to the user so the user can view the Web pages

Internet Relay Chat: live chat area of Internet where people can have real-time conversations via IRC software

Internet Service Provider is a company that provides access to the Internet such as Xtra, Clear and Ihug

a form of computer language 
Listserve

LMC

Modem

Newsgroup

NZCOM

Online

Protocol

Real life

Real time

Signature

Search engine

Server

Software

Surfing

Synchronous communication

Upload e-mail list that allows discussion by automatically sending posts to all participants on the list

Lead Maternity Carer

electronic devise that converts data to electrical impulses that can be relayed through a telephone line

asynchronous text-based forum for communication, similar to bulletin board

New Zealand College of Midwives

variety of activities the user can carry out when connected to the Internet

language spoken between computers to help them exchange information

refers to offline living

activities or resources whose actions and reactions occur immediately, with no delay

a file composed by user that is automatically added to each e-mail message, usually containing identifying and contact details

a service that allows users to search the Internet for information

computer or software providing information over a network, including Internet

instructions written by humans to make computers 'do' things

looking for information on the Internet

simultaneous communication

taking information from your personal computer and loading it onto the Internet 
URL

Web page

Web site

Windows

WWW
Uniform Resource Locator: describes where information is stored on the Internet (for example www.midwife.org.nz )

a file in HTML format that be displayed by a browser

one or more web pages

operating system for personal computers created by the Microsoft Company

World Wide Web: global hypertext system that allows users to develop their own sites and access other users' sites

(Hine, 2000; Jordan, 1999; Mann \& Stewart, 2000). 


\section{Chapter One}

\section{Introduction}

\subsection{My interest in the Internet}

\subsection{What this study is about}

This thesis explores the use of the Internet by midwives in New Zealand. It describes a pilot study, which took the opportunity to trial the use of the Internet as a research tool. The pilot study also tested a survey designed to discover how midwives regard and utilise the potential of the Internet to revolutionise the provision of maternity care.

\subsection{The Internet as source and tool for research}

I am a prolific user of the Internet in all aspects of my midwifery life, as educator, student and clinician. I believe the Internet has the potential to be an invaluable tool for national and international midwifery collaboration, as well as knowledge development. Thus, I am interested in the Internet both as a source for research based information and as a research tool. This is a new area for midwifery knowledge development.

\subsection{Discovery of the Internet}

I discovered the Internet when I moved to New Zealand from England in 1996. I was a Lead Maternity Carer (LMC) midwife for nearly three years before I commenced my current position as midwifery lecturer. In common with other writers (Pattanaik,1999), I utilised e-mail in order to keep in touch with friends and family who lived abroad. E-mail is electronic communication written in a form akin to letter writing (Huntley, 1999). One 
types the words one wants to articulate and when instructed, the computer sends the 'letter' to the person who has been named. When the receiver next opens her computer mailbox, the letter is waiting ready to be opened (Huntley,1999). The advantage is an almost spontaneous delivery of post compared to a delay of several days if sent by the conventional postal service (Korenman, 1999). I found that I was far more motivated to write small but very regular postings via e-mail rather than large, infrequent traditional letters. This form of communication is cheaper than conventional postage, or telephone calls. A further advantage is that one can attach files to one's e-mail and send documents, pictures/photographs, research articles, questionnaires and so on. However, I feel e-mail lacks the personal touch that a letter conveys. Another problem is that it is very easy to send an e-mail in conversation without really considering how it reads to the person on the other end. Huntley (1999) recommends that one always re-reads an e-mail before it is sent in order to avoid unintentionally offending someone.

\subsection{E-mail discussion lists}

After a few weeks of using the Internet, I found midwifery e-mail discussion groups, or lists. There were a number of e-mail lists or groups that were specific to midwifery. An email list is a group of people with a similar interest who use listservers or programs that automatically deliver a message produced by one member of the group to the whole group (Bowles, 1996). Thus, electronic discussions are generated providing the facility for reflection on practice; debate on ethics and politics; information sharing; networking and professional support (Anthony, 1996). I needed this contact with midwives because of my physical and professional isolation, living in a rural area of New Zealand. 


\subsection{Membership of discussion lists}

I joined several discussion groups including Fensende (

http://www.fensende.com/Users/swnymph) owned by Sabrina Cuddy, which is a group of midwives and other health professionals based in the United States of America (USA); Alaska (http://www.alaska.net/ zeldacrm), a group of midwives also based in the USA, managed by Zelda Collett-Paule; Ozmidwifery (http://www.acegraphics.com.au) which is made up of midwives and consumers of maternity services based in Australia, owned by Ace Graphics and Andrea Robertson. The discussion lists provided me with clinical support and facilitated information sharing. I clearly remember when a discussion about the management of the second stage of labour impacted on my clinical practice. One writer talked about how one should wait and let nature take its course, which is now the approach I take when attending a birthing mother. However, I often found that there was a huge amount of post that easily became side tracked from clinical matters. Another common problem was 'flaming', a term coined by e-mail users. 'Flaming' is a unprovoked and disruptive attack on someone for his or her opinion, usually unprovoked (Wallace, 2001). Indeed, online behaviour tends to be less inhibited than face-to-face contact because there are not the cues that otherwise affect social interaction, giving rise to increased conflict (Collins, 1992). 


\subsection{New Zealand Midwives' List}

The discussion lists I had been a member of, although very informative and supportive, did not cater to my needs as a New Zealand midwife in a political and professional climate that was quite different from that of the USA, the United Kingdom (UK) or Australia. There was a lot of interest in the idea of e-mail communication amongst colleagues, especially as the geography of New Zealand means that midwives are unable to personally keep in touch as much as they would like. As a result, I set up a midwifery e-mail group specifically for New Zealand midwives in 1997 (

http://be.onelist.com/group/nzmidwives). Recruitment to the list was mostly by word of mouth. It started with about half a dozen members and has slowly grown over the last four years to a current membership of over 60 midwives, student midwives and consumers interested in the maternity services (Stewart, 2000a). There was some sharing of information, but it was the clinical issues that generated the most responses. Dialogue was usually generated from events in clinical practice. Discussions would range from methods of induction of labour, to how one should manage undiagnosed breech presentation of a baby when a woman was in labour.

I am no longer a member of the New Zealand Midwives List because the focus of my time has currently changed from clinical practice to research. I have recently joined the Midwifery Research list managed by Jane Sandall in the UK, which aims to support midwives involved in research (http://www.mailbase.ac.uk/lists/midwifery-research). I 'lurk' on this list hoping to increase my knowledge of midwifery research. 'Lurking' is when one reads but does not respond (Penn,1997). 


\subsection{My experience of the Internet at work}

\subsection{Use of Internet in the role of midwifery lecturer}

I use the WWW extensively in my work as a midwifery lecturer. It has enabled me to keep up-to-date with the latest research findings, and international midwifery and obstetric thinking. There are a variety of search engines that 'surfers' can use to find information on the Internet. I use a search engine called Copernic, which can be downloaded free of charge from the Internet (www.copernic.com). It is a search engine that combines all the main search engines: AltaVista, Excite, HotBot, Infoseek, Lycos, WebCrawler, Yahoo, MSN web search and Netscape Netcentre. Consequently, the effect is to considerably reduce time searching for information.

I have been able to make use of information found in online journals such as the Association of Radical Midwives (http://www.radmid.demon.co.uk) and the British Medical Journal (http://www.bmj.com). I also receive regular e-mail newsletters such as that from Midwifery Today (http://www.midwiferytoday.com) and PrenatalEd ( http://www.prenataled.com). I am able to incorporate the information in my lectures, and share it with midwifery students and colleagues. I also regularly access databases that are available on the Internet, such as Cochrane (http://www.campbellreviews.com/cochrane/cochrane-frame.html) and Medline (http://omni.ac.uk/medline). I have been able to share my knowledge of useful web sites in the regular column I write for the New Zealand College of Midwives Journal (Stewart, 1998a; Stewart, 1998b; Stewart, 1999a; Stewart, 1999b; Stewart 2000b; Stewart, 2001; Stewart 2002a). I am also 
about to start writing a monthly column about the Internet for an international midwifery journal, The Practising Midwife (http://www.thepractisingmidwife.com) (Stewart, 2002b) with the view of compiling a book in the near future, for midwives on how to use Internet.

\subsection{Use of Internet in the role of midwifery practitioner}

Along with other midwives, I have my professional details published on the NZCOM 'Search for a midwife' web site (http://www.midwife.org.nz) (see Appendix One). These include my contact details and philosophy of practice. As a lecturer and midwife I only manage to provide LMC midwifery care for one or two women per year, and my two current clients 'found' me because of my advertising on the NZCOM web site. I have acquired more clients via the Internet than a colleague who is in the same situation as me, who advertised through the telephone 'Yellow Pages'. I have occasionally found myself giving midwifery advice and counselling by e-mail to pregnant women. These women are either friends or family, or strangers who have contacted me because they have come across my details on the NZCOM web site. An example of this is a woman who e-mailed me asking for information and advice about vaginal birth following caesarean section. She had had several caesarean sections and wanted to explore the issues before her next pregnancy. I was able to give her information and support at a time when she was desperate for help, and had received little during face-to-face encounters with health professionals. 


\subsection{Job interview}

I experienced a job interview by video conferencing in 1999. The interviewers were in the UK and I was in New Zealand. The process was hugely expensive and inconvenient at the time because I had to travel three hours to access a company that had the video conferencing technology. Nonetheless, this was still a lot more convenient than travelling to the UK. Nowadays, video conferencing at home is feasible with PC video cam, scanner and microphone.

\subsection{Internet Relay Chat}

I regularly employ Internet Relay Chat (IRC), which is spontaneous text messaging using software such as Microsoft Messenger Service (http://messenger.msn.co.nz). Whilst I use IRC for personal purposes, there is the potential for midwives to use this for spontaneous communication and collaboration, whereas e-mail is asynchronous and does not allow for real time communication.

\subsection{The Internet and education}

\subsection{Cost of accessing resources}

I have also used the Internet extensively in my post-graduate studies. Currently my Internet Service Provider (ISP) (http://www.paradise.net.nz) charges me \$NZ 25 per month for up to 250 hours of Internet use. It can be difficult and expensive to access books and journals about the Internet in New Zealand because the work is mostly generated in the USA and UK. The Internet allows me to access this work instantly and at 
minimal cost. An example is the work by Don Dillman on Internet survey, which I have found to be an invaluable resource. His book 'Mail and Internet Surveys' (Dillman, 2000) costs over \$NZ 200 to buy, whereas one can access his work virtually free of charge on the Internet (http://survey.sesrc.wsu.edu/dillman/papers.htm). This does rely though, on authors posting their work on the Internet in the first place.

\subsection{International dialogues}

Another exciting aspect of the Internet I have been able to employ is the ability to communicate and collaborate with people I might not ordinarily be able to contact, or have the presumption to do. Professor Steve Jones is an American academic who has written and edited several influential works about the Internet, such as Doing Internet Research (1999). I approached him by e-mail and we have had several useful conversations about Internet research, and he connected me to the Association of Internet Researchers' e-mail discussion list (http://aoir.org/airjoin.html).

I have 'spoken' to many other prominent Internet researchers after finding their e-mail addresses in books and articles they have published conventionally, or by finding their web sites. Almost without exception they have given me ideas, advice or information about resources.

\subsection{International collaboration}

I have become friends with Sara Wickham, who is a midwife and lecturer in the UK. We 'met' on the Fensende discussion list and have developed a relationship by e-mail. Our 
mutual interests in midwifery and Internet research has inspired us to collaborate with writing an article about Internet research. Despite being 12,000 miles apart we have been able to develop a paper by means of e-mail, which has been published in Midwifery Information and Resource Service digest (MIDIRS) (Wickham \& Stewart, 2001).

\subsection{New Zealand midwives and their use of Internet resources}

\subsection{Questions about midwives and their use of the Internet}

It is this interest in the Internet and the implications for midwives and the women in their care, that has lead me to ask how midwives in New Zealand use the Internet. How many midwives have access to the Internet and use it? Do they use the Internet solely for searching out information, or do they exploit it more fully for communication and

collaboration, as well as development of practice and support? Has consumers' use of the Internet had an effect on their practice and how do midwives feel about that? What are the barriers to use of the Internet? What resources do they want to see developed by the profession? Is the Internet another important tool in their 'bag of tricks' or do midwives in New Zealand see it as an unnecessary technological invasion of their lives?

\subsection{Significance of this study}

I believe it is important to know how midwives are using the Internet so that the leaders of the profession such as the New Zealand College of Midwives (NZCOM), providers of education and employers of midwives can look at where the gaps are, and what they can do to improve midwives' access to the Internet and the way they use it. All this can be done with the view to improving quality of practice by increasing access to information. 
Increasing communication, collaboration and networking between midwives will also assist in developing the profession, both nationally and internationally.

\subsection{Pilot for national study}

My ultimate aim is to carry out a national survey of midwives because it is important to establish how many midwives in New Zealand are using the Internet. This information can then be utilised by NZCOM, employers of midwives and educational institutions to plan what Internet resources need to be provided for midwives and whether these resources are economically viable. However, for the time being I have concentrated on completing a pilot study.

I have chosen to survey midwives in New Zealand about their use of the Internet by webbased questionnaire because it seemed logical to use the Internet as a tool for research. There is little information about the Internet as a research tool in midwifery literature, so I hope to generate knowledge for midwives regarding the Internet as a tool for research. I have elected to employ the survey approach because it allows for the collection of data from a large population relatively easily, without incurring huge costs (Wagstaff, 2000).

A pilot study is a small-scale version of a larger study (Wagstaff, 2000). This pilot study was exploratory, and gave me the opportunity to test a questionnaire as well as the Internet as a research tool (Oppenheim, 1992). It allowed me to explore how feasible e-mail snowballing/chain letter was as a method of recruiting participants, in addition to how appropriate a web questionnaire was as a method of surveying midwives. It also 
enabled me to gather information about cost, administration, time involved and organisational issues (Wagstaff, 2000). The results will inform a larger, national study in the future.

In addition, this pilot study allowed me to broadly explore issues regarding the Internet such as how to search for information; how search engines are useful; what databases are available; what are some useful web sites; how to use e-mail discussion lists and so on. This information I will be able disseminate to students and midwives in my roles as lecturer and writer.

\subsection{Conclusion}

\subsection{E-health}

E-health is the process of providing healthcare by electronic means, in particular via the Internet (Pretlow, 2000). E-health covers a broad spectrum from medical advice services, provision of commercial health care products, to providing real-time consultations via video conferencing. A major force behind e-health is the increase in demand for health information and resources from consumers (Eysenbach, Ryoung Sa \& Diepgen, 1999). This will inevitably increase pressure on health professionals to become familiar with Internet technology. It will allow consumers to have the same access to information as health professionals, increasing consumer empowerment and involvement in decisionmaking. This in turn will be an added incentive for health professionals to provide evidence-based information, as consumers are increasingly likely to challenge them because of what they find on the Internet (Eysenbach et al, 1999). Another factor is the 
drive to provide health care to those who ordinarily have difficulty accessing resources, such as people living in rural and remote areas, with transport problems, physical or emotional disabilities, or with low income (Whitten, Steinfield \& Hellmich, 2001).

There are a numbers of facilities that health consumers want to be able to access such as laboratory results, as well as being able to make appointments and order prescription refills (Larkin, 2001). Consumers want to be able to find out information about health professionals as well as learn about medical conditions. Pregnancy rates highly as a topic for exploration on the Internet (Larkin, 2001).

E-health has the potential to revolutionise the working life of the midwife in New Zealand. The technological capability is available for midwives to carry around their own personal computer (PC) which they can use to maintain client records, access results of medical tests and carry out specific monitoring such as maternal blood pressure and fetal heart monitoring (DoctorGlobal, 2000; Healthvision, no date; Kleist, 1996).

\subsection{Potential of the Internet}

Midwives are just beginning to recognise the potential of the Internet for networking and collaboration, as well as teaching and learning, practice development and research (Stensland Kurokawa, 1996; Fleck \& Levy, 1999). In these days when there is an increasing emphasis on midwives providing evidence-based practice (Sandall, 1998; Page, 2000), the Internet has the potential to be able to provide up-to-date information for midwives, even those who work in the remote areas of New Zealand. 


\subsection{Diffusion of innovations}

The adaptation of the Internet by midwives may take some time. According to Everett Rogers (1995) there are certain conditions that have to exist before a population adopts an innovation. This is what Rogers calls the 'diffusion of innovations' (1995). In this instance, Rogers defines diffusion as the process by which the innovation is communicated among members of a certain social system.

Midwives will only adopt the Internet if they perceive it to be advantageous (Rogers, 1995). The Internet will be calculated in terms of economic advantage as well as convenience, social prestige and satisfaction. If these terms are not met, the rate of adoption of the Internet will be slow. Adoption will also depend on midwives' previous experience and whether the Internet is consistent with their own values as well as requirements. Adoption will be a lot faster if midwives perceive the Internet to be easy to learn and use, and are given the opportunity to experiment and observe the results of use of the Internet. Diffusion of an innovation is a social process. The Internet is much more likely to be adopted by midwives if they see that their peers have had a positive experience of the Internet, and adopted it themselves (Rogers, 1995). Rogers' work will be explored in greater depth in Chapter Two. 


\subsection{Structure of the thesis}

This thesis consists of two parts. Part One, (from Chapters Two to Seven) describes the pilot study. In Part Two which consist of Chapters Eight and Nine, I reflect on the learning achieved during the process of this study and make recommendations for further Internet research.

Chapter Two provides the background and context to the study by explaining what the Internet is and how it is used. I discuss issues that are generated, such as who are excluded from the Internet community and cyberfeminisim. The effect of the Internet on the medical and midwifery professions is discussed, including how the Internet may affect the relationship between health professional and patient/client. Chapter Two also provides a picture of midwifery in New Zealand and how e-health has been experienced in New Zealand.

Chapter Three presents details of a literature review. The review discusses how midwives and other health professionals may utilise the Internet as well as the advantages and disadvantages of e-health. The review describes resources that midwives may access such as education, e-mail discussion groups, electronic databases, electronic journals, and personal web sites. Finally, an explanation of the hypothesis of the study will be given as well as a rationale of why the study was carried out.

Chapter Four describes the process of data collection and analysis. This includes the development of the questionnaire and the design of the survey web site, in addition to 
selection of the sample and ethical considerations. Chapter Five presents the results of the analysis. Chapter Six contains the discussion of the results and Chapter Seven contains recommendations for a national study.

In Part Two, Chapter Eight consists of my reflection on the learning I gained during the process of this study. Chapter Nine contains recommendations for future Internet research.

For those readers who are not familiar with Internet terminology, I have provided a glossary of terms at the beginning of the thesis. The reader will note that I have referenced a great deal of Internet material that I have been collecting over several years. I have cited the Uniform Resource Locator (URL) and the date I accessed them. However, because of the ephemeral nature of the Internet it may not be possible to find all the web sites as I have cited them. 


\section{Chapter Two}

\section{Background}

\subsection{Introduction}

This chapter will describe the current state of midwifery in New Zealand in order to indicate the potential capability for the use of the Internet in midwifery practice and education. The chapter will then go on to describe the development of the Internet and the possibilities for e-health. The chapter will explore how e-health has been taken up by the medical and midwifery professions, both internationally and in New Zealand. I will discuss how midwives are beginning to recognise the potential of the Internet including the role the Internet plays in providing evidence for best-practice. I will suggest that Rogers' theory of 'diffusion of innovations' can give some insight into why and how midwives are adopting this innovation into their midwifery practice. Finally, I will discuss the questions that have been raised about midwives' use of the Internet in New Zealand, and how I aim to find out the answers to those questions.

\subsection{Midwifery in New Zealand}

\subsection{Current situation}

In 2000, 2081 qualified midwives reported to the New Zealand Nursing Council that they were working in midwifery (New Zealand Health Information Service (NZHIS), 2001). One hundred and eighty of these midwives had a direct-entry qualification; 909 midwives carried a midwifery caseload; 1025 worked in a hospital; 57 worked in management and administration; 73 worked in education; 11 worked as professional advisors, developing 
policy and 6 worked in research. The age of the midwives ranged from 20 to 59, with the greatest number of midwives between 40-54 years old. The greatest numbers of midwives worked between 33 and 40 hours per week, with the next largest number of midwives working between 17-32 hours per week. The average income for midwives working full time across the profession is $\$ 48,000$ (Guilliland, 2001a).

\subsection{Lead Maternity Carer}

Annually, around 57,000 women give birth each year in NZ and continuity of care is mandated as the preferred model of care for all women (Guilliland, 2001b). This is provided by a Lead Maternity Carer (LMC). The LMC is responsible for providing primary maternity care for healthy low risk women including labour and birth, and is paid according to a modular payment schedule consisting of four modules - first trimester, second and third trimester, labour and birth, 4-6 weeks post natal. The midwife LMC may be self-employed, or employed by a hospital or other health provider such as an iwi (Maori tribe) or community based primary health care organisation. In 1998/9 over 50 per cent of women had a self-employed midwife-LMC; 21 per cent had a hospital-employed LMC- midwife; 13 per cent had a general practitioner (GP) - LMC and 12 per cent an obstetrician- LMC (Guilliland, 2001b). Midwives may prescribe medications that are pertinent to childbirth; order diagnostic tests such as blood tests and ultrasound scans, and refer to obstetricians or paediatricians when problems are detected (Calvert, 1998). 


\subsection{Hospital midwives}

Hospital core services, including secondary maternity care for women with complex health needs, are provided by employed midwives who work on rostered shifts (Calvert, 1998). The midwives may provide labour and birth midwifery care for women whose LMC is a doctor. Hospital midwives also run the antenatal clinics and inpatient wards, as well as delivery suites.

\subsection{Midwifery education}

Under-graduate midwifery education is provided in New Zealand in the form of a threeyear direct entry Bachelor degree (Pairman, 2000). Postgraduate midwifery programmes have also been developed to Masters and Doctor of Philosophy level.

\subsection{Potential of the Internet for midwives}

The potential of the Internet for midwives ranges from being a source of evidence-based information that can be integrated into midwifery practice, to networking and collaboration with other midwives both nationally and internationally. It may be particularly valuable for the large number of midwives in New Zealand who are self employed, or working in independent practices, who may be geographically or professionally isolated from colleagues. Historically midwives who have mostly worked as hospital employees have accessed their ongoing education in the form of in service programmes offered by their employer. Nowadays, hospital and self-employed midwives are expected to look further afield for professional development opportunities. 
Internet technology is developing in a way that can provide practical clinical support for midwives, such as the home monitoring of a pregnant woman's blood pressure. This could be an attractive option for women and midwives in rural areas of New Zealand. The results would be sent via the Internet to the midwife. It would keep the women at home with their families, and reduce midwives' travelling and time costs. Furthermore, the Internet has the capability for keeping the women's maternity record on a secure Internet based programme, which would make it accessible from wherever the midwife and woman were located. This would facilitate access for consultations any time or place, allow the woman to have control over her records, and facilitate ease of electronic claiming and transfer of data into national databases. Audio and video capabilities of the Internet would further enhance the experience for the woman and the midwife by facilitating synchronous communication (Pretlow, 2001; Healthvision, no date). Women are even 'broadcasting' the births of their babies over the Internet ( http://www.time.com/time/community/transcripts/chattr061798.html ) which may impact on the way the midwife practices.

In order to fully appreciate the potential of the Internet for both midwifery practice and research, it is useful to understand the history of its development. 


\subsection{The development of the Internet}

\subsection{History of the Internet}

The Internet is an international communication system based on a series of telephone links and computers (Sinclair, 1997). It was first developed in the USA during the Cold War as part of nuclear defence, to enable speedy communication (Lakeman,1997). Initially, the Internet was the domain of governments and universities who utilised the Internet to send prompt communication in the form of e-mail, as well as store and recover text documents (Drake, 1999). However, the World Wide Web (WWW), which was developed in the early 1980 s, provides a far more flexible system of communication that incorporates graphics, sound, video and user interaction (Hardey, 1996; Drake, 1999). Information is stored on the WWW on individual pages that are linked together to form a huge computer library (Drake, 1999).

\subsection{Internet users}

Initially, the population of Internet users were white, male, and residents of the industrialised world, educated and wealthy (Coomber, 1997). In 1998, the average age of Internet users in New Zealand (NZ) was 35 years; average income of NZ\$50,000-60,000 with 38 per cent of respondents earning over NZ\$70,000; educated to tertiary level, and 76 per cent of Internet users were male (Infotech, 1998).

However, the population of Internet users has grown since 1998 and is becoming more similar to the general population. It has been estimated that at least 42 per cent of 
households in New Zealand have computers (Statistics New Zealand, 2000). In July 2000, 51 per cent of Internet users in the USA were women, whilst in New Zealand the percentage had increased to 47.7 from 24 per cent in 1998 (Nielson NetRatings, 2000). In May 2001, Nielson NetRatings reported that 1,620,945 people used the Internet in New Zealand. Seventy-three per cent of Internet users in New Zealand access the Internet at least once or twice a week (Statistics New Zealand, 2000).

\subsection{Access to the Internet}

The general public has access to the Internet through facilities such as public libraries and cybercafes. In June 2001, MacDonalds opened its first Australasian cybercafe in Dunedin, where one can have 15 minutes free use if one spends more than six dollars on food (Munro, 2002). The economic cost is decreasing with the availability of secondhand computer equipment and free ISP such as zfree, i4free and freenet (Internet Magazine NZ, 2001).

The unequal provision of Internet access to the white, educated and wealthy male has resulted in the development of 'CyberFeminism', which is defined as a philosophy that acknowledges power differences between women and men in the digital community (Hawthorne and Klein, 2000; Woodlock, 1999). An example of this is the use of 'signatures', which are files that are automatically added to the end of e-mails, usually with contact details (Hine, 2000). Murray (1997) suggests that by including job title, qualifications and place of work the e-mail author is claiming the authority to speak. By signing oneself with a full job title and so on, one is displaying one's 'power'. This 
behaviour contrasts with the beliefs of writers who maintain that cyberspace is a social leveller (Spender, 1995). Murray (1997) found that it was more likely to be a man that signed himself with his full job title and so on.

The Developing World continues to be excluded from the population of users because of poverty, quality of information and communication technology (Daly, 1999). Millions of people do not have access to a telephone line, let alone the Internet. One example is India, where only 0.4 per cent of the population had access to the Internet in 2001 (eMarketer, 2001). One of the obstacles to the growth of the Internet in India is the poor quality and coverage of telecommunication infrastructure (eMarketer, 2001).

\subsection{Possibilities of e-health}

\subsection{Health consumers and the Internet}

The Internet has the potential to provide services that have far reaching effects for consumers. Seekers of online health information are growing at twice the speed of the general online population (Sanborn, 2000). Pretlow (2001) believes e-health will increase in popularity with health consumers because it facilitates their independence, and brings healthcare to their homes similar to the days when doctors paid 'house calls'.

Women and their families will be able to receive interactive management programs and online real time consultations, as well as access support groups and information (Healthvision, no date). Consumers have been quick to recognise the potential for sharing 
advice, opinions and personal experience. Health consumers are finding the Internet is reducing their feelings of isolation (Ehrenberger \& Murray, 1998).

Women in particular are enjoying the positive aspects of anonymity, constant accessibility and availability of the Internet, especially as they are often the ones responsible for family health care (Pew Internet and American Life Project, 2000). The Pew Internet and American Life Project is an organisation based in Washington, that funds and carries out research into the effects of the Internet on the everyday life of Americans. A telephone survey of 2109 adults in America conducted between July 24 and August 20, 2000 by the Pew Internet and American Life Project (2000), found that 63 per cent of women with Internet access have researched health information online, compared to 46 per cent of men. Eighty per cent of men and women are concerned with the quality of information found online, with 58 per cent of these people checking the reliability of the information they have found. Having said that, 51 per cent of survey participants said their last online search affected their decisions about their healthcare; 48 per cent believed the Internet improved the way they looked after themselves, and 55 per cent reported the Internet improved their access to health information.

\subsection{Birthing women}

Women can obtain advice or opinions about any number of birthing issues from vaginal birth following caesarean section (http://www.childbirth.org), to the services one should expect from a midwife (http://www.birth.net.nz). Parents are using the Internet to share their birth stories with the world 
(http://www.thelaboroflove.com/birthstories/index.shtml). These in themselves are rich sources for research, both qualitative and quantitative.

\subsection{Evidence-based practice}

One of the rapidly growing concepts in healthcare is that of evidence-based practice (EBP) (Muir Gray, 1999). EBP is the practice of making clinical decisions based on individual expertise coupled with the best available clinically relevant research, as well as the understanding and values of the patient or woman (Sackett, Rosenberg, Gray, Haynes \& Richardson, 1996; Ellrodt \& Keckley, 2001). Evidence-based practice is driven by the questions: is the care effective? Do benefits outweigh the costs? Is it acceptable to women? (Walsh, 1996). Evidence-based care is based on research evidence rather than what has been done routinely for years, or 'how I was taught' (Page, 2000).

Health consumers are increasingly aware of the importance of receiving reliable, evidence-based information on which to base informed decisions about their healthcare (Sandall, 1998; Harding, 2000). Midwives constantly have to make decisions together with women, yet it can be time-consuming and expensive to keep track of the latest research evidence, especially if midwives subscribe to more than one relevant journal (Walsh, 2000).

The concept of evidence-based practice has grown since the early 1990s (Renfrew, 1997a). One result has been the systematic review, which aims to be an unbiased and rigorous review of research evidence including meta-analysis (Renfrew, 1997b). One such review tool is the Cochrane Pregnancy and Childbirth Database, which is a 
specialist electronic database available on CD Rom or via the Internet (Glanville, Haines \& Auston, 1998; Dickson, 2000). The reviews are carried out by a variety of people, including obstetricians, midwives and consumer representatives and are regularly updated (Renfrew, 1977b). Another example of evidence-based initiatives is the development of clinical guidelines based on research such as such as the National Institute for Clinical Excellence (Page, 2000).

Resources such as the Cochrane database and evidence-based guidelines ensure midwives are able to keep up to date with recent developments in clinical practice, as well as sustain them when they are 'arguing' with people who do not support evidence-based practice (Renfrew, 1997b). There have been criticisms of evidence-based practice including lack of access to evidence-based databases and resources, as well as lack of training and time (Glanville et al, 1998). However, the Internet provides easy and convenient access to sources of evidence-based information. It is such an exciting and valuable tool for midwifery practice with the potential power to improve midwifery care (Kinniburgh, 2001). The Internet also supports the empowerment of the health consumers, who are able to access the same information as health professionals (Ellrodt \& Keckley, 2001).

\subsection{Medicine and e-health}

\subsection{International web sites}

Medicine has taken no time at all to see the benefits of the Internet, and medical advice sites are readily available such as doctorglobal.com (http://www.doctorglobal.com). This 
web site is owned and operated by a team of doctors who offer online consultations in clinics ranging from general medicine to sexual health. These consultations are private and incur a cost to the consumer. The site also offers the ability to create one's own health record, which would contain details of each health consultation or episode. Record updates could be entered from the doctor, pharmacist, hospital, pathology services and even overseas health services.

There are always concerns about the increase of technology in health care. An example involves electronic health records. Advocates of electronic records emphasise the advantages of lowered costs, continuity and consistency of medical care and records, as well as providing data for research. However, there are anxieties about privacy and confidentiality; who would have access to the records, as well as how difficult would it be to delete information that may be disadvantageous to a person's current health treatment (Merkes, 2000a). Computer and Internet breakdown could inhibit access to the records just at a time when access was vital.

Obgyn.com (http://www.obgyn.net/home.htm) is a web site managed from the USA and is a network for doctors, medical professionals and women, specifically dealing with women's health issues. The site contains a myriad of articles and information about issues facing birthing women including lupus, pre-eclampsia and breech, and it has a strong North American influence that may not be relevant for New Zealand. It also produces an e-mail newsletter. 
Medscape.com ( http://womenshealth.medscape.com ) is a similar web site managed in the USA. Targeted at North American physicians, midwives can find useful information about any issues regarding women's health, sign in for a weekly e-mail newsletter and access various databases such as Medline. One has to register but the services are free of charge.

\subsection{Medicine and the Internet in New Zealand}

In New Zealand, one of the major Internet providers Xtra, offers an 'ask the expert' option on their home page (http://xtra.co.nz/health ). One can question physicians in numerous areas of health, and ask questions as diverse as 'is heavy vaginal discharge normal?' to 'what's the lump on my finger?' These are not private consultations as with doctorglobal.com and are free of charge. One can browse through all the questions asked and answers given by the various doctors.

There have been two studies carried out recently into the use of the Internet by GPs. The first study was a postal survey of GPs in the Southland and Otago regions who were known to the Department of General Practice in the Dunedin School of Medicine, asking them about their use of the Internet and their impressions of patient use of online medical resources (Eberhart-Phillips, Hall, Herbison, Jenkins, Lambert, Ng \& Rankin, 2000). There was a 65 per cent response rate to the 259 questionnaires sent out. Fifty five per cent of respondents had access to the Internet at home and 36 per cent had access at work. Sixty eight per cent of respondents said they used the Internet at least monthly, while 71 per cent indicated they used the Internet to search for medical information. 
The second study was a postal and fax survey of 456 randomly selected GPs in New Zealand (Kerse, Arroll, Lloyd, Young \& Ward, 2001). These GPs were asked about their access to the Internet and their use of the Cochrane database. There was an 83 per cent response rate. Forty per cent of respondents had access to the Internet at work, and 76 per cent had home access. Fifty six per cent of respondents had used the Internet with regard to a patient. Although half of the GPs knew about the Cochrane database, only 15 per cent had used it. Seventy one per cent of respondents had had patients who had spoken to them about information found on the Internet, and 25 per cent were concerned about the quality of the information. Some respondents ( 25 per cent) said the Internet had changed their practice and two-thirds of them viewed the changes as positive. There was concern about the effect on the doctor-patient relationship with 27 per cent of respondents expressing concern about the undermining of doctor-patient trust, with 45 per cent of GPs concerned about resource implications.

\subsection{Effect of the Internet on relationship of consumers and health professionals}

There is discussion in medical literature about the effect of consumers becoming highly informed through use of the Internet (Jadad, 1999). There is a fear that consumers are now more knowledgeable than the 'all-knowing' doctor, and in turn concern about the effects that has on the doctor-patient relationship (Eberhart-Phillips et al, 2000). Some doctors have articulated an anxiety that the Internet will diminish trust between doctor and patient (Eberhart-Phillips et al, 2000). There is talk about the Internet necessitating an approach of partnership, teamwork and cooperation (Pemberton \& Goldblatt, 1998). 
Midwives in New Zealand have practised this philosophy for some years (Guilliland \& Pairman, 1995), and certainly there is evidence that midwives welcome the open access that the Internet provides to information (Loy, 2001a).

\subsection{Guidelines for dealing with Internet-literate patients}

Pemberton and Goldblatt (1998) have issued guidelines for doctors on how to deal with Internet-literate patients, which can also apply to midwives. These guidelines advise:

\section{Do}

Try to react in a positive manner to information from the Internet.

Warn about the variability in the quality and reliability of material from the net.

Warn about your time constraints regarding information overload.

Develop a strategy for dealing with Internet information from patients (eg get patient to e-mail summary before visiting).

Accept patient and family contributions as part of the management team.

Accept that they may have valid information that you have not come across.

\section{Don't}

* Be dismissive or paternalistic.

* Refuse to accept Internet material.

* Try to one-up your patients and their families regarding the information.

Break normal rules of patient confidentiality via the Internet.

Be derogatory of comments made by others on the Internet

Ironically, the elements of these guidelines have been enshrined in the Midwives Code of Practice since 1993 (NZCOM, 1993). 


\subsection{Midwives and e-health}

Midwives are only just recognising the potential of the Internet for midwifery research, professional practice and education.

\subsection{John Loy's research}

There are very few examples of midwives using the Internet as a tool for research, and even fewer examples of research carried out into how midwives use the Internet, which is why John Loy's (2001a) work is so important. Loy (2001a) surveyed British midwives and student midwives about their use of the Internet using a paper and electronic version of a questionnaire. He attached his survey to the MIDIRS web site (http://midirs.org.uk). The midwife could access the questionnaire via the web site and download it into a word processing program onto a computer, complete the questionnaire and then e-mail it back to Loy. In order to capture non-users as well as users, Loy also distributed his questionnaire on paper. Loy recruited participants by advertising on two e-mail discussion lists based in the United Kingdom (UK), as well as in the MIDIRS digest. Loy added an incentive for the midwife to complete the questionnaire. The incentive was of being put into a draw to win one year's subscription to MIDIRS. He distributed 500 paper questionnaires and had a response rate of just over 20 per cent with 141 completed questionnaires, although he did not make it clear in his published report whether the responses were from the paper or Internet questionnaire. 
Loy (2001a) found that 55 per cent of respondents had access to the Internet at work, and 95 per cent had home access. Respondents were using the Internet frequently, with 45 per cent using it 2-3 times per week. Loy established that 65 per cent of respondents were aware of an increase in the use of the Internet by women in their care, and nearly 50 per cent of midwives had been asked to discuss information presented to them by their clients. The midwives were mostly positive about the increase in consumers' use of the Internet and felt that it was a move toward a more equal partnership between midwives and women. Thirty per cent of respondents had had experience of e-mail discussion lists The barriers to use of the Internet were mostly time and training. Respondents were familiar with online databases, with over 75 per cent having used an online database, and nearly 50 per cent had taken advantage of the electronic version of the British Medical Journal or Lancet.

The limitations of the study were the small number of respondents, which meant that the study was not representative of the general population of midwives in the UK. A further limitation was the questionnaire design, which restricted the detail of data obtained. Despite the limitations, I believed the study was worth replicating in New Zealand to build on the information that Loy gathered, which would add an international perspective. It would give a picture of Internet use by a community of midwives that differed in roles and responsibilities from midwives in the UK. Loy's questionnaire was easily accessible to me via e-mail, once I obtained Loy's permission to use it and incorporated questions about most of the issues that I wanted to explore in my research. 


\subsection{Midwives' use of the Internet}

One example of how a midwife has used the Internet in her professional practice is Jude Stensland Kurokawa (1996). Jude was the only midwife for 350 miles in Montana, USA. She rarely met other midwives because of the distance to travel and she worked on her own. Jude wrote that midwives, especially rural midwives should avail themselves of the support, education and camaraderie that is generated by electronic communication. Electronic communication helped Jude to find new friends, develop her midwifery skills and increase her knowledge. A further advantage of the Internet for Jude in her rural practice was that she was able to access online databases such as Medline, which she had been unable to access otherwise because she was too many miles away from a library. Midwives in New Zealand, especially rural midwives face the same challenges: practising in isolation, possibility of burnout, fears about level of income, and finding locums for holidays and professional development (Patterson, 2000). They too could find the same practice support as Jude by utilising the Internet and its resources.

\subsection{Midwifery education on the Net}

The Internet allows flexible delivery of education, especially for students who live in remote and rural areas (Fahy, Evans \& McDonald, 1999). Online education is likely to appeal to rural midwives in New Zealand, who live some distances from education providers. The extra cost of flights and accommodation are all factors that the rural midwife has to carefully consider before she embarks on a postgraduate program of study. Time away from her practice may mean the midwife looses revenue from missing 
a birth. Online education allows the midwife to stay at home and organise her study around the commitments of her practice.

Online course delivery allows students to work at their own pace, and encourages the learner's independence (Bachman \& Panzarine, 1998). It is particularly attractive for students who are busy juggling work and home responsibilities (Bachman \& Panzarine, 1998). Students can be supported in their self-directed learning with discussion groups, collaborative learning groups, online assessment tasks as well as direct e-mail with lecturers (Fahy et al, 1999).

There are examples of midwifery education utilising the Internet being offered in Australia. One such example is organised by the University of Southern Queensland for registered nurses training to become midwives in the rural Cairns region (Brampton, 2000). This course combines interactive CD-ROM and Internet, as well as local residential schools to provide midwifery education/knowledge. Support and mentoring is provided by local midwives, as well as the university lecturers. The outcome of the course is full midwifery registration.

As far as I am aware, there are very few midwifery education programs available on the Internet based in New Zealand. Otago Polytechnic in Dunedin offers a paper entitled 'Applied science for registered midwives on the Internet' (http://www.tekotago.ac.nz/PolyPublicCourses/P_Domestic_SchoolCourseLists.cfm ). It offers 16 modules covering all the systems of the body. The mode of delivery is via 
weekly chat room sessions and daily email communications. Electronic exercises are undertaken as part of the assessment requirements. The paper can either be studied in isolation or used in a midwifery degree program.

\subsection{Internet resources that are available to midwives and support}

\subsection{E-mail discussion lists}

Spender (1995) maintains that the Internet can generate scholarly discourse.

E-mail, newsgroups, bulletin boards and synchronous chat groups are all examples of forums that facilitate increased exchange of information as well as the opportunity to keep up to date with current issues (Sudweeks \& Simoff, 1999). These forums facilitate the articulation of new ideas, brainstorming, collaborative efforts and consensus creation (Rojo, 1995).

E-mail discussion lists provide online forums that facilitate collaborative sharing of information, support for participants, networking and help with professional queries that overcome constraints of time and geographical distance (Anthony, 1996; Rojo, 1995; Bowles, 1996; Murray, 1997; Berge, 2000). Discussion lists can provide a safe environment to propose ideas that receive feedback from people with a wide spread of experience and skills (Berge, 2000). The disadvantages are overload of mail and irrelevance of content as well as conflict and inappropriate posts (Fahy, 2000; Rojo, 1995; Berge, 2000). Midwifery e-mail discussion lists addresses all manner of issues 
from the clinical approach to meconium stained amniotic fluid to whether women should be offered a choice of caesarean section (Fahy, 2000).

Loy (2001a) found that only 30per cent of the midwives he surveyed used e-mail discussion lists. Whilst those that accessed this resource valued it for networking, tracking down information and stimulating conversation, the majority of midwives were reluctant to make use of this facility. Sinclair (2001) feels that e-mail discussion lists are one avenue of contributing to discussion of professional issues, and a technological tool that can be utilised for professional development.

\subsection{Electronic databases}

It is vital for midwives to be able to search for evidence of 'best practice' in order to develop midwifery practice. Developing and utlising computer skills to do this is a very important part of professional midwifery practice (Sinclair, 2001). Electronic databases, newsletters and journals are all resources where midwives discover such evidence. The utilisation of these tools can enhance midwives' personal professional development as well as facilitate another element to midwives' partnership with women, in facilitating women's informed decision-making.

There are various databases available to midwives. The Cochrane database is usually free to students of universities and polytechnics; otherwise midwives have to pay to access it (http://www.cochranelibrary.com/clibhome/clib.htm). The abstracts can be accessed free of charge (http://www.cochrane.org/cochrane/revabstr/g010index.htm). The PubMed Medline database is free of charge (http://www.ncbi.nlm.nih.gov/PubMed). CINAHL is 
usually available free of charge through university and polytechnic libraries (Brown, 1999).

As far as I am aware, the MIDIRS database is the only midwifery specific database available online. Since its launch in June 2000, over 2500 midwives have signed up to this service (Loy, 2001a).

\subsection{Evidence-based guidelines}

Guidelines have been developed to aid midwives search databases

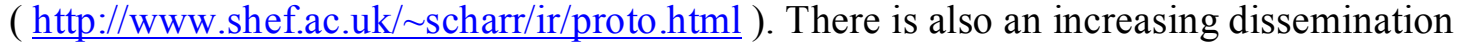
of information about databases and web sites, which should increase midwives' awareness of what is available (Sandall, 1999; Oldershaw, 2000). A number of midwifery journals such as MIDIRS regularly produce web site reviews (Loy, 2001b).

There is online access to groups that have produced guidelines based on bestpractice/evidence-based practice. The New Zealand Guidelines Group sends free Bulletins by e-mail free of charge to midwives. The purpose of the Bulletin is to summarise news and information about evidence based healthcare activities in New Zealand (http://www.nzgg.org.nz/bulletin/current.cfm). Midwives can access the Group's web page and check out the evidence-based guidelines that are being produced by health professionals (http://www.nzgg.org.nz). The National Institute for Clinical Excellence (NICE) guidelines were set up by the National Health Service in the UK in 1999 
(http://www.nice.org.uk) (See Appendix Two). Midwives can access guidelines on such issues as caesarean section, induction of labour and electronic fetal monitoring (EFM). The guidelines are also presented in a user-friendly format specifically created for consumers. Evidence-based guidelines about Anti-D immunoglobulin can be found at the web site of the Royal Australian and New Zealand College of Obstetricians and Gynaecologists (http://www.ranzcog.edu.au ). Royal College of Obstetricians and Gynaecologists (http://www.rcog.org.uk/guidelines/eb_guidelines.html ) has more guidelines on induction of labour, EFM, management of infertility and induced abortion.

As Kerse et al (2001) points out, it is one thing having access to up-to-date evidence, evaluating the evidence and integrating it into practice is quite another. The New Zealand Guidelines Group has produced a booklet that can be downloaded from the Internet on how to evaluate and implement evidence-based guidelines ( http://www.nzgg.org.nz/development/nzgg guideline handbook.pdf). This booklet is a useful tool for midwives involved in developing evidence-based practice guidelines.

\subsection{Electronic journals}

Midwives are exhorted to publish their research in scholarly journals as a way of generating midwifery knowledge and also to conform to academic pressure (Hardey, 1996). Publishing one's research findings on the Internet is now a very real possibility. This can be done either through one's own web site or via electronic journals. 
There are hundreds of electronic journals, which can be confusing for midwives. The British Journal of Midwifery (http://www.britishjournalofmidwifery.com) has a selection of articles online, as does the Association of Radical Midwives (http://www.radmid.demon.co.uk), and Association for Improvements in the Maternity Services (AIMS) (http://www.aims.org.uk). Midwifery Today ( http://www.midwiferytoday.com) features a newsletter that is distributed weekly by email. There are various medical journals that publish articles online, such as the British Medical Journal (http://www.bmj.com) and Medical Journal of Australia ( http://www.mja.com.au). As yet, there is nothing similar being produced in New Zealand. This is not unexpected as the midwifery profession is still in the early stages of producing an internationally recognised academic paper journal, in the form of the New Zealand College of Midwives' Journal. Loy (2001a) found that nearly 40 per cent of midwives he surveyed would prefer electronic delivery of midwifery journals.

The advantages of electronic journals are that they have the potential to reach a much larger audience than that of paper journals (Sparks, 1999). They do not have the manufacture and distribution costs of conventional publications (Hardey, 1996). They may be more easily accessible for midwives than some paper journals, especially for midwives who cannot afford to buy their own copies of journals and who are unable to visit libraries that keep copies of particular journals (Hardey, 1996). This is especially relevant for midwives in New Zealand because of the dominance of foreign currency, which makes it very expensive to buy journals from overseas. A further advantage is the immediacy of publication (Sparks, 1999). Once an article has been accepted for 
publication in an electronic journal, it can be made obtainable online almost immediately. One common feature that is particularly valuable in electronic journals is the facility for immediate connection, by e-mail, to the author of the article.

Disadvantages of electronic journals are that one needs a computer, modem and software to be able to read them unlike hard copy that can be read without any technical equipment, any time, any place (Sparks, 1999). Paper can survive a multitude of environmental hazards and can be kept until it deteriorates. However, Internet publications can be fleeting at times; connection links may break down or there may be an incompatibility of software (Sparks, 1999).

It is the attitude of some that the academic credibility of electronic journals is inferior to paper journals especially if they are not peer-reviewed, and because of the prevalent view that anything published on the Internet is 'trivia and trash' (Hardey, 1996). However, many electronic journals are peer-reviewed and of course, one could answer that academic credibility is not as important as having one's work read by a limitless audience. Journals such as Sociological Research Online ( http://www.socresonline.org.uk/socresonline) are rigorous in their editing procedures, and authors find the process of submitting work for electronic publication as strenuous as in paper journals (Peters, 1998).

Plagiarism is an increasing problem because of the ease with which material can be copied and transported (Barrie \& Presti, 2000). There are various ways of preventing this such as password protection, digital watermarking (Sparks, 1999) and the use of software 
that is designed to detect plagiarism (Barrie \& Presti, 2000). To reduce this problem, emphasis must be continually placed on the ethics of respecting individuals' intellectual property and copyright.

\subsection{Other electronic resources}

It is possible for midwives to carry out a range of activities via the Internet. One can order midwifery books and teaching equipment from MIDIRS and Ace Graphics ( http://www.acegraphics.com.au). However, for midwives in New Zealand this is an expensive endeavour because of the current weakness of the New Zealand dollar.

One can also find information about midwifery conferences, as well as submit abstracts, register and pay. The 2002 NZCOM conference is advertised on the Internet (http://www.nzcom.org.nz/conference2002). The next International Congress of Midwives conference is in April 2002, in Austria. Midwives can find details and register (http://www.icm-congress.com/content.html .

\subsection{Personal web sites}

Personal home pages are an opportunity for people to construct 'virtual' identities (Chandler, 1998). The form and content of the home page reflects personality, personal and professional interests, and biographical details. Further clues to personality are the links to other web pages (Slevin, 2000). Midwives may develop home pages purely for personal reasons - for example, to share news with family and friends (Wallace, 2001). Or they may use personal web sites as an avenue for advertising and generating 
information for women and their families, as well as communicating with colleagues (Bush, Wooldridge, Foster, Shaw \& Brown, 1999). There has been little information in midwifery or nursing press to support midwives developing their own home pages (Van Carrapiett, 1999; Shellenbarger \& Thomas, 1996). So it may be that they have to turn to a professional web designer to help them (Knuth, 1998). Additional considerations that can be prohibitive are that maintaining personal web sites are time consuming, and midwives may not want to open themselves up to a potential audience of millions of people (Wallace, 2001).

Rather than fearing the expansion of Internet technology, some midwives identify with nurses who are concerned that there is a danger of being left behind by groups who have a vested interest in the Internet, such as the medical profession (Desborough, 1999). Writers have talked about the authoritative knowledge of medicine (Jordan, 1997). Is this going to extend into cyberspace? Is the Internet going to be manipulated so that medicine can continue to maintain professional power over women? Cyberfeminists would argue that midwives are already disadvantaged by the fact they are women (Spender, 1995). Will midwives be further left behind if they 'allow' medicine to dominate the Internet as it is seen to do in 'real' life? Having said that, there is evidence to suggest that compared to nurses, midwives are quick to take up opportunities to learn and make use of computers (Fleck \& Levy, 1999). This thesis is not intending to supply definitive answers, but rather open the debate to the midwifery community. 


\subsection{Midwives and the Internet in New Zealand}

\subsection{Electronic claiming}

One technological development that will increase options for midwives is electronic claiming of payment from Health Benefits Limited (HBL) (no date). Currently, a pilot project involving four midwives is being carried out, which will be extended to 60 midwives at some stage. If successful, the service will be offered to all New Zealand midwives although no time line has been suggested. In an initial survey carried out by HBL, $60-70$ per cent of midwives indicated they would be interested in this form of claiming for payment (HBL, no date).

\subsection{New Zealand College of Midwives' web site}

NZCOM has its own web site (http://www.midwife.org.nz) (see Appendix Three). The web site has a 'Search for a midwife' facility in which midwives can advertise their services and contact details, so that women can see what midwives are available in their area. The site also has details about its philosophy and objectives, services and policies, consensus statements and information about pre- and-post midwifery education. It has articles of interest, and information on midwifery practice, employment matters and rural codes, that can be downloaded as word documents. The web site also has Internet links to La Leche League, Parents Centre and Plunket.

NZCOM is looking at increasing the Internet facilities it provides for its membership. 
The NZCOM Quality Plan for 2001-2003 includes 'development of an efficient electronic search capability to support the promotion of best practice/evidence based practice, particularly for self-employed midwives without a practice base' (Guilliland, 2001b). I feel that the availability of quality information will become even more important to midwives as competency-based practicing certificates and credentialing becomes a requirement (Pairman \& Guilliland, 2001). Midwives who have not kept up to date with midwifery issues will have to look at ways of becoming informed in order to prove their competency to practice.

\subsection{Home pages}

I have found a few examples of local New Zealand midwives' web pages, such as those of Karen Walker (http://www.midwife.co.nz) and Michelle Lord (http://www.mysite.xtra.co.nz/ FOSKINandLORD). Wendy Earle and Carol Soutter ( http://www.goldenbaymidwives.com ) developed their web page as part of the requirements of a post-graduate program. The midwives of the Auckland University of Technology have a home page where they provide a 'ask the midwife' service for consumers (http://www.aut.ac.nz/groups/autmidwives/msie/800x600/ask.html).

\subsection{Marketing}

Midwives can use the Internet to advertise their services through sites such as the NZCOM 'Find a midwife' or via their own personal home pages. As far as I can see, there has been little discussion in the midwifery press about the use of the Internet for midwifery marketing. This may be because they achieve an adequate caseload through 
more conventional means such as word of mouth? Midwives may not feel a need to develop the technical skills to develop a home page.

\subsection{Barriers to use of the Internet}

\subsection{Fear of litigation}

Increasingly, doctors worry about litigation from face-to-face encounters with patients, and the Internet adds another dimension to this fear (Kassirer, 2000). Doctors and midwives risk being sued for giving advice, diagnoses and prescribing without examining the patient. Unlike verbal conversations, electronic dialogue leaves permanent records, which can be a concern to health professionals who worry about the potential for litigation. The ethical implications also need to be considered. Is it ethical to give advice to a person via the Internet without having any knowledge of their background, and without examining them? As yet, there has been little work in this area.

\subsection{Time Constraints}

Another barrier is time constraints (Pemberton \& Goldblatt, 1998). It can be quite timeconsuming 'surfing' the Internet looking for information, and then trying to decipher it when people present you with pages of material that have been downloaded from the Internet.

\subsection{Face to face versus electronic interactions}

A further obstacle to health professionals' use of the Internet is concerns about reducing face-to-face contact with people. Practitioners can discover a lot of information from 
non-verbal clues such as physical appearance and tone of voice (Kassirer, 2000). This information can be lost in electronic communication. In turn, practitioners commonly utilise the 'laying on of hands' to show empathy and support, give comfort and reassurance (Kassirer, 2000). This is problematic with electronic interaction. On the other hand, the element of anonymity with electronic communication can be liberating and lead to the loss of inhibition (Spender, 1995). Some people feel more comfortable typing out their experiences and feelings because they can express themselves better than in a normal conversation (Spender, 1995; Lakeman, 1997).

Despite concerns about the lack of face-to-face interaction, emotional support, help and assistance seems to be regularly given on the Internet. Jean Camp (1996) relayed an example of how e-mail support can make a difference in real life which midwives can relate to. She was a member of Systers, a mailing group for women involved in computer science. She was to present a paper at an important conference of mostly men, but was still breast-feeding her five month old son. She sent a worried message to the list that morning asking for advice about how to handle the situation. She received lots of responses from women, who had been in similar situations, all reiterating that everything would be fine. Jean attended the conference feeling so much stronger, knowing that she would survive the experience whatever happened.

\subsection{Computer skills}

Negative attitudes to computers have been cited as a barrier to the use of the Internet (Fleck, 1999). Nurses have been shown to be most reluctant to learn about this new 
medium, seeing neither its necessity nor relevance to nursing, or having the time to use it (Farmer, Richardson \& Lawton, 1999; Agnew, 1995). However, midwives have been far more interested in developing their Internet skills (Fleck \& Levy, 1999).

Despite this readiness to explore new technology, midwives are being hampered by a lack of competence and confidence in their computer skills. In a survey of 446 midwives in Northern Ireland, Sinclair (2001) found that midwives perceived their skills were low with word processing as well as use of databases and finding information on the Internet. Only one third of midwives surveyed were able to search databases for information. In a survey of 63 community nurses, midwives and health visitors in the remote Western Isles of Scotland, less than ten per cent of respondents had used databases such as Cochrane, Medline and Cumulative Index to Nursing and Allied Health Index (CINAHL) (Farmer, Richardson \& Lawton, 1999). Only one respondent had used the Internet to search for job-related information.

\subsection{Computer training}

Computer training for midwives has been found to be extremely variable in quality and quantity. Sinclair (2001) argues that technology education must be included in midwifery curriculum. This finding was substantiated by Loy (2001a) who was concerned to find that only 55 per cent of British student midwives surveyed had been offered computer training from the universities at which they were enrolled. No more than 50 per cent of registered midwives had been offered computer training by their employers or institution of study. 
Dale Spender (1996) argues that this lack of information technology (IT) education is indicative of the wider marginalisation of women and computer knowledge. In view of this, as midwifery is a profession dominated by women, one should expect to find that there is a low level of Internet availability for midwives.

\subsection{Age and use of Internet}

Scott (1998) writes that the Internet is the toy of the young, which is significant for the midwifery population of New Zealand because the age of the greatest number of midwives is between 40 and 54 years old (NZHIS, 2001). Scott (1998) feels that the over 40-age group neither understands, has the knowledge nor can relate to computers. However, Sinclair (2001) found no association between the age of midwives and computer use. The greatest age of midwives answering her survey was 30 to 39 years.

\subsection{Critiquing information found on the Internet}

Considering the plethora of health information found on the Internet, it is no wonder that health professionals and consumers are increasingly concerned about the quality and credibility of that information (Merkes, 2000b; Eastin, 2001; Wyatt, 1997). The quality of health information varies considerably, from useful to outright hazardous (Eysenbach, Ryoung Sa \& Diepgen, 1999). It is not unknown for unqualified individuals to pose as doctors, giving bogus advice to people seeking information and advice (Yellowlees, 2000). There has also been discussion about cases of misdiagnosis and wrong treatment 
that has caused death, although there is currently little evidence to dispute or confirm this concern (Smith, 2001).

Little research has been carried out into how health professionals and consumers search for and judge information found on the Internet. However, Eysenbach and Kohler (2002) have found that Internet users explore only the first few links provided by a general search engine; when considering credibility of a web site, users look at appearance and design rather than who the authors or owners of the web site are; Internet users do not read disclaimers or discloser statements; few users remember from where they retrieved information, or who stood behind the web sites. These findings make it all the more important that web sites provide reliable information.

There have been various evaluation tools developed to protect Internet users from unreliable information (Orson, 2000). Alongside the growth of web sites have been academic and commercial criteria that have examined the quality of health web sites (Gagliardi \& Jadad, 2002). Gagliardi and Jadad (2002) have reviewed instruments that give web sites awards for quality. The review has shown that the award systems continue to be created but they usually stop operating soon after their release. Therefore, Internet users cannot place too much credence to awards given to web sites for quality. Alternative strategies for evaluating a web site must be developed.

When reading material in journals or books, there is a good chance that it has undergone some sort of editorial or peer review. Anyone can publish information on the Internet via 
web pages, discussion groups or bulletin boards, and generally there is no form of quality control (Ward, 2001). Well meaning sources of information may be misleading, misinformed or simply out of date (Gomez, DuBois \& King, 1998). Maintaining a web site is time consuming and needs to need updated at least two to three times per year (Gomez et al, 1998). The nature of the Internet is such that what is published one day, has been moved or deleted the next (Drake, 1999). Some people take the view that anything published on the Internet is 'trivia and trash' (Hardey, 1996). Guidelines have been published as to evaluate information found on the Internet (Kirk, 1999; Montecino, 2001).

\subsection{Guidelines for evaluating the Internet}

A compilation of these guidelines are:

Who is the author/source? Is there a way of contacting the author?

What is the author's reputation and qualifications? Is the author a person you recognise as an expert in the subject covered? Has the author had other work published either online or hard copy?

* Is the information reliable and accurate? Is the publication date clearly indicated?

Is the information presented in an objective, balanced manner?

How does the web site compare to other sites on the same subject? Are there links to other reputable sites?

Does the author publish clear and reputable references that you can investigate?

How reputable is the publisher? Does the publisher have an agenda for publishing the material eg is the material published by a commercial site that is advertising 
services/products? Extensions on web addresses give clues as to where the site resides.

.ac - education site in New Zealand

.edu - education site overseas

.govt/gov - government site

.org - organisation

.com - commercial site

.net - network infrastructure

Other extensions include abbreviations for countries, such as au for Australia and nz for New Zealand.

How well is the site maintained? When was the site last updated?

Is it easy to move around the site and locate information?

There are various barriers to the adoption of the Internet by midwives in their

professional practice including fear of litigation, time constraints, reduction of face-toface interaction, inadequate computer skills and lack of training, in addition to concerns about quality of information found on the Internet. There may be broader conceptual reasons why midwives are slow to adopt innovations such as the Internet, which is why I have chosen to consider Rogers' Theory of Diffusion of Innovations (1995).

\subsection{Diffusions of innovations}

Everett M. Rogers (1995) has written about the diffusion of innovations, which may explain why, and how midwives will adopt this new innovation - the Internet. Viewing 
midwives' uptake of the Internet through Rogers' theoretical lens would suggest the following: midwives will only adopt the Internet if they perceive it to be advantageous. The midwife will pass through a process before making the decision whether to adopt or reject the new innovation, depending on how she gathers knowledge and experience of the innovation. She will adopt the Internet as long as she does not perceives it as too difficult to use and is given the opportunity to trial it. The rate at which the midwife will adopt the Internet will depend on which category of adopter she fits into as well as whether the Internet has reached a point of critical mass. A change agent may affect the midwife's decision to adopt the Internet, and one must consider the likely consequences to any decision to adopt or reject this innovation.

\subsection{Adoption of the Internet}

The rate of adoption is the speed with which the Internet is adopted by midwives. The Internet will be calculated in terms of economic advantage as well as convenience, social prestige and satisfaction. In other words, midwives will say that an advantage of the Internet is that it is cheaper than using the telephone. If these terms are not met, the rate of adoption of the Internet will be slow. Adaptation will also depend on midwives' previous experience and whether the Internet is consistent with their own values as well as requirements. Adoption will be a lot faster if midwives perceive the Internet to be easy to learn and use, and are given the opportunity to experiment and observe the results of use of the Internet. Diffusion of an innovation is a social process. The Internet is much more likely to be adopted by midwives if they see that their peers have had a positive experience of the Internet, and adopted it themselves. Trialability is another factor. 
Midwives will adopt the Internet if they are given the opportunity to try it out first (Rogers, 1995).

\subsection{The innovation-decision process}

The midwife will pass through a process before making the decision whether to adopt or reject the new innovation (Rogers, 1995). Firstly, the midwife gains some knowledge of the Internet and learns a little of how it works. Secondly, persuasion takes place when the midwife gains a favourable or unfavourable impression of the innovation. Then the midwife takes part in activities that will lead to her making a decision about whether to adopt the Internet or reject it. Fourthly, implementation transpires when the midwife puts the Internet into use. Finally, the midwife confirms her decision by seeking reinforcement of the innovation-decision. Otherwise, she will reverse her decision to adopt or reject the Internet if she is exposed to conflicting messages about the Internet (Rogers, 1995).

\subsection{Rate of adoption of the Internet}

There are other variables that affect the rate of adoption. An innovation is much more likely to be adopted if the decision to adopt is up to the individual. The Internet will be adopted at a higher rate by an individual midwife at home, than the local hospital. An innovation will be adopted at a slower rate if the decision to adopt has to be made by a number of people. The rate of adoption will depend on the appropriateness of the channel of communication. A complex idea is more likely to be adopted if it is communicated on a one-to-one basis rather than communicated by mass media. The nature of the social system will affect the rate of adoption. By this Rogers (1995) means the norms and level 
of communication of the system. Finally, the rate of adoption will depend on how the change agent operates.

\subsection{Categories of adaptors}

Midwives can be categorised according to how they adopt innovations. The innovator is almost fanatical about new ideas and innovations. She is willing to take risks and has a high level of technical knowledge because she has to be able to cope with the uncertainty of the innovation. The early adopters are the people that others look to. They are not on the fringe like the innovators are. They are only ahead of their peers, which is why they are regarded as role models. The early majority take some time to make up their minds before they take up an innovation. They are followers rather than leaders. A midwife who is a member of the late majority is a person who adopts an innovation after the average midwife. She is pressurised by peers to adopt an innovation and will only do so after all the uncertainly about the innovation has been removed. The laggard is the last midwife in the group to adopt an innovation. Laggards tend to be suspicious of change and innovations. It may be that their resources are restricted so they cannot economically take on the innovation.

\subsection{Critical mass}

In one sense there is no point in a midwife becoming connected to the Internet if no other midwives are connected. Therefore, a critical mass is achieved at a point when enough individuals have adopted the innovation to make its future rate of adoption selfsustaining. After a critical mass has been achieved, the rate of adoption gathers speed. 
Strategies can be employed for getting to critical mass. The strategies include targeting top influential people in an organisation or social system; persuading individuals that the innovation is very desirable; introducing the innovation to a group that is likely to adopt the innovation immediately; and giving incentives until a critical mass is achieved (Rogers, 1995).

\subsection{Change agent}

A change agent is an individual employed to influence people's decision-making processes, usually to adopt an innovation. It may be that a hospital employs a change agent to influence midwives to adopt a certain computer system. The change agent will only be successful if she spends a good amount of time communicating with the individual she is attempting to influence. Success also depends on the change agent being seen to have credibility by the people she is influencing. If she is seen to have nothing in common with the client-system, change will be difficult to achieve. Change agents should be aware of the needs of the people they are attempting to influence. Change will be difficult to affect if there is no compatibility between the people's needs and the innovation. The change agent also needs to be empathic with the people they are influencing. To be able to do this, the change agent must have good interpersonal skills (Rogers, 1995).

\subsection{Consequences of innovations}

Consequences are the result of the adoption or rejection of an innovation. Sometimes the consequences are not what were expected or desired. Desired consequences are the 
functional effects of an innovation on an individual or social system. Undesired effects are dysfunctional effects of the innovation. It may be that the effects are desirable for the social system but undesirable for certain individuals. Direct consequences are the changes to individuals or social system as a result of the innovation. Indirect consequences may be the result of the original consequence. Anticipated consequences are the expected results of the innovation. Unanticipated consequences are results of the innovation that are not expected.

\subsection{Conclusion}

\subsection{The research question}

The Internet is a relatively new area for midwifery research so it is difficult to know where to start when exploring midwives' use of the Internet. Thus, I feel it is appropriate to carry out a pilot survey that determines what areas will lend themselves to additional exploration in a national study. I have struggled to know what particular facet of the Internet to investigate in depth because there are many fascinating issues to explore, especially as all these areas are new to midwifery research. So I have started with a survey of how midwives in New Zealand use the Internet with the view that it is a beginning point for future research. It is possible that midwives do not fully utilise all the resources available to them such as advertising, personal web pages, databases, e-mail discussion groups and so on. The Internet is a resource that can enhance clinical practice, for example by providing access to evidence-based practice, as well as development of midwifery knowledge. So if midwives do not fully exploit the Internet, I believe that the development of the profession will not be as comprehensive as it could be. 


\subsection{Pilot study}

I have designed a pilot study with two main aims. The first aim is to trial a survey of midwives' use and attitudes toward the Internet. The second aim is to trial the use of the Internet as a research tool. These aims will be discussed in greater depth in the next chapter.

\subsection{Internet as a tool for research}

The Internet is a relatively new medium for research. Internet research has two elements to it. Firstly, it can provide material for research such as computer-mediated communication, synchronous real-time interviews, video-conferencing, interactive meetings or conferences, focus groups and web sites (Costigan, 1999; George \& Hughes, no date). The Internet can also be employed for recruiting participants for research studies, as well as being an effective and economic tool for collecting information (Costigan, 1999).

There is a dearth of midwifery research, both using the Internet as a tool and source for research. Miller, King, Lurie and Choitz (1997) applied a survey through an Internet bulletin board to question certified nurse-midwives (CNM) about conflict and collaboration in their practice. Bulletin boards are computerised meetings where people can deposit and gather information (Mann \& Stewart, 2000). Miller et al (1997) concluded that a larger, national study of CNMs would be more appropriately served by a mailed questionnaire that allowed for open-ended questions and responses. Sara 
Wickham (1999) used e-mail and electronic dialogue to question midwives about their knowledge of postnatal anti-D administration and explore their attitudes. She was able to talk with midwives in such diverse locations as Australia, Japan and Mexico.

A pilot study should generate knowledge about use of the Internet as a research tool. It should enable the production of information for midwives about the advantages and disadvantages of using the Internet as a tool for research, so that if they choose to use the same method, they can incorporate the outcomes of my experience into their research.

\subsection{Summary}

The Internet has expanded rapidly over the last few years and presents a number of possibilities for e-health. Consumers' interest in e-health is growing significantly and this has ramifications for health professionals. Doctors and midwives are recognising the potential of the Internet including the role it plays in providing evidence for best practice. Rogers' theory of the diffusion of innovations suggests why and how midwives adopt the Internet. This has led me to devise a pilot study that will survey midwives in New Zealand about their use and attitudes to the Internet. The next chapter will describe the method employed and the aims of a pilot study. 


\section{Chapter Three}

\section{Methodology}

\subsection{Introduction}

This chapter will describe the aims of the study and provide a rationale for why I chose the particular methodology. The chapter will then go on to examine the study design which will include a discussion of how I used the questionnaire developed by John Loy and modified it for use in New Zealand. I will explain how the sample was recruited and the sampling issues that needed to be considered in the research. I will give details about the pre-test and clarify issues that are specific to Internet questionnaire design. I will discuss analysis issues as well as points of interest around ethics and the Treaty of Waitangi.

\subsection{Aims of the study}

\subsection{Internet use and attitudes}

My ultimate goal is to carry out a national survey of midwives in New Zealand to find out how they use the Internet, and their attitudes to the Internet. I consider the survey approach will be appropriate for this because it allows for collection of data from a large population, relatively easily without incurring huge costs (Wagstaff, 2000). However, survey research is not without its problems. In order to discover these problems and iron them out before I embark on a national study, a decision was made to carry out a pilot study. 
I carried out this study because I believed it was important to know how midwives in New Zealand were using the Internet. Leaders of the profession such as NZCOM, providers of education and employers of midwives, will be able to use the information gathered to look at where the gaps are, and what they can do to improve midwives' access to the Internet and the way they use it. All this can be done with a view to improving quality of practice by increasing access to information. Increasing communication, collaboration and networking between midwives will also work towards developing the profession, both nationally and internationally.

\subsection{Internet research}

I have chosen to survey midwives in New Zealand about their use of the Internet by web-based questionnaire because it seems logical to use the Internet as a tool for research. Thus, another aim of this pilot study was to allow me to explore how appropriate a web-based questionnaire is as a method for surveying midwives. I intended to discover what similarities and differences exist between traditional survey method and Internet survey. I also wanted to find out what issues one must consider when designing an Internet questionnaire. There is little information about the Internet as a tool for research in midwifery literature, so one of my research aims was to generate knowledge for midwives regarding the Internet as a tool for research.

\subsection{E-mail snowballing}

The pilot study recruited midwives using an e-mail snowballing method. I chose this approach as a way of finding out how much of an electronic midwifery network existed in New Zealand. The other aim was to find out how effective e-mail snowballing was as 
form of recruitment, especially as it was a method of recruitment that I had not seen being explored in the midwifery literature.

\subsection{Design}

The design is a descriptive survey using a questionnaire. The survey was administered by the Internet using a questionnaire developed in the UK and modified for use in New Zealand. The pilot study was been designed to test the questionnaire, examine the feasibility of applying a survey via the Internet, and test a method of analysis.

\subsection{Reminders}

Reminders are known to increase response rates (Oppenhein, 1992). However, the questionnaire was completely anonymous, so it was impossible to send reminder e-mails because there was no way of knowing who had submitted a questionnaire and who had not. I did not offer incentives because of financial constraints and I would not have known who to send them to. Whilst small incentives have been found to be helpful for increasing return rates for paper questionnaire (Oppenhein, 1992), there appears to be differing opinions about the value of incentives for Internet research. Witmer, Colman and Katzman (1999) report that incentives are a requirement, whereas Brennan, Rae and Packeral (1999) found that they make little difference to response rates. Problems with incentives are that they can encourage multiple submissions, falsification of data or misrepresentation of identity (Batagelj Lozar \& Vehovar, 1998). 


\subsection{The survey tool}

\subsection{Questionnaire}

Burns and Grove (1993) encourage researchers to use previously developed questionnaires as a blueprint. My study was informed by the study carried out by John Loy (2001a) as described in Chapter Two. I had several e-mail conversations with Loy about his research, and obtained permission from him to use his questionnaire as a framework, which I was able to download from the Internet (Loy, 2000). Whilst I was aiming to obtain similar information as Loy, I needed to adjust the questions and change the format of the questionnaire in order to improve the quality of data received (Burns \& Grove, 1993).

The questionnaire I developed consisted of 72 questions (see Appendix Four). Loy placed tick boxes before the questions, however I placed tick boxes following the questions as advised by Dillman (2000). The questionnaire was divided into eight sections. Loy's questionnaire had only three sections. By splitting the questionnaire into more sections, I aimed to make the questionnaire easier to follow and complete. Section One asked general questions about use of the Internet, which aimed to gain the respondents' interest in the survey. Loy commenced his survey asking for demographic details, but this is contrary to recommendations that they are gathered at the end of the survey (Dillman, 2000). So I gathered demographic data in the last section of the questionnaire. 
I found that I had to look very carefully at how I constructed a question. There were times when Loy asked a question which had an assumption embedded in it. For example, one question asked 'what are the main barriers to your use of the Internet?' The question assumed that there were barriers to use of the Internet. In the questionnaire I developed, I split the question in half and asked if there were any barriers to use of the Internet. If the respondent replied in the affirmative, she was then asked what the barriers were.

Loy did not differentiate between work, home and study in his questions which made it very difficult to work out where and how midwives were using the Internet. Thus, in Sections Two, Three and Four of the questionnaire, I separated out the three locations and asked about use of the Internet according to the location. One issue to consider in New Zealand is how one defines 'place of work'. For the majority of midwives in the UK 'work' means a hospital. However, in New Zealand, the self-employed midwife's place of work may be based in her home. Therefore, the midwife will use the Internet for work and personal reasons in the same location. I also gave respondents the opportunity to write text answers to questions about what information they found on the Internet and how they incorporated it into their practice.

One problem with some of Loy's questions was that he gave options to answer and qualified the answer, which could have been misleading. This is exemplified by his question that asked about the respondents' experience of finding information. The respondents were given the options of replying:

\section{Easy, I have no problems}


Fairly OK, but I have encountered some difficulties

Difficult, but I have found useful information eventually

Impossible, I have never really found anything of use.

I changed the format of the options for reply, with the intention of preventing any confusion over the answers:

Easy

Reasonably easy

Difficult

Impossible

In the work section, I asked an additional question about using the Internet to deliver lectures, tutorials or counselling to students. This additional question was directed toward any midwifery lecturers answering the survey. In the study section, I asked a question about being enrolled in a program of study delivered via the Internet in order to ascertain how many midwives were accessing education via the Internet. Loy asked about respondents' knowledge of NHSnet and The National Electronic Library for Health. I did not ask those questions because I believed they were not relevant to New Zealand midwives.

Section Five solicited information about use of the Internet by consumers. In addition, I asked if midwives had gained clients via the Internet and by which channel including the NZCOM 'search for a midwife' facility. I also asked questions about delivering midwifery care via the Internet. The problem with this was how one would define 'midwifery care'. In the questionnaire I defined midwifery care as advice, diagnosis, or 
prescription of treatment, and gave respondents the opportunity to write what other care they may give.

Section Six enquired about use of e-mail discussions lists/groups. I expanded this section and asked about the lists that midwives belonged to, including the New Zealand Midwives List. I split Loy's question about respondents' impressions of e-mail discussion lists, into two questions about advantages and disadvantages.

Section Seven elicited information about Internet resources. Loy asked about resources that are available via a 'gateway'. Not knowing what a gateway was myself, I changed the question and asked respondents what resources they had made use of. I used New Zealand examples to illustrate what I meant, such as The New Zealand Nursing Council as an example of a statutory body. I then used the same list of resources and asked what midwives would like to be able to access in the future. I added electronic claiming as an issue that would affect New Zealand midwives. I also gave the respondents the opportunity to write resources that I had not included. Loy asked for respondents' views on registering a personal profile of interests on a gateway. I did not include this question because I did not see the need for that information. Loy asked about respondents' use of the British Medical Journal and Lancet. I did not include this question because the journals are medical rather than midwifery resources. Loy also asked if respondents thought it would be useful to have midwifery journals in the same format as the British Medical Journal and Lancet. I did not ask this question because I had already addressed the issue in the earlier question about what resources midwives would like to access in 
the future. In addition, I asked if respondents had their details on the NZCOM web site and if they had their own personal web site.

Section Eight gathered demographic information used for statistical classification and comparisons. I changed some of the job titles to fit the New Zealand situation and did not include student midwives. I also incorporated urban/rural as categories. The age categories I reduced from ten-year intervals to five-year intervals. This was to fit with the categories in the 1999 New Zealand Workforce Statistics report (NZHIS, 2001). Loy asked in which year had midwives qualified. I changed that to ask how many years midwives had been qualified.

I also had to keep in mind that the context in which Loy surveyed midwives was different than that of New Zealand midwives. Midwives in the UK are mostly employed by a hospital and do not work in relationships with women over a period of months. Many midwives in New Zealand are LMCs and self employed, which may mean that their use of the Internet differs from midwives in the UK. 
Figure 1 outlines the differences in recruitment processes between this pilot study carried out in New Zealand and John Loy's study in the UK.

\begin{tabular}{|c|c|}
\hline John Loy - United Kingdom & Sarah Stewart - New Zealand \\
\hline 1. Surveyed midwives and students. & 1. Surveyed midwives only. \\
\hline $\begin{array}{l}\text { 2. Survey downloaded from web and } \\
\text { returned by e-mail. Required word } \\
\text { processing computer program. }\end{array}$ & 2. Web-based survey. \\
\hline $\begin{array}{l}\text { 3. Recruitment via web, e-mail, discussion } \\
\text { groups, paper. }\end{array}$ & 3. Recruitment via e-mail networking. \\
\hline 4. Surveyed Internet users and non-users. & 4. Only accessible to Internet users. \\
\hline 5. Used incentive. & 5. No incentive. \\
\hline $\begin{array}{l}6 . \text { Very large potential population of } \\
\text { midwives. }\end{array}$ & $\begin{array}{l}\text { 6. Potential population of approximately } \\
2000 \text { midwives. }\end{array}$ \\
\hline
\end{tabular}

Figure 1. Differences in recruitment process

\subsection{Survey length}

There is disagreement about the impact of the length of survey and response rates.

Batagelj, Lozar and Vehovar (1998) found respondents were less likely to complete the questionnaire if it took them longer than 20 minutes to finish because they lose interest, whereas Farmer (no date) believed 15 minutes is the maximum before respondents begin to make errors such as not fully completing questions. In contrast, Witmer et al (1999) maintained that length had no bearing on response rate. The survey I developed took between 10 and 15 minutes to complete depending on the midwife's familiarity with computer technology.

\subsection{Web site}

The questionnaire was posted on a web site (http://www.midwifesurvey.co.nz) that had been developed for that particular purpose (see Appendix Five). The other possibility 
would have been to attach it to a web site that already existed such as that of NZCOM, the Graduate School of Nursing and Midwifery at the Victoria University of Wellington, or the Otago Polytechnic. However, by developing a specific site I avoided potential problems of control, access and technology.

The web site was made up of three pages which contained information about the survey and how to operate the web site, information about ethical issues and frequently asked questions (FAQs) (see Appendix Six). Links were provided to these organisations so that participants could be assured of the scholarly intent of the web site and could verify my credentials, which researchers have established is important for participants to be able to do (Hamilton, 1999; Smith, 1997).

\subsection{Pre-testing the questionnaire}

I carried out a pre-test involving six midwives and two Internet scholars. The purpose of pre-testing the questionnaire was two-fold. Firstly, to ensure the questionnaire was both valid and reliable (Cluett, 2000) and secondly, to 'test' the web site. One of the midwives was a colleague who admitted to being 'computer phobic' so I was confident that if she could operate the web survey, anyone could! I also put out a request for advice about Internet research to the e-mail discussion list, which is facilitated by the Association of Internet Researchers (air-1@info.comm.uic.edu). I had several responses, including Kim Sheehan (2001) in the USA, who was experienced in e-mail and web surveys. She promised to give me advice about the set up of the questionnaire when it was fully 
developed. A statistician, who was able to give an opinion as to whether the questionnaire lent itself to statistical analysis, also critiqued the questionnaire.

My colleagues were asked to comment on the information e-mail as suggested by Cluett (2000), considering both content and process matters.

1. Would you carry on and do the survey or delete the letter as junk mail?

2. Is the information clear, or do I need to change it?

3. Are there any confidentiality issues for you. - if so, what are they?

4. Would you be happy to send on this letter to colleagues, and e-mail me back to say you've done it, or do you think I'm asking too much of midwives?

They were also requested to comment on the Internet questionnaire (Wagstaff, 2000).

1. Are the instructions to the questionnaire clear/could you 'work' the survey?

2. How long did it take you to complete the questionnaire?

3. Did you feel the questions were appropriate and relevant?

4. Are there any topics you feel need to be included or taken out? 
A summary of the feedback provided is found in Figure 2.

\begin{tabular}{|c|c|c|}
\hline $\begin{array}{l}\text { Information e-mail and } \\
\text { survey before pre-test }\end{array}$ & Feedback & $\begin{array}{l}\text { Changes made to information } \\
\text { e-mail and survey }\end{array}$ \\
\hline $\begin{array}{l}\text { Midwives asked to forward } \\
\text { e-mail letter to five } \\
\text { colleagues. }\end{array}$ & This was an imposition. & $\begin{array}{l}\text { Midwives were asked to forward } \\
\text { letter to as many colleagues as they } \\
\text { were able. }\end{array}$ \\
\hline $\begin{array}{l}\text { Photo of myself on front } \\
\text { page of survey. }\end{array}$ & $\begin{array}{l}\text { Photo was good - helped to } \\
\text { form 'relationship' with } \\
\text { respondent. }\end{array}$ & No change. \\
\hline $\begin{array}{l}\text { Black was the colour of the } \\
\text { background of the survey } \\
\text { introduction pages. }\end{array}$ & Colour was too dark. & $\begin{array}{l}\text { Colour changed to purple, which is } \\
\text { perceived to be the midwifery } \\
\text { colour in New Zealand. }\end{array}$ \\
\hline $\begin{array}{l}\text { Three introductions pages } \\
\text { to survey, containing } \\
\text { instructions for survey, } \\
\text { details about ethical issues } \\
\text { such as confidentiality, and } \\
\text { FAQs. }\end{array}$ & $\begin{array}{l}\text { The three survey } \\
\text { introduction pages were too } \\
\text { long, which may put } \\
\text { respondents off. }\end{array}$ & $\begin{array}{l}\text { Information was made a lot more } \\
\text { concise. Font was changed from } \\
\text { New Times Roman to Arial to make } \\
\text { it 'friendlier' for respondents to } \\
\text { read. A separate page was made } \\
\text { with further research information, } \\
\text { which respondents could access if } \\
\text { they so wished. The design was } \\
\text { changed so that basic information } \\
\text { such as my contact details and } \\
\text { ethical information were accessed } \\
\text { before they could enter the survey. }\end{array}$ \\
\hline One page containing FAQs & $\begin{array}{l}\text { Did not know what 'FAQs' } \\
\text { meant. }\end{array}$ & $\begin{array}{l}\text { FAQs was written in full - } \\
\text { frequently asked questions. }\end{array}$ \\
\hline $\begin{array}{l}\text { Survey contained } 73 \\
\text { questions. }\end{array}$ & Too long. & $\begin{array}{l}\text { No major change. Length of time to } \\
\text { complete was just over ten minutes, } \\
\text { which I did not consider to be too } \\
\text { long. }\end{array}$ \\
\hline $\begin{array}{l}\text { Survey covered a variety of } \\
\text { areas such as midwives' use } \\
\text { of Internet; attitudes to } \\
\text { consumers' use of Internet; } \\
\text { resources; e-mail discussion } \\
\text { lists etc. }\end{array}$ & $\begin{array}{l}\text { Questions covered too } \\
\text { broad an area and not } \\
\text { enough depth. }\end{array}$ & $\begin{array}{l}\text { No change to format of questions. } \\
\text { This study was meant to be a } \\
\text { precursor to further research and } \\
\text { issues could be explored in greater } \\
\text { depth in the future. }\end{array}$ \\
\hline $\begin{array}{l}\text { Links to the Victoria } \\
\text { University of Wellington, } \\
\text { New Zealand College of } \\
\text { Midwives, and Otago } \\
\text { Polytechnic were provided } \\
\text { in the information pages. }\end{array}$ & $\begin{array}{l}\text { Links should be put at end } \\
\text { of survey. If people become } \\
\text { diverted to other web pages, } \\
\text { they may not come back } \\
\text { and complete the survey. }\end{array}$ & $\begin{array}{l}\text { Links to these web pages were } \\
\text { provided at the end of the survey to } \\
\text { provide credibility to the survey. } \\
\text { People could check me out through } \\
\text { all these web sites. }\end{array}$ \\
\hline
\end{tabular}

Figure 2. Process of pre-testing Internet information and questionnaire 


\subsection{Sampling method}

\subsection{Inclusion criteria}

The study was restricted to registered midwives in New Zealand. The aim was that students and midwives practising outside New Zealand would not be incorporated. I did not want to include student midwives because I made the assumption that they would all have access to the Internet at their educational institutions, and I feared that might skew data results. Midwives practising outside New Zealand were excluded, as the focus of the study was midwives use of the Internet in New Zealand.

\subsection{Sampling technique}

The sampling technique used was 'convenience sampling' (Wagstaff, 2000). This technique uses the most readily available sample of respondents (Beanland \& Schneider, 1999). Due to financial and time constraints I needed to obtain as much data as possible in a short time. The advantage of this sampling technique is that the sample is easy to access, but has the disadvantage that the researcher cannot guarantee every member of the population has an equal chance of being selected (Wagstaff, 2000). This leads to a higher risk of bias than other methods of sampling (Beanland \& Schneider, 1999). Thus, the results of this study would enable me to draw conclusions about the sample but not relate them to the whole population of midwives. 


\subsection{Recruitment}

Midwives were recruited to this study by using a form of snowballing, which takes advantage of networking, in this case electronic network of midwives who practice in New Zealand (Beanland \& Schneider, 1999). Midwives were asked for help with recruiting other midwives to the study (see Appendix Seven). The advantage of this form of recruitment was that it was a quick way of gathering a large amount of data in a short amount of time. It also ensured the financial and time costs of recruitment were kept to a minimum. However, it was likely the respondents would only contact colleagues with whom they had e-mail contact, not those midwives who were not connected by e-mail.

I commenced the chain by e-mailing all the midwives whose e-mail addresses were already known to me, with information about the research and web site. The e-mail addresses were obtained from my personal address book. I also searched the NZCOM 'Search for a midwife' and 'Everybody - Search for a midwife'. I chose not to send the email to the New Zealand Midwives' E-mail list because I was concerned that it breached 'netiquette' by sending unsolicited mail that could be perceived as being 'junk' mail, otherwise known as 'spam' (Fieldon \& Garrido, 1998). However, I was fairly confident it would find its way to the list through other contacts. I chose not to use verbal or paper recruitment methods because I was very keen to see how far the electronic network extended in New Zealand by using e-mail only. 
I searched the Internet for e-mail contact details of the midwifery teaching staff of the polytechnics and universities of New Zealand that offer under-graduate and post-graduate studies:

Otago Polytechnic

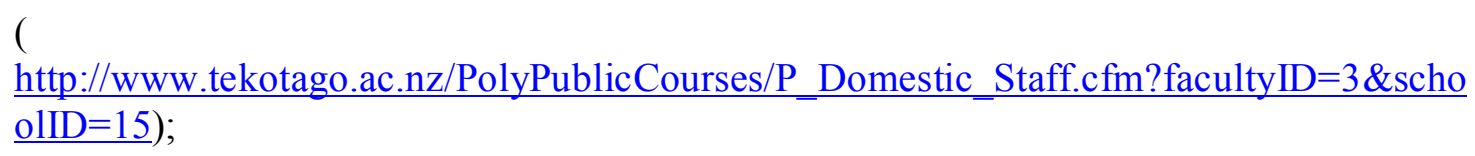

Finally, I searched the Internet for e-mail details of hospital core and employed midwives (http://www.everybody.co.nz/hospitals/hosp_index.html). This did not reveal many e-mail addresses, but I did get side tracked and found the web site of South Auckland Health (http://www.sah.co.nz/reframe.cfm?to $=0.02 .03 .07 .03)$, which provided photos and phone contact details of senior midwives. This problem becoming 'side tracked' when surfing can be quite time consuming and frustrating, and is a limitation of this method of recruitment. 


\subsection{E-mail snowballing}

The information e-mail contained details of the study; how to access the web site and invited midwives to access the web-based survey. The midwives were also asked if they could pass on the survey information by e-mail to other colleagues whom they knew to have e-mail addresses. In turn, these midwives were asked to do the same. In addition, the information e-mail included details of the password, which was required to access the questionnaire.

This method of recruitment had the potential to reach the total population of midwives who use the Internet in just a couple of hits. E-mail 'snowballing' or networking has been found to be very successful for research purposes (Thomas, Leeseberg Stamler, Lafreniere \& Dumala, 2000). For example, a group of school children in Taylorsville, North Carolina, USA sent an e-mail message to 32 people in an attempt to see how far it travelled. Within one month they had received a half million replies (Schuessler, 2001). Whilst I was not expecting anything like that response, I was quite hopeful that I would find out that the electronic midwifery network in New Zealand was nationally extensive. In another study, Thomas et al (2000) surveyed an international population of women about their perceptions of breast health education and screening by way of a web questionnaire. Women were asked to e-mail their friends with details of the survey. At least 593 participants were recruited to the study, although the authors do not inform the reader of the final number of participants (Thomas et al, 2000). It must be said that Thomas et al also used other methods of advertising like newspaper and radio. 
In order to monitor the effectiveness of this method of recruitment, midwives were asked to inform me when they received the information e-mail. Theoretically, that would have allowed me to check how far the information was being sent. The number of people who responded to me could also be compared to the actual number of completed surveys. It was made very clear that e-mail addresses would be kept confidential and not published. There was no way for me to know how many of those midwives went on to complete the survey.

\subsection{Considerations specific to Internet survey}

\subsection{Technological issues}

Technology itself can cause problems for Internet research. The software used to develop questionnaires may not be compatible with some computers. For instance, questionnaires can be difficult to translate from one format to another - from hard copy into a computer format (Miller et al, 1997). Comley (no date) found that his questionnaire using HTML (HyperText Markup Language used to create web pages) did not work with certain Internet browsers such as Microsoft Internet Explorer 3.0. I aimed to keep the survey as simple as possible and used HTML rather than the more advanced programming language such as Java, which would have made it inaccessible for people with older computers. For others, the process of downloading the survey and responding may be too slow, increasing the probability of non-response (Dillman, Tortora \& Bowker, 1998). Computer screen configuration and modem speed may also affect how people respond to 
the survey (Miller et al, 1997). I pretested the survey using as many Internet browsers as possible.

\subsection{Constructing the survey}

There are a numbers of considerations one must take when constructing a web survey, not least meeting the demands of computer logic with questionnaire logic (Dillman, 2000). It is important to remember that there are a lot of people with minimal computer skills as well as little experience with electronic surveys (Dillman, 2000). Whilst one can assume that most people have completed a paper survey at some time in their lives, one cannot take for granted the same for electronic survey. This was a real challenge for me as I have competent computer skills. I had to keep reminding myself to ensure that instructions on how to use the survey were very clear. This is where it was so valuable to test the survey on my 'computer phobic' colleague.

Researchers have the technological resources to develop surveys using sophisticated page set up, interactive graphics, video and audio features which would theoretically make the survey far more interesting for respondents to complete compared to paper survey. Ironically, these facilities take a long time to download and soak up a lot of memory providing poorer results than plain questionnaires (Dillman et al, 1998). Thus, the questionnaire I developed had a plain appearance with no detailed graphics, printed in black against a white background with purple highlighting of headings. The colour purple is recognised as the 'midwifery' colour in New Zealand, so I used it hoping to increase 
midwives' motivation to complete the survey. The only feature was the photo of myself that was scanned into the survey program.

\subsection{Principles for design of Internet questionnaire}

When designing the questionnaire, I closely followed the following principles as indicated in Figure 3. 


\begin{tabular}{|c|c|}
\hline $\begin{array}{l}\text { Principles for web based questionnaire } \\
\text { design (Dillman, Tortora \& Bowker } \\
\text { 1998). }\end{array}$ & $\begin{array}{l}\text { Principles applied to questionnaire } \\
\text { design: } \\
\text { http://www.midwifesurvey.co.nz }\end{array}$ \\
\hline $\begin{array}{l}\text { Introduce the questionnaire with a welcome } \\
\text { screen that is motivational, emphasising } \\
\text { the ease of responding, and instructing } \\
\text { respondents on how to proceed to the next } \\
\text { screen. }\end{array}$ & $\begin{array}{l}\text { The first page contained my photograph. It } \\
\text { listed the actions to be taken by midwives } \\
\text { in order to complete the survey. }\end{array}$ \\
\hline $\begin{array}{l}\text { Begin questionnaire with a question that is } \\
\text { easily comprehended and answered, to set } \\
\text { the tone of the survey. Do not use drop- } \\
\text { down boxes or scrolling. }\end{array}$ & $\begin{array}{l}\text { First question was about the location of } \\
\text { Internet use. It did use a drop-down box } \\
\text { with very clear instructions about } \\
\text { where/how to use the computer mouse. } \\
\text { Demographic details were requested at the } \\
\text { end of the survey. }\end{array}$ \\
\hline $\begin{array}{l}\text { Present question in a conventional format } \\
\text { similar to that normally used in paper } \\
\text { questionnaires. }\end{array}$ & $\begin{array}{l}\text { Each question was clearly numbered. The } \\
\text { question stem was separated from answer } \\
\text { space, and justified to the left. The answer } \\
\text { spaces were listed vertically and to the } \\
\text { right of the question. }\end{array}$ \\
\hline $\begin{array}{l}\text { Limit line length to decrease long line of } \\
\text { prose extending across respondents' screen }\end{array}$ & $\begin{array}{l}\text { Different computers and screens were used } \\
\text { to pretest survey and a deliberate attempt } \\
\text { was made to shorten width of question. }\end{array}$ \\
\hline Provide instructions with every question. & $\begin{array}{l}\text { Major operational instructions given at } \\
\text { beginning of questionnaire, with specific } \\
\text { response instructions given with each } \\
\text { question. }\end{array}$ \\
\hline $\begin{array}{l}\text { Do not require respondents to provide a } \\
\text { reply to each question. }\end{array}$ & No 'forcing' mechanism used. \\
\hline Scroll question to question. & $\begin{array}{l}\text { Links provided to skip past questions that } \\
\text { respondents were not required to answer. }\end{array}$ \\
\hline $\begin{array}{l}\text { Use symbols or words to convey a sense of } \\
\text { progress through the questionnaire without } \\
\text { employing advanced programming. }\end{array}$ & $\begin{array}{l}\text { The questionnaire used a scroll instead of } \\
\text { screen-by-screen approach. The } \\
\text { respondents could either check the location } \\
\text { of the scroll bar, or scroll down to the end } \\
\text { of the page to check their progress. }\end{array}$ \\
\hline $\begin{array}{l}\text { Be cautious about using questions that are } \\
\text { known to be difficult to analyse eg open- } \\
\text { ended questions, although there is evidence } \\
\text { that people are more likely to write detailed } \\
\text { answers to open-ended answers on } \\
\text { computers compared to paper (Schaefer \& } \\
\text { Dillman, 1998). }\end{array}$ & $\begin{array}{l}\text { Pretested questionnaire by programming } \\
\text { questions through SPSS. Have used } \\
\text { minimal number of open-ended questions. }\end{array}$ \\
\hline
\end{tabular}

Figure 3. Principles for questionnaire design 


\subsection{Survey protection}

The questionnaire could have been completed by people who it was not intended for, which is a particular problem with the Internet (Woong Yun \& Trumbo, 2000). However, the method of recruitment chosen for this research should have limited this problem because individuals were privately targeted by e-mail, as opposed to more public appeals for participants via nationwide paper or Internet advertisements. The survey could only be opened with a generic password that was supplied in the information e-mail that was sent to participants. The password 'vertex' was specifically known to midwives, and unlikely to be known by the general public. This provided some protection for the web site but would not completely prevent non-midwives getting into the questionnaire. I could have allocated specific individual passwords but did not have the financial or technological support for this measure. The other strategy I could have employed was to ask midwives' for their New Zealand Nursing Council identity numbers. The problems would have been that I had no way of checking the accuracy of the numbers and it would have compromised the anonymity of the research.

\subsection{Costs}

The costs of Internet survey are perceived to be a lot lower than postal survey, which is one of the reasons why I chose this method of research. Costs of paper and envelopes, printing, postage and data entry can almost be eliminated (Dillman, 2000). Farmer (no date) maintained that Internet is 50 per cent less expensive than telephone survey, and 20 
per cent less expensive than mail. Comley (no date) noted that his postal survey cost 2750 pounds compared 375 pounds for his e-mail survey. However, I have to concur with other writers who question this perception (Batagelj et al, 1998). I found the costs of developing the web site to be significant (NZ\$769.50), especially as I had to change computer programmer half way through the project. I had the additional cost of paying to use an independent Internet server to lodge the survey (\$NZ75 per year), whereas the original plan was to use a server at my place of work, which would have been free of charge. However, once the web site was up and running, there were minimal costs especially as my ISP plan only cost \$NZ25 per month.

\subsection{Timing of survey}

I chose to have the survey online for a month because that is generally accepted to be a reasonable time frame for web surveys (Batagelj et al, 1998). Electronic surveys significantly reduce the time required for implementation, from weeks to hours and days compared to postal survey (Dillman, 2000). Comley (no date) received responses to his electronic survey in an average of four days compared to ten days for the postal survey. Lakeman (1997) received all the responses to his survey within two weeks.

\subsection{Data Analysis}

\subsection{Data handling}

There are visible advantages to using the Internet as a tool for research. Data handling and analysis is speedier because there is no problem with deciphering handwriting (George \& Hughes, no date). Data does not need to be transcribed, nor does it lose 
accuracy in the process (Medlin, Roy \& Ham Chai, 1999). Material can be directly fed into analysis software or word processing programs (Murray, 1996) and does not cause storage problems (George \& Hughes, no date).

My original plan had been to set up the web site in such a way that data would be transmitted from the Internet server directly into a Microsoft Excell spreadsheet using Common Gateway Interface (CGI) script. The only thing I would need to do would be to 'cut and paste' the data into SPSS. Unfortunately, the web designer who was working with me was unfamiliar with CGI script and found the technology beyond his capability. I was required to employ another programmer and found myself forced into a situation where time and financial constraints meant I had to alter my plans. Consequently, data was e-mailed to me in numerical form and I had to enter the data myself into Statistical Package for Social Science (SPSS), which is a statistical analysis program for social science studies and ideal for this type of small study (Mead, 2001). This meant that the margin for human error was increased as well time taken for data analysis. The questions are mostly closed questions, which are easier to electronically analyse than open questions (Wagstaff, 2000). The disadvantage with this is that the data generated is likely to be quite superficial (Beanland \& Schneider, 1999).

\subsection{Data analysis}

The data generated from the questionnaire was nominal, ordinal and text. Nominal data is data that has been given a number as a form of identification (Cluett, 2000). The number has no mathematical value. I used descriptive statistics to analyse the data. Descriptive 
statistics use numbers to describe information (Cluett, 2000). Ordinal measurement places data in order or rank, but the intervals between the ranked data are not always equal (Beanland \& Schneider; Burns \& Grove, 1993). The only text was from the openended questions. The text answers were assigned a nominal value but were not regrouped or re-classified because they were too few to justify this. The numerical data was entered into and analysed by a statistician I employed to help me deal with the data entry and analysis. The questionnaire was processed through SPSS before data was collected. The aim was to prevent problems with analysing data once it was too late to do anything about it. I knew nothing about SPSS or how it worked so I sent out a request to the Midwifery research list asking for information about SPSS. I was sent an 'Introduction to SPSS for Windows' attached to an e-mail, by Marianne Mead (2001) a midwifery lecturer in the UK.

For this type of nominal data the single information that can be given is frequency, the number of items in a group and percentages (Cluett, 2000). Frequencies allowed me to look at the distribution of data and check for errors such as incorrect data entry. I was able to identify any answers that were outside the normal range. I also carried out random checking of data entry. Once any errors were corrected, I was able to use mode, skewness and range to generate a picture of distribution. Mode is the value in a set of numbers that occurs the most (Clegg, 1992). Skewness refers to the direction of the distribution of numbers (Clegg, 1992). A normal distribution curve is symmetrical where the mean, median and mode all have the same value. The mean is the mathematical average obtained by adding all the measurements together and dividing them by the number of 
measurements (Cluett, 2000). The median is the midpoint of the data when the measurements are placed in numerical order. A skewed distribution curve is nonsymmetrical and has its peak off centre (Beanland \& Schneider, 1999). The range is the difference between the highest and lowest numbers. I was also able to carry out cross tabulations to compare one variable with another.

I had hoped to use the chi-square $\left(\chi^{2}\right)$ test to measure 'goodness of fit', measurement of the significance of distribution of individual variables (Clegg, 1992). In other words, the chi square test determines whether the frequency in a category is more than one would expect by chance (Beanland \& Schneider, 1999). The chi square test also measures relatedness; the significance of relationships between variables (Cluett, 2000). The chi square value can be looked up in significance tables. Unfortunately, I found that in most cases the cell size was not large enough for the chi square test to be valid (Clegg, 1992).

\subsection{Validity}

Validity refers to how well a research tool such as a survey actually measures what it sets out to measure (Burns \& Grove, 1993). The validity of data collected depends on the respondents' truthful reply (Wagstaff, 2000). The survey questions were innocuous so there were no anticipated reasons why respondents would have difficulty with being truthful in completing this survey. In addition, the midwives should have felt safe in answering the questions truthfully as there is currently no controversy within New Zealand about the value of midwives using the Internet. Validity would also be enhanced 
because of the 'novelty value' of using the Internet for survey (Woong Yun \& Trumbo, 2000). People who use the Internet are thought to be altruistic and keen to help one another (Wallace, 2001).

\subsection{Dissemination}

Once the study report is examined I plan to disseminate the results to midwifery colleagues via the New Zealand College of Midwives' Journal and other international midwifery journals and conferences. I also plan to write a report and post it on the New Zealand Midwives' List, Midwifery Research List and the AOIR list. I feel it is important to disseminate the result to these lists considering that they have given me so much help in the past. Also it will mean that the results are disseminated to the international communities of midwives and Internet researchers. Finally, I will present a report on the original survey web site, so that participants and anyone can read the results of the survey.

\subsection{Ethical considerations}

\subsection{Ethics of Internet research}

The ethical issues of Internet research are just as important to consider as in off-line research. This is an area that is currently much debated, and international guidelines are in the process of being formulated (Bowers, 1998). The issue of copyright or intellectual property is not helped by the fact that much communication crosses international boundaries and may be affected by differing copyright legislation (Murray, 1996). 
Hamilton (1999) has found that online researchers do not consistently inform subjects about the research into which they have enrolled. This has serious implications for the integrity of on-line research, as does Hamilton's other finding that there are a number of projects that have not been submitted to an Ethics Committee for approval. Both measures are obligatory with off-line research. Ethical approval was given for this study by the Human Ethics Committee of the Victoria University of Wellington.

\subsection{Informed consent}

I dealt with the issues of informed consent by providing information pages that respondents had to open before they could go onto the survey. I provided information about my research supervisor and the Human Ethics Committee of Victoria University, as well as details as to how to contact me and my supervisor. I chose not to ask respondents to submit an online consent form (http://www.psycdawgs.com) to simplify the research process. Nonetheless, I informed participants that completing the survey implied consent (Baron \& Siepmann, 1999). Patricia Schneider (2000) is a midwife who has carried out qualitative research via the Internet. We started writing to each other when we 'met' on the Midwifery Research List. Patricia recruited midwives to her research via the Internet and e-mail, but 'snail mailed' the participants the information letter and consent form to be returned by stamp-addressed envelope. I considered this method but decided that whilst this might be appropriate for a qualitative study, it was unnecessary for a quantitative study. 


\subsection{Anonymity}

An advantage of web survey is that the entries can be anonymous compared to e-mail, which automatically displays who the sender is (Lakeman, 1997). The survey programming was set up in such a way that e-mail addresses were stripped from data before they were sent to me.

I posted the e-mail information letters to individual midwives rather than using the "copy to' facility, which would have meant that midwives could have seen whom else the mail was sent to. This was more time consuming but it ensured that midwives had complete confidentiality. This was in response to a discussion I followed on the Association of Internet Researchers' discussion list (Burns, 2001; Johns, 2001). A post-graduate student had been accused of a breach of confidentiality by sending a mass e-mail with a list of 70 e-mail addresses in the recipients' space. This had severe consequences for him as a student researcher. I had intended doing the same thing, so this e-mail discussion may have prevented me from having the same difficulties. Both the computer programmer and statistician signed confidentiality forms confirming that they would not divulge any details of the research data (see Appendix Eight).

\subsection{Netiquette}

The Internet researcher should be just as considerate of people on the Internet as she would be if she were interacting with people in real life. The Internet researcher should be aware of netiquette, which is the term to describe the accepted rules of good behaviour on the Internet (Fieldon \& Garrido, 1998). One breaches netiquette when one advertises 
on discussion lists; uses capital letters because it means one is SHOUTING; uses discussion lists as a lazy way of researching information instead of visiting the library; quotes personal communications without the permission of the writer; appropriates people's intellectual property without acknowledging the source; uses abusive or antagonistic language or 'flames' (Musker, 1997; Fieldon \& Garrido, 1998).

\subsection{Treaty of Waitangi issues}

One issue that I considered was the use of the Internet by Maori midwives and the general population of Maori in New Zealand. There are a number of web sites that are specific to Maori (http://www.maori.org.nz), as well as the Maori Internet Society ( http://www.maori2000.com/hiringa2/history.htm). Nevertheless, Maori are less likely to have access to the Internet, compared with the European population in New Zealand, with the greatest barrier being cost (Te Puni Kökiri/ Ministry of Maori Development, 2001).

The population of midwives may have included Maori midwives. However, the study did not gather any data regarding ethnicity. Thus, I did not make any formal representation to Maori groups. I offered a Maori colleague the opportunity to critique the questionnaire at the pre-testing stage, to ensure it did not contravene the three principles of the Treaty of Waitangi: protection, participation and partnership (Guilliland \& Pairman, 1995). The results of the study will be disseminated to the Maori Midwives' Collective, Nga Maia and to Maori midwives via the New Zealand College of Midwives. 
Certainly, it would be interesting to be more specific about how Maori midwives use the Internet, and to find out whether they are disadvantages in this area. Nonetheless, that is another research question that can be dealt with in the future.

\subsection{Conclusion}

This chapter has described the methodology and design of the pilot study carried out to find out how midwives in New Zealand use the Internet. This chapter has described the development of a web-based questionnaire and considered how technological issues impact on the design and implementation of Internet survey. Sample and recruitment issues have been discussed as well as data analysis. Finally, ethical and Treaty of Waitangi issues were considered.

The next chapter contains the results from this survey. Details of the electronic network will be given, as well as the results from 54 completed surveys. Results will be published that illustrate how midwives use the Internet for study, and at home. The reader will be able to find out about midwives' perceptions of consumers' use of the Internet and how it has affected their practice. The chapter also contains results about midwives' use of email discussion lists and Internet resources. Background information about the midwives will be presented that will classify midwives and allow for statistical analysis. 


\section{Chapter Four}

\section{Results}

\subsection{Introduction}

This chapter will describe the results of the pilot study, which investigated how midwives in New Zealand used the Internet. Firstly, the chapter will describe the outcome of the e-mail information letter followed by the results from the completed surveys, including response rate and demographics. Results about midwives' use of the Internet at work to assist clinical decision-making and at home for study will be presented. The chapter will show results about consumers' use of the Internet, as well as how midwives feel about consumers having greater access to information on the Internet. The findings about midwives' use of the Internet to give midwifery care, and e-mail discussion lists will be revealed.

\subsection{Response rate}

One hundred and ten (110) information e-mails were sent out. Seventeen (17) e-mails were 'bounced' back to me because there was an error with the e-mail address, or the addresses were unknown. There were 35 e-mail responses from midwives regarding the original information e-mail that I sent out, inviting midwives to complete the survey. Ten of the responses came from midwives to whom I had not sent the original information e-mail. 
Fifty four (54) completed questionnaires were received from the web-based survey. It is impossible to work out the questionnaire response rate because I have no idea how many midwives received the information e-mail and knew about the study. Theoretically, all practising midwives $(n=2081)$ have access to the Internet, so compared to that number; the response rate would be extremely poor at 2.56 per cent. However, if one compared the responses with the total number of information e-mails known to be sent out $(n=110)$, minus the 17 information e-mails that were not received $(n=93)$, the response could be said to be 58.5 per cent. 


\subsection{Content of e-mail responses}

Several e-mails included comments about the web site and questionnaire. Table 1

describes the contents of the e-mails sent to me.

Table 1. Content of e-mail responses

\begin{tabular}{|l|l|l|}
\hline $\begin{array}{l}\text { Content of e-mail responses } \\
\text { received by researcher }\end{array}$ & $\begin{array}{l}\text { Responses from midwives } \\
\text { who received the original } \\
\text { information e-mail }\end{array}$ & $\begin{array}{l}\text { Responses from midwives who } \\
\text { did not receive the original } \\
\text { information e-mail }\end{array}$ \\
\hline Completed survey & 6 & 3 \\
\hline Received e-mail & 5 & 3 \\
\hline Unsure of password to survey & 4 & 4 \\
\hline $\begin{array}{l}\text { Personal/social mail from } \\
\text { colleagues }\end{array}$ & 3 & \\
\hline $\begin{array}{l}\text { Apology for being too late to } \\
\text { complete the survey }\end{array}$ & 3 & \\
\hline Will complete survey & 2 & \\
\hline $\begin{array}{l}\text { Unsure of where to send } \\
\text { information e-mail - NZ or } \\
\text { abroad }\end{array}$ & 1 & \\
\hline $\begin{array}{l}\text { Cannot access the survey - try } \\
\text { another e-mail address }\end{array}$ & 1 & $\mathbf{1 0}$ \\
\hline Total & $\mathbf{2 5}$ & \\
\hline
\end{tabular}

One midwife also commented that she liked the information about ethical issues; two

midwives liked the photo; and two midwives felt the questionnaire was well designed, easy to complete and interesting. 


\subsection{Response times}

The majority of responses were received in the first week following the posting of the e-mail information letter inviting midwives to take part in the survey. Table 2 provides a breakdown of the time it took for responses to be received.

Table 2. Time that responses were received

\begin{tabular}{|l|c|c|}
\hline $\begin{array}{l}\text { Time that responses } \\
\text { were received }\end{array}$ & Number of responses & $\begin{array}{l}\text { Percentage of } \\
\text { responses }\end{array}$ \\
\hline 0-24 hours & 4 & 7.5 \\
\hline $25-48$ hours & 8 & 15.0 \\
\hline 3-7 days & 15 & 27.5 \\
\hline 8-14 days & 16 & 29.5 \\
\hline 15-21 days & 4 & 7.5 \\
\hline 22-28 days & 7 & 13.0 \\
\hline Total & $\mathbf{5 4}$ & $\mathbf{1 0 0 . 0}$ \\
\hline
\end{tabular}




\subsection{Demographics}

\subsection{Employment}

Respondents were asked to describe their midwifery employment, being given the opportunity to identify more than one category. Respondents defined themselves as having multiple roles and practising in more than one geographical area, therefore the numbers in the Table 3 add up to more than 54.

Table 3. Employment of respondents

\begin{tabular}{|l|l|}
\hline $\begin{array}{l}\text { Characteristics of } \\
\text { respondents }\end{array}$ & $\begin{array}{l}\text { Number of respondents. Some } \\
\text { respondents recorded more than one role. }\end{array}$ \\
\hline Self-employed LMC & 24 \\
\hline Midwifery lecturer & 16 \\
\hline Hospital midwife & 15 \\
\hline Rural midwife & 10 \\
\hline Urban midwife & 8 \\
\hline Midwifery manager & 5 \\
\hline Employed LMC & 4 \\
\hline Research midwife & 3 \\
\hline Midwifery adviser & 1 \\
\hline Expert witness & 1 \\
\hline Total & $\mathbf{8 7}$ \\
\hline
\end{tabular}




\subsection{Age, employment status and years qualified as registered midwife}

Other characteristics of the respondents were age, employment status and years qualified as a registered midwife as described in Table 4. Respondents were most likely to be in the age group 40-49 years and in full time employment. Three respondents did not answer the question about employment status. They were either not practising as a midwife or did not answer the question.

Table 4. Characteristics of respondents

\begin{tabular}{|l|r|c|}
\hline Characteristics & Number & Percentage \\
\hline Age & & \\
$25-29$ & 2 & 3.6 \\
$30-34$ & 5 & 9.3 \\
$35-39$ & 7 & 13.0 \\
$40-44$ & 18 & 33.3 \\
$45-49$ & 12 & 22.2 \\
$50-54$ & 5 & 9.3 \\
$55-59$ & 5 & 9.3 \\
\hline Total & $\mathbf{5 4}$ & $\mathbf{1 0 0}$ \\
\hline Employment status & & \\
Full-time & 36 & 66.7 \\
Part-time & 15 & 27.8 \\
Missing & 3 & 5.5 \\
\hline Total & $\mathbf{5 4}$ & $\mathbf{1 0 0}$ \\
\hline Years qualified & & \\
$1-4$ & 6 & 11.1 \\
$5-9$ & 9 & 16.7 \\
$10-14$ & 10 & 18.5 \\
$15-19$ & 8 & 14.8 \\
20-24 & 11 & 20.4 \\
$25-29$ & 7 & 13.0 \\
35 years and over & 3 & 5.5 \\
\hline Total & $\mathbf{5 4}$ & $\mathbf{1 0 0}$ \\
\hline
\end{tabular}




\subsection{Education}

Thirty-three respondents were currently enrolled in, or had undertaken study in the last three years. One respondent cited two courses of study. The greatest number of respondents had either achieved or were studying for a Masters degree. Table 5 describes the level of education amongst respondents. Twenty respondents did not answer this question.

Table 5. Level of professional education

\begin{tabular}{|l|l|c|}
\hline Qualification achieved or currently studied & Number & Percentage \\
\hline Masters degree & 18 & 33.75 \\
\hline Batchelor degree & 7 & 13.0 \\
\hline Post-graduate diploma & 5 & 9.75 \\
\hline Doctor of Philosophy & 2 & 3.0 \\
\hline Post-graduate certificate & 1 & 1.75 \\
\hline Other & 1 & 1.75 \\
\hline Missing & 20 & 37.0 \\
\hline Total & $\mathbf{5 4}$ & $\mathbf{1 0 0}$ \\
\hline
\end{tabular}




\subsection{Use of the Internet}

\subsection{Location of Internet use}

Respondents were asked where they usually used the Internet? They were most likely to use the Internet 'mainly at home' as shown in Table 6. Self-employed LMC midwives were most likely to use the Internet at home.

Table 6. Location of Internet use

\begin{tabular}{|l|c|c|}
\hline Location & Number & Percentage \\
\hline Mainly at home & 42 & 77.7 \\
\hline Mainly at work & 6 & 11.1 \\
\hline $\begin{array}{l}\text { An equal combination of work } \\
\text { and home }\end{array}$ & 2 & 3.7 \\
\hline $\begin{array}{l}\text { An equal combination of home } \\
\text { and university/polytechnic }\end{array}$ & 3 & 5.6 \\
\hline Missing & 1 & 1.9 \\
\hline Total & $\mathbf{5 4}$ & $\mathbf{1 0 0}$ \\
\hline
\end{tabular}




\subsection{Frequency of access to the Internet}

There was a high level of Internet usage as shown in Table 7. Of the 51 respondents who answered this question, $46(85.2 \%)$ respondents accessed the Internet at least once a week. Three (5.6\%) respondents did not answer this question.

Table 7. Frequency of access to the Internet

\begin{tabular}{|l|c|c|}
\hline Frequency & Number & Percentage \\
\hline Daily & 21 & 38.9 \\
\hline Once a week & 16 & 29.6 \\
\hline 2-3 times per week & 9 & 16.7 \\
\hline Once a month & 4 & 7.4 \\
\hline 2-3 times per year & 1 & 1.9 \\
\hline Missing & 3 & 5.6 \\
\hline Total & $\mathbf{5 4}$ & $\mathbf{1 0 0}$ \\
\hline
\end{tabular}

\subsection{Description of use of the Internet}

Table 8 shows that respondents were more likely to describe their use of the Internet as an equal combination of personal, work and study. One $(1.9 \%)$ respondent did not answer this question.

Table 8. Description of use of the Internet

\begin{tabular}{|l|l|l|}
\hline Description & Number & Percentage \\
\hline $\begin{array}{l}\text { Equal combination of } \\
\text { personal, work and study }\end{array}$ & 30 & 55.6 \\
\hline Mainly personal & 16 & 29.6 \\
\hline Mainly work & 5 & 9.3 \\
\hline Mainly study & 2 & 3.7 \\
\hline Missing & 1 & 1.9 \\
\hline Total & $\mathbf{5 4}$ & $\mathbf{1 0 0}$ \\
\hline
\end{tabular}




\subsection{E-mail addresses}

Respondents mostly had home e-mail addresses as shown in Table 9. Fewer than half the respondents had work e-mail addresses, but only some had e-mail addresses at the institution at which they studied. Respondents were able to indicate more than one answer.

Table 9. Location of personal e-mail addresses.

\begin{tabular}{|l|c|l|}
\hline Location & Number $(\mathbf{n}=\mathbf{5 4})$ & Percentage \\
\hline Home & 51 & 94.4 \\
\hline Work & 26 & 48.1 \\
\hline Institution of study & 9 & 16.7 \\
\hline
\end{tabular}




\subsection{Help with the Internet}

Respondents were most likely to seek help with the Internet from friends and family as indicated in Table 10. Colleagues and online help were the next most frequent sources of help with Internet issues.

Table 10. Help with the Internet

\begin{tabular}{|l|l|l|}
\hline Source of help & $\begin{array}{l}\text { Number } \\
(\mathbf{n = 5 4 )}\end{array}$ & Percentage \\
\hline Family and friends & 45 & 83.3 \\
\hline Online & 22 & 40.7 \\
\hline Colleagues & 21 & 38.8 \\
\hline IT support at work & 11 & 20.4 \\
\hline $\begin{array}{l}\text { IT support at } \\
\text { university/polytechnic }\end{array}$ & 6 & 11.2 \\
\hline Books/manuals & 5 & 9.25 \\
\hline Computer outlet & 4 & 7.5 \\
\hline Other & 3 & 5.5 \\
\hline
\end{tabular}

\subsection{Access to the Internet}

Respondents were asked about their use of the Internet at work, institution of study and home. Table 11 shows that there were missing answers from each category as the category was not applicable, thus the percentage values relate to the number of respondents who answered that particular category, rather than the total number of respondents $(\mathrm{n}=54)$. For example, $98.1 \%(53 / 54)$ respondents had access to the Internet at home. 
Table 11. Access to the Internet

\begin{tabular}{|l|l|l|l|}
\hline Place of access & Number & $\begin{array}{l}\text { Total responding to this } \\
\text { question }\end{array}$ & Percentage \\
\hline Work & 30 & 51 & 58.8 \\
\hline Institution of study & 20 & 26 & 76.9 \\
\hline Home & 53 & 54 & 98.1 \\
\hline
\end{tabular}

\subsection{Searching for midwifery information}

Respondents were asked if they used the Internet to search for midwifery information.

Table 12 presents results that indicate where respondents used the Internet to search for information. The majority of respondents search for information at home.

Table 12. Searching for midwifery information

\begin{tabular}{|l|l|l|l|}
\hline $\begin{array}{l}\text { Place where Internet was used } \\
\text { to search for information }\end{array}$ & Number & $\begin{array}{l}\text { Total responding to } \\
\text { this question }\end{array}$ & Percentage \\
\hline Work & 27 & 34 & 79.4 \\
\hline Institution of study & 14 & 18 & 77.8 \\
\hline Home & 50 & 52 & 96.2 \\
\hline
\end{tabular}

\subsection{Ease of access to the Internet}

Table 13 shows how easily accessible the Internet was for respondents who searched for information at work and the institution of study.

Table 13. Ease of access

\begin{tabular}{|l|l|l|l|}
\hline $\begin{array}{l}\text { Place where Internet was } \\
\text { used to search for } \\
\text { information }\end{array}$ & $\begin{array}{l}\text { Easily } \\
\text { accessible } \\
(\mathbf{\% )}\end{array}$ & $\begin{array}{l}\text { Not easily } \\
\text { accessible (\%) }\end{array}$ & $\begin{array}{l}\text { Total responding } \\
\text { to this question }\end{array}$ \\
\hline Work & $25(83.3 \%)$ & $5(16.6 \%)$ & 30 \\
\hline Institution of study & $16(80.0 \%)$ & $4(20.0 \%)$ & 20 \\
\hline
\end{tabular}




\subsection{Experience of searching for information}

Table 14 shows that respondents were more likely to find the experience of searching for information on the Internet reasonably easy.

Table 14. Experience of searching for information

\begin{tabular}{|l|l|l|l|}
\hline $\begin{array}{l}\text { Experience of searching } \\
\text { for information }\end{array}$ & Work (\%) & $\begin{array}{l}\text { Institution } \\
\text { of Study (\%) }\end{array}$ & Home (\%) \\
\hline Easy & $4(13.7 \%)$ & $1(7.2 \%)$ & $8(16.32 \%)$ \\
\hline Reasonably easy & $21(70.5 \%)$ & $8(7.14 \%)$ & $30(61.22 \%)$ \\
\hline Difficult & $3(10.4 \%)$ & $5(35.71 \%)$ & $8(16.3 \%)$ \\
\hline Impossible & $1(3.5 \%)$ & 0 & $3(6.2 \%)$ \\
\hline $\begin{array}{l}\text { Total responding to this } \\
\text { question }\end{array}$ & $\mathbf{2 9}$ & $\mathbf{1 4}$ & $\mathbf{4 9}$ \\
\hline
\end{tabular}




\subsection{Main reasons for using the Internet}

Table 15 demonstrates the main reasons for using the Internet at work, institution of study and at home. Respondents could answer more than one category.

Table 15. Main reasons for using the Internet

\begin{tabular}{|l|l|l|l|}
\hline $\begin{array}{l}\text { Reasons for using } \\
\text { the Internet }\end{array}$ & Work (\%) & $\begin{array}{l}\text { Institution } \\
\text { of study (\%) }\end{array}$ & $\begin{array}{l}\text { Home } \\
(\mathbf{\%})\end{array}$ \\
\hline $\begin{array}{l}\text { To satisfy a specific } \\
\text { information need for } \\
\text { yourself }\end{array}$ & $26(48 \%)$ & $15(27.8 \%)$ & $47(75.5 \%)$ \\
\hline To keep up to date & $20(37 \%)$ & $5(9.25 \%)$ & $36(66.7 \%)$ \\
\hline $\begin{array}{l}\text { Communication and } \\
\text { collaboration }\end{array}$ & $12(22.3 \%)$ & $4(7.5 \%)$ & $28(52.9 \%)$ \\
\hline $\begin{array}{l}\text { To satisfy a specific } \\
\text { information need for } \\
\text { a woman in your care }\end{array}$ & $15(27.8 \%)$ & $3(5.5 \%)$ & $31(57.5 \%)$ \\
\hline $\begin{array}{l}\text { To satisfy a specific } \\
\text { information need for } \\
\text { a colleague }\end{array}$ & $10(18.5 \%)$ & $4(7.5 \%)$ & $23(52.6 \%)$ \\
\hline $\begin{array}{l}\text { Other reasons for } \\
\text { using the Internet }\end{array}$ & $7(13 \%)$ & $1(1.9 \%)$ & $8(14.9 \%)$ \\
\hline $\begin{array}{l}\text { Never used the } \\
\text { Internet at this } \\
\text { location }\end{array}$ & $3(5.5 \%)$ & $3(5.5 \%)$ & 0 \\
\hline
\end{tabular}




\subsection{Barriers to use of the Internet}

Table 16 presents results about barriers to use of the Internet. Time and insufficient training were the main barriers to use of the Internet. Respondents could answer more than one category.

Table 16. Barriers to the use of the Internet

\begin{tabular}{|l|l|l|l|}
\hline Barriers & $\begin{array}{l}\text { Work } \\
(\mathbf{\%})\end{array}$ & $\begin{array}{l}\text { Institution } \\
\text { of study (\%) }\end{array}$ & $\begin{array}{l}\text { Home } \\
(\mathbf{\%})\end{array}$ \\
\hline $\begin{array}{l}\text { Insufficient } \\
\text { time }\end{array}$ & $20(37.5 \%)$ & $11(20.4 \%)$ & $32(59.25 \%)$ \\
\hline $\begin{array}{l}\text { Insufficient } \\
\text { training }\end{array}$ & $9(16.7 \%)$ & $5(9.25 \%)$ & $16(29.7 \%)$ \\
\hline None at this location & $9(16.7 \%)$ & $3(5.5 \%)$ & $8(14.9 \%)$ \\
\hline Other barriers & $3(5.5 \%)$ & $5(9.25 \%)$ & $7(13 \%)$ \\
\hline $\begin{array}{l}\text { Speed of computer/ } \\
\text { modem }\end{array}$ & $3(5.5 \%)$ & $1(1.9 \%)$ & $10(18.5 \%)$ \\
\hline $\begin{array}{l}\text { Cost of } \\
\text { computers }\end{array}$ & $3(5.5 \%)$ & $2(3.70 \%)$ & $3(5.5 \%)$ \\
\hline $\begin{array}{l}\text { Cost of } \\
\text { online time }\end{array}$ & 0 & 0 & $3(5.5 \%)$ \\
\hline
\end{tabular}

\subsection{Incorporation of midwifery information found on the Internet into midwifery practice}

Table 17 describes how many respondents incorporated information found on the Internet at work and institution of study, into their practice. Respondents were more likely to incorporate information found at work into their practice, as opposed to information found on the Internet at the institution of study. Respondents were not asked if information found at home was incorporated into their practice. 
Table 17. Incorporation of midwifery information found on the Internet into midwifery practice.

\begin{tabular}{|l|l|l|l|}
\hline $\begin{array}{l}\text { Incorporation of } \\
\text { information into } \\
\text { practice }\end{array}$ & Yes (\%) & No (\%) & $\begin{array}{l}\text { Total responding } \\
\text { to this question } \\
(\%)\end{array}$ \\
\hline Work & $27(81.81 \%)$ & $6(18.18 \%)$ & $33(61.1 \%)$ \\
\hline Institution of study & $11(68.75 \%)$ & $5(31.25 \%)$ & $16(29.62 \%)$ \\
\hline
\end{tabular}

\subsection{Internet training}

Table 18 demonstrates that not even half the respondents have been offered Internet training at work or at an institution of study.

Table 18. Internet training

\begin{tabular}{|l|c|c|l|}
\hline Training & Yes (\%) & No (\%) & $\begin{array}{l}\text { Total responding to } \\
\text { this question (\%) }\end{array}$ \\
\hline Work & $13(43.33 \%)$ & $17(56.66 \%)$ & $30(55.5 \%)$ \\
\hline Institution of study & $7(43.75 \%)$ & $9(56.25 \%)$ & $16(29.62 \%)$ \\
\hline
\end{tabular}

\subsection{The use of the Internet to deliver lecturers, tutorials or counselling}

Respondents were asked if they used the Internet to deliver lectures, tutorials or counselling. Very few respondents have used the Internet to deliver lecturers, tutorials or counselling. Eight (14.9\%) respondents used the Internet to deliver lectures, tutorials and counselling. Twenty-one (38.9\%) respondents did not use the Internet.

\subsection{Enrolment in a program of study delivered via the Internet}

Respondents were asked if they had ever enrolled in a program of study delivered by the Internet. Only three (5.5\%) respondents had enrolled in a program of study delivered via 
the Internet. Thirteen $(24.1 \%)$ respondents had never enrolled in an Internet program of study.

\subsection{Information found on the Internet}

Respondents were asked to write in free text, examples of the information they found on the Internet at work, institution of study and at home. The information respondents found on the Internet could be broken down into four groups. The first group, 'clinical practice' included examples such as "waterbirth", "breastfeeding" and "breech". The next group, 'professional issues' included examples such as "NZCOM and related sites", as well as "information about jobs abroad". The third group was 'information for women'. The final group was 'teaching and learning' which included "looking for information on trends in midwifery education". In Table 19 I have recorded the instances of information found in each category and the location of where the information was found. Respondents were able to give more than one example of information found on the Internet therefore rows may total more than 54 .

Table 19. Instances of information found on the Internet

\begin{tabular}{|l|l|l|l|l|l|}
\hline & $\begin{array}{l}\text { Clinical } \\
\text { practice }\end{array}$ & $\begin{array}{l}\text { Professional } \\
\text { issues }\end{array}$ & $\begin{array}{l}\text { Information } \\
\text { for women }\end{array}$ & Teaching/Learning & $\begin{array}{l}\text { Total of } \\
\text { location } \\
\text { responses }\end{array}$ \\
\hline Work & 57 & 10 & 1 & 2 & $\mathbf{6 4}$ \\
\hline $\begin{array}{l}\text { Institution } \\
\text { of study }\end{array}$ & 7 & 7 & 0 & 2 & $\mathbf{1 6}$ \\
\hline Home & 59 & 34 & 3 & 1 & $\mathbf{9 7}$ \\
\hline $\begin{array}{l}\text { Total of } \\
\text { category } \\
\text { responses }\end{array}$ & $\mathbf{1 2 7}$ & $\mathbf{4 5}$ & $\mathbf{4}$ & $\mathbf{7}$ & $\mathbf{1 8 3}$ \\
\hline
\end{tabular}


Table 20 illustrates how respondents used information found on the Internet. I have categorised their answers into the same four groups - clinical practice, professional practice, information for women and teaching/learning. Respondents were able to give more than one example of how information found on the Internet was used.

Table 20. Explanations of how information found on the Internet was used

\begin{tabular}{|l|l|l|l|l|c|}
\hline & $\begin{array}{l}\text { Clinical } \\
\text { practice }\end{array}$ & $\begin{array}{l}\text { Professional } \\
\text { issues }\end{array}$ & $\begin{array}{l}\text { Information } \\
\text { for women }\end{array}$ & Teaching/Learning & $\begin{array}{l}\text { Total of } \\
\text { location } \\
\text { responses }\end{array}$ \\
\hline Work & 4 & 3 & 21 & 16 & $\mathbf{4 4}$ \\
\hline $\begin{array}{l}\text { Institution } \\
\text { of study }\end{array}$ & 1 & 0 & 0 & 17 & $\mathbf{1 8}$ \\
\hline Home & 12 & 8 & 16 & 42 & $\mathbf{7 8}$ \\
\hline $\begin{array}{l}\text { Total of } \\
\text { category } \\
\text { responses }\end{array}$ & $\mathbf{1 7}$ & $\mathbf{1 1}$ & $\mathbf{3 7}$ & $\mathbf{7 5}$ & $\mathbf{1 4 0}$ \\
\hline
\end{tabular}

Examples of how information found on the Internet for 'clinical practice' included "to update clinical practice" and "find out about blue and black cohosh". Examples of information used for professional issues included "online purchasing of water birthing pool". Respondents used the Internet to find information to "pass onto clients" and " "to help women make decisions". As for teaching and learning, respondents said they used the Internet to find information to "pass onto colleagues", to "discuss with students" and for "assignments". 


\subsection{Use of the Internet by consumers}

\subsection{Respondents' impressions of use of the Internet by women receiving midwifery}

care

Respondents were more likely to say they were aware of an increase in use of the Internet by women in their care. They were also more likely to have spoken to women about information found on the Internet. Table 21 present these results.

Table 21. Respondents' impressions of use of the Internet by women receiving midwifery care

\begin{tabular}{|l|l|l|l|}
\hline & Yes (\%) & No (\%) & $\begin{array}{l}\text { Total responding to this } \\
\text { question (\%) }\end{array}$ \\
\hline $\begin{array}{l}\text { Aware of an increase } \\
\text { in use of Internet by } \\
\text { women }\end{array}$ & $38(70.4 \%)$ & $11(20.4 \%)$ & $49(90.8 \%)$ \\
\hline $\begin{array}{l}\text { Talked to women } \\
\text { about information } \\
\text { found on the Internet }\end{array}$ & $38(70.4 \%)$ & $11(20.4 \%)$ & $49(90.8 \%)$ \\
\hline
\end{tabular}




\subsection{Quality of information found on the Internet}

Table 22 shows that respondents were most likely to think that the information found on the Internet was of average to good quality. Seventeen (31.4\%) respondents did not answer this question.

Table 22. Quality of information found on the Internet

\begin{tabular}{|l|c|c|}
\hline $\begin{array}{l}\text { Impression of } \\
\text { information being } \\
\text { accessed }\end{array}$ & Number & Percentage \\
\hline Average & 18 & 33.4 \\
\hline Good & 15 & 27.8 \\
\hline Very good & 2 & 3.7 \\
\hline Poor & 2 & 3.7 \\
\hline Missing & 17 & 31.4 \\
\hline Total & $\mathbf{5 4}$ & $\mathbf{1 0 0}$ \\
\hline
\end{tabular}

\subsection{Ability to critique information found on the Internet}

Almost half the respondents felt they were able to critique information found on the Internet reasonably well. Table 23 presents this result. Six respondents did not answer this question.

Table 23. Ability to critique information found on the Internet

\begin{tabular}{|l|l|l|}
\hline $\begin{array}{l}\text { Ability to critique } \\
\text { information }\end{array}$ & Number & Percentage \\
\hline Reasonably well & 23 & 42.7 \\
\hline Not sure & 13 & 24.1 \\
\hline Not very well & 7 & 13.0 \\
\hline Very well & 5 & 9.2 \\
\hline Missing & 6 & 11.0 \\
\hline Total & $\mathbf{5 4}$ & $\mathbf{1 0 0}$ \\
\hline
\end{tabular}




\subsection{Impact on midwifery practice of consumers accessing information on the}

\section{Internet}

Respondents felt that consumers accessing information on the Internet had an impact on midwifery practice $(n=32,59.25 \%)$. There were mixed feelings about the impact on midwifery practice, with only half of the respondents who answered this question feeling positive about it $(n=23,42.49 \%)$. Seventeen of $46(31.48 \%)$ respondents replied that consumers accessing information on the Internet had had an impact on their own personal practice. Respondents were more likely to be positive about the impact of consumer access to information on the Internet on their personal midwifery practice. Table 24 indicates details of these results

Table 24. Impact on midwifery practice of consumers accessing information on the Internet

\begin{tabular}{|l|l|l|l|}
\hline & & & $\begin{array}{l}\text { Total responding to } \\
\text { this question (\%) }\end{array}$ \\
\hline $\begin{array}{l}\text { Consumers accessing information on } \\
\text { the Internet has had an impact on } \\
\text { midwifery practice }\end{array}$ & Yes (\%) & No (\%) & $49(90.74 \%)$ \\
\hline $\begin{array}{l}\text { Feelings about impact on midwifery } \\
\text { practice }\end{array}$ & $32(59.25 \%)$ & $17(31.48 \%)$ & \\
$\begin{array}{l}\text { Positive about impact } \\
\text { Unsure about impact }\end{array}$ & $23(42.49 \%)$ & & $47(87.03 \%)$ \\
Concerned about impact & $21(38.8 \%)$ & & \\
\hline $\begin{array}{l}\text { Consumers accessing information on } \\
\text { the Internet has had an impact on } \\
\text { respondents' own midwifery practice }\end{array}$ & $\begin{array}{l}\text { Yes (\%) } \\
\text { Feelings about impact on respondents' } \\
\text { own midwifery practice }\end{array}$ & No (\%) & $46(85.17 \%)$ \\
$\begin{array}{l}\text { Positive about impact } \\
\text { Unsure about impact }\end{array}$ & $12(2.2 \%)$ & & \\
Concerned about impact & $8(14.81 \%)$ & & $22(40.7 \%)$ \\
\hline
\end{tabular}




\subsection{Procurement of clients}

Table 25 presents the results. The majority of respondents said that they had not obtained a client through the Internet. Of the avenues through which clients were obtained, the NZCOM 'Search for a midwife' facility was the most successful avenue, followed by e-mail communication and personal web site.

Table 25. Gaining a client through the Internet

\begin{tabular}{|l|l|l|l|}
\hline & Number (\%) & $\mathbf{( \% )}$ & $\begin{array}{l}\text { Total responding } \\
\text { to this question } \\
(\%)\end{array}$ \\
\hline Gained a client through the Internet & $\begin{array}{l}\text { Yes (\%) } \\
10(18.51 \%)\end{array}$ & $\begin{array}{l}\text { No (\%) } \\
38(70.37 \%)\end{array}$ & $48(88.8 \%)$ \\
\hline $\begin{array}{l}\text { Avenue through which client was } \\
\text { gained }\end{array}$ & $\begin{array}{l}5(50 \%) \\
\text { E-mail communication }\end{array}$ & & \\
$\begin{array}{l}\text { NZCOM 'Search for a midwife' } \\
\text { Midwifery Today 'Search for a midwife } \\
\text { Personal web site }\end{array}$ & $\begin{array}{l}(90 \%) \\
(10 \%)\end{array}$ & & \\
\hline
\end{tabular}




\subsection{Midwifery care delivered via the Internet}

Table 26 describes how respondents were asked about their experience of delivering midwifery care via the Internet. The majority of respondents did not deliver care via e-mail and Internet. Respondents who did give care via the Internet described it as being in the form of advice $(n=6,75 \%)$ and other forms $(n=3,37.5 \%)$. Respondents who did administer midwifery care via the Internet were likely to give it no more than two or three times per month $(n=4,50 \%)$. Midwifery care was most likely to be given to women in the respondent's care $(n=6,75 \%)$.

Table 26. Delivering midwifery care via the Internet

\begin{tabular}{|c|c|c|c|}
\hline & $\begin{array}{l}\text { Number } \\
(\%)\end{array}$ & & $\begin{array}{l}\text { Total responding } \\
\text { to this question } \\
(\%)\end{array}$ \\
\hline $\begin{array}{l}\text { Deliver midwifery care via } \\
\text { e-mail and Internet }\end{array}$ & $\begin{array}{l}\text { Yes (\%) } \\
8(18 \%)\end{array}$ & $\begin{array}{l}\text { No (\%) } \\
36(81.81 \%)\end{array}$ & $44(81.48 \%)$ \\
\hline $\begin{array}{l}\text { Form of the care } \\
\text { Advice } \\
\text { Other }\end{array}$ & $\begin{array}{l}6(75 \%) \\
3(37.5 \%)\end{array}$ & & \\
\hline $\begin{array}{l}\text { Frequency of care given } \\
\text { 2-3 times per year } \\
\text { Once a month } \\
\text { 2-3 times per month }\end{array}$ & $\begin{array}{l}4(50 \%) \\
3(37.5 \%) \\
1(12.5 \%)\end{array}$ & & $8(14.81 \%)$ \\
\hline $\begin{array}{l}\text { Category of consumers } \\
\text { A woman in your care } \\
\text { Casual acquaintance who has } \\
\text { approached you because you } \\
\text { are known to be a midwife } \\
\text { Unknown person } \\
\text { Friend or family } \\
\text { Other }\end{array}$ & $\begin{array}{l}6(75 \%) \\
4(50 \%) \\
4(50 \%) \\
2(25 \%) \\
1(12.5 \%)\end{array}$ & & \\
\hline
\end{tabular}




\subsection{E-mail discussion lists}

Respondents were asked about their experience of e-mail discussion lists or groups. Just over half $(\mathrm{n}=28,54.9 \%)$ the respondents who answered had experience of e-mail lists. Of the respondents who answered $23(82.2 \%)$ were most likely to say that they had experience of the New Zealand Midwives' List. Respondents cited a range of advantages and disadvantages to e-mail discussion lists. Eight of 20 (28.57\%) respondents expressed that they changed their midwifery practice as a result of e-mail discussion. Table 27 presents these results. Respondents gave examples of other e-mail discussion lists experienced, which were: the UK midwifery researchers list; US homebirth list; UK midwives group and Midwifery Today. 
Table 27. E-mail discussion Lists

\begin{tabular}{|c|c|c|c|}
\hline & $\begin{array}{l}\text { Number } \\
(\%)\end{array}$ & & $\begin{array}{l}\text { Total responding to } \\
\text { this question (\%) }\end{array}$ \\
\hline $\begin{array}{l}\text { Experience of e-mail } \\
\text { discussion lists for midwives }\end{array}$ & $\begin{array}{l}\text { Yes (\%) } \\
28(54.9 \%)\end{array}$ & $\begin{array}{l}\text { No (\%) } \\
23(45.1 \%)\end{array}$ & $51(94.44 \%)$ \\
\hline $\begin{array}{l}\text { E-mail lists experienced } \\
\text { New Zealand Midwives' List } \\
\text { Midwifery research List } \\
\text { Oz midwifery List } \\
\text { Fensende List } \\
\text { Other }\end{array}$ & $\begin{array}{r}23(82.2 \%) \\
4(14.4 \%) \\
3(10.8 \%) \\
3(10.8 \%) \\
1 \quad(3.6 \%) \\
\end{array}$ & & \\
\hline $\begin{array}{l}\text { Advantages of e-mail } \\
\text { discussion lists } \\
\text { Good means of networking } \\
\text { Great for tracking information } \\
\text { Stimulating discussion } \\
\text { Invaluable way of keeping up to } \\
\text { date } \\
\text { Facilitates reflection of practice }\end{array}$ & $\begin{array}{r}15(53.6 \%) \\
11(39.3 \%) \\
21(75.0 \%) \\
5(17.9 \%) \\
14(50.0 \%) \\
12(42.9 \%) \\
3(10.8 \%) \\
\end{array}$ & & \\
\hline $\begin{array}{l}\text { Disadvantages of e-mail } \\
\text { discussion lists } \\
\text { Too much social chitchat } \\
\text { Too many messages posted } \\
\text { Not enough messages posted } \\
\text { Needs some sort of editorial } \\
\text { control } \\
\text { Lazy way of doing research } \\
\text { Too much conflict } \\
\text { Discussion has no relevance to } \\
\text { my own professional needs }\end{array}$ & $\begin{array}{l}4(14.4 \%) \\
7(25.0 \%) \\
7(25.0 \%) \\
1 \quad(3.6 \%) \\
8(28.6 \%) \\
4(14.4 \%) \\
7(25.0 \%)\end{array}$ & & \\
\hline $\begin{array}{l}\text { Change of practice as a result } \\
\text { of e-mail discussion }\end{array}$ & $\begin{array}{l}\text { Yes (\%) } \\
8(28.50 \%)\end{array}$ & $\begin{array}{l}\text { No (\%) } \\
20(71.50 \%)\end{array}$ & $28(42.59 \%)$ \\
\hline
\end{tabular}

\subsection{Internet resources available to midwives}

Respondents were asked about Internet resources available to midwives. The most commonly used resources were bibliographic databases $(n=41,75.9 \%)$, professional bodies $(n=40,74 \%)$, electronic journals $(n=39,72.2 \%)$, midwifery resources shop $(n=37$, 
$68.51 \%)$ and reports and research papers $(n=36,66.7 \%)$. There was a high level of interest in all resources being made available on the Internet in the future. Table 38 shows which Internet resources respondents have accessed in the past and which resources respondents would find useful to access in the future.

Table 28. Internet resources available to midwives

\begin{tabular}{|l|l|l|}
\hline Resources & $\begin{array}{l}\text { Have accessed in the } \\
\text { past (\%) }\end{array}$ & $\begin{array}{l}\text { Would be useful to access } \\
\text { in the future (\%) }\end{array}$ \\
\hline Bibliographic databases & $41(75.9 \%)$ & $42(77.7 \%)$ \\
\hline Professional bodies & $40(74 \%)$ & $47(87 \%)$ \\
\hline Electronic journals & $39(72.2 \%)$ & $47(87 \%)$ \\
\hline $\begin{array}{l}\text { Midwifery } \\
\text { book/video/resources shop }\end{array}$ & $37(68.51 \%)$ & $45(83.3 \%)$ \\
\hline $\begin{array}{l}\text { Reports and research } \\
\text { papers }\end{array}$ & $36(66.7 \%)$ & $48(88.8 \%)$ \\
\hline Statutory bodies & $30(55.5 \%)$ & $39(72.2 \%)$ \\
\hline $\begin{array}{l}\text { Conference and course } \\
\text { details }\end{array}$ & $20(37 \%)$ & $44(81.48 \%)$ \\
\hline $\begin{array}{l}\text { E-mailed } \\
\text { newsletter/updates }\end{array}$ & $17(31.48 \%)$ & $41(75.9 \%)$ \\
\hline Job advertisements & $16(29.62 \%)$ & $31(57.4 \%)$ \\
\hline Online tutorial & $7(13 \%)$ & $41(75.9 \%)$ \\
\hline Support groups & $7(13 \%)$ & $36(66.7 \%)$ \\
\hline Electronic claiming & & $31(30.32 \%)$ \\
\hline
\end{tabular}

Respondents identified other resources that they have accessed in the past:

Databases and web sites for consumers, Association for Improvement in Maternity Services (AIMS), Home Birth Association, New Zealand Ministry of Health, International Ministry of Health, other libraries, Accident Compensation Corporation (ACC), Health and Disability Commission, Parents Centre, American and British obstetric journals and E conferences.

Respondents also acknowledged resources that they would find useful to access in the future: education forums, E conferences and 'more the better'. 


\subsection{Web sites}

Table 29 shows how many respondents have their personal details posted on the NZCOM 'Search for a midwife' web site $(n=20,38.46 \%)$. Eight $(15.1 \%)$ respondents have their own personal web sites.

Table 29. Personal web sites

\begin{tabular}{|l|l|l|l|}
\hline & Yes (\%) & No (\%) & $\begin{array}{l}\text { Total responding to } \\
\text { this question (\%) }\end{array}$ \\
\hline $\begin{array}{l}\text { Details on the NZCOM } \\
\text { web site }\end{array}$ & $20(38.46 \%)$ & $32(61.53 \%)$ & $52(96.29 \%)$ \\
\hline Personal web site & $8(15.1 \%)$ & $45(84.9 \%)$ & $53(98.2 \%)$ \\
\hline
\end{tabular}




\subsection{Databases}

Table 30 deals with results about respondents' experience of online databases. Nearly all the respondents had had experience of online databases $(n=48,50.6 \%)$. Of the choice of databases given, respondents $(\mathrm{n}=8,15.1 \%)$ were least likely to access the ERIC database, which is a database that contains education material. The majority of respondents found databases easy to use $(n=40,80 \%)$. Respondents were very enthusiastic about the MIDIRS database, with $21(36.63 \%)$ having had experience of the MIDIRS database and $25(83.3 \%)$ likely to use it in the future.

Table 30. Online databases available to midwives

\begin{tabular}{|c|c|c|c|}
\hline & Number (\%) & & $\begin{array}{l}\text { Total responding to } \\
\text { this question (\%) }\end{array}$ \\
\hline $\begin{array}{l}\text { Experience of } \\
\text { online databases }\end{array}$ & $\begin{array}{l}\text { Yes (\%) } \\
48(50.6 \%)\end{array}$ & $\begin{array}{l}\text { No (\%) } \\
6(11.32 \%)\end{array}$ & $53(98.2 \%)$ \\
\hline $\begin{array}{l}\text { Databases } \\
\text { experienced } \\
\text { Medline } \\
\text { Cochrane } \\
\text { CINAHL } \\
\text { ERIC } \\
\text { Other }\end{array}$ & $\begin{array}{r}42(79.25 \%) \\
43(81.2 \%) \\
36(66.6 \%) \\
8(15.1 \%) \\
14(26.4 \%)\end{array}$ & & \\
\hline $\begin{array}{l}\text { Ease of use } \\
\text { Easy } \\
\text { Not very easy }\end{array}$ & $\begin{array}{l}40(80 \%) \\
10(20 \%)\end{array}$ & & $50(92.6 \%)$ \\
\hline $\begin{array}{l}\text { Experience of } \\
\text { MIDIRS } \\
\text { Midwifery } \\
\text { database }\end{array}$ & $\begin{array}{l}\text { Yes (\%) } \\
21(36.63 \%)\end{array}$ & $\begin{array}{l}\text { No (\%) } \\
32(60.4 \%)\end{array}$ & $53(98.2 \%)$ \\
\hline $\begin{array}{l}\text { Likely to use } \\
\text { MIDIRS database } \\
\text { in the future }\end{array}$ & $\begin{array}{l}\text { Yes (\%) } \\
25(83.3 \%)\end{array}$ & $\begin{array}{l}\text { No (\%) } \\
5(16.6 \%)\end{array}$ & $30(55.5 \%)$ \\
\hline
\end{tabular}




\subsection{Favourite web site}

Respondents identified a range of favourite web sites:

NZCOM, La Leche League, midwifery research, having a baby on the Net 2000, pregnancy and childbirth, swnymph@,fensende.com, www.jiscmail.ac.uk, Midwifery Today, CINAHL, Medline, The Farm, MIDIRS, Databases-full text, Expanded academic, Assocation of Radical Midwives, www.wairuabirthing.co.nz, about.com (pregnancy and birth), Pubmed, Sheffield, no favourite.

\subsection{Desired resources for the future}

Respondents identified a range of resources that they would like to have made available in the future. These were: develop my web site to be more comprehensive on breech birth, free Cochrane database access, midwifery management of aspects of care network, hospital midwives to be able to access information from other hospitals in NZ, up to date midwifery text book, drug information, online mentoring system, British Journal of Midwifery, specific midwifery search engine, interactive clinical scenarios, topic focussed with medical/midwifery/ sociological/ psychological publications, order equipment from NZ, online educational sessions that can be used for portfolio - for rural midwives, New Zealand midwifery educators' forum, access from work, new midwifery developments, NZCOM newsletters - local and national, network for rural/remote midwives. 


\subsection{Conclusion}

This chapter has presented the results of the web-based survey completed by 54

midwives in New Zealand. A limited analysis has been undertaken as this was a pilot study only, designed to test the feasibility of web-based survey in this population, and to test a questionnaire developed to find out how midwives in New Zealand use the Internet. 


\section{Chapter Five}

\section{Discussion}

\subsection{Introduction}

This chapter will proceed to discuss the results of the pilot study of how midwives in New Zealand use the Internet. The discussion in this chapter and the next three chapters will centre on how this research could be repeated in the future.

\subsection{Method of recruitment}

\subsection{E-mail information letter}

Of the 110 emails that I sent out, 17 were returned because there was either an error with the e-mail address, or the addressee was unknown. Eight of these returns were from the e-mail address found on the NZCOM 'Search for a Midwife' web site. This illustrates one of the problems with e-mail and the Internet. Information changes quickly. Midwives need to inform the managers of web sites of these changes, otherwise midwives may lose out on opportunities to procure clients because of inaccurate contact information. 


\subsection{Snowballing}

Of the 35 e-mail responses I received, only 10 came from midwives who I had not sent the original information e-mail to. In this instance, the e-mail snowballing/chain letter approach to recruiting respondents to a study was not successful because I had only 54 completed questionnaires. If I had known who the non-responders were, I could have interviewed them to find out the reasons why they did not complete the questionnaire. In a repeat study, it may be better to invite only known midwives to the study, so at least I know how many have been asked to participate.

\subsection{Junk mail}

The problem with this e-mail snowball approach was that midwives may have considered the e-mails as a form of electronic junk mail or chain letter, and deleted it accordingly (Witmer et al, 1999). It is easier and quicker to hit the 'delete' button on the computer than it is to dispose of a paper questionnaire. They may have seen it as an intrusion on their privacy, which may have elicited a hostile response (Witmer et al, 1999). Indeed, one midwife verbally commented to me that she thought I was very 'cheeky' and appeared surprised that the Victoria University Ethics Committee would approve such a method of recruiting research subjects.

\subsection{Electronic network of midwives in New Zealand}

I suspect the electronic network extends further than this study was able to demonstrate. At the moment there is no way of knowing who is connected to the Internet by e-mail. 
Maybe, the NZCOM could act as a focal point and expand the 'Search for a Midwife' idea or develop a database of e-mail addresses, so that all midwives could be included and without personal cost. To allay privacy fears, the e-mail addresses could be for the use of midwives only.

\subsection{Promotion of survey}

I chose to promote the survey by e-mail because it was a cheap option compared to advertising in a midwifery journal, and is a significant way of increasing response rates (Batagelj et al, 1998). Midwives could access the web site from the e-mail within a couple of seconds as long as they had compatible software. It would take three to four minutes to actively log-on to the Internet and find the location of the web site after reading about it on paper. This would require a higher level of motivation and be more likely to increase the chances of mistakes (Farmer, no date). A further problem may be that midwives have access to e-mail but not to the World Wide Web, although, theoretically all midwives in New Zealand have the means to use public facilities such as libraries and cybercafes.

\subsection{Response rate}

\subsection{Survey response rate}

One problem with this methodology was that I was unable to calculate a response rate because I had no idea how many midwives had received the survey information. It would be possible to calculate a response rate if utilising an e-mail discussion list because one could find out the number of members. Posting paper surveys would almost completely 
eliminate this problem, except that one could never be sure that every single midwife received their survey. The alternative is to use some sort of identifier although I am not sure how one would do that. Response times were fast. Fifty per cent of responses were received by the end of the first week (see Table 2), which is likely to be faster than postal returns (Comley, no date)

\subsection{Limitations of questionnaires}

A limitation of questionnaires, paper or electronic are low response rates, and incomplete answers (Houstan, 1996). Comley (no date) writes that response rates to all surveys in the UK are declining. There appears to be mixed evidence about response rates to electronic surveys. Selwyn and Robson (1998) believe that electronic surveys have a greater response rate than conventional post. Miller et al (1997) had a 71 per cent return to a survey posted on a bulletin board which canvassed nurse-midwives in the USA. Brennan, Rrae and Parackal (1999) achieved a 46 per cent response rate to their web survey. However, Comley (no date) had a 13.5 per cent return on his commercial electronic survey using e-mail compared to 15.4 per cent return from his postal survey. Witmer et al, (1999) had a 20.7 per cent return rate to their survey that was administered using e-mail and web. There does seem to be a growing consensus it is only a matter of time before surveys conducted through a web site becomes the major survey method (Comley, no date; Woong Yun \& Trumbo, 2000). 


\subsection{Increasing response rates}

Response rates can be increased if respondents are interested in the subject being researched; the survey has an interesting appearance; and the questions have a logical and coherent progression (Witmer et al, 1999). I published a picture of myself at the beginning of the survey in order to capture the respondents' interest and build a rapport with the respondents. Web surveys can be programmed in such a way that respondents are forced to answer all the questions before they can submit the questionnaire. I decided not to employ that tactic because respondents may have a legitimate reason for not answering the question and be forced into entering false answers; respondents may get so irritated with the constraint that they do not complete the survey; forcing people into answering questions goes against the principle that participation in the research should be voluntary (Dillman et al, 1998). There were certain questions in the survey that had a low response rate. In a future study, it will be important to look at the questions that had a low response rate, and consider how the questions can be improved so that a greater response rate is achieved.

\subsection{Motivation}

People have to be interested in the subject that is being researched (Witmer et al, 1999). I believed there would be sufficient interest in the research to ensure a good response because of its novelty value. Also, people who use the Internet are known to be altruistic and keen to help one another (Wallace, 1999). I was depending on midwives' good will 
and ability to complete the survey, send on the recruiting information to other midwives, and contact me when they receive the information e-mail.

\subsection{Sampling}

Due of the nature of this study and sampling method, I was unable to gather data from midwives who did not use the Internet in any shape or form. This is another reason why I was not able to generalize my results to the whole midwifery population. The main reason is because of the nature of convenience sampling. The survey was unable to exclude participants who did not fit the sample profile, so ultimately I have no way of knowing if that was the case. Theoretically, anyone who found the web site could have submitted a questionnaire. Access to the Internet is potentially available to all midwives be it through a personal computer, computer at work or institution of study, or places such as cybercafe and public library. However, realistically midwives who did not have regular access to e-mail and the Internet were excluded which is an important bias to acknowledge.

\subsection{Demographics}

\subsection{Employment}

The major flaw of this study was the initial definition of midwives and their employment. One key aim of the study was to look at how Internet use differed between the different groups of midwives, for example comparing hospital midwives' Internet use with selfemployed midwives. The questionnaire provided respondents with the opportunity to 
choose more than one category of employment (Table 3). The respondents selected more than one role, such as lecturers who also defined themselves as self-employed LMCs; self-employed midwives who worked hospital shifts. Thus, respondents did not differentiate themselves into a single given group. This coupled with small numbers made it impossible to carry out detailed analysis.

It was my belief that hospital midwives would have reduced access to the Internet at work compared to self-employed midwives, which would impact on their use of the Internet for work purposes. Loy (2001a) reported in his study that of the respondents who were hospital midwives, only 55 per cent had access to the Internet at work. I was surprised to find that of the respondents working in a core facility (defined as hospital midwives and managers) 11 out of 18 respondents (61\%) replied that they had access to the Internet at work. I expected this number to be lower. It may well be different if a larger population of hospital-based midwives are surveyed. The other problem with definition is 'employed LMC'. The LMC may be employed by a community group/employer, thus she would not see the hospital as her place of work.

I expected the greatest number of respondents to be self-employed midwives and lecturers, which was the case. This was because I had few e-mail addresses of hospital midwives - my e-mail contacts were mostly with self-employed midwives and teaching colleagues. Also, I obtained e-mail addresses from the NZCOM web site where mostly LMC midwives advertise their services. There is no need for hospital midwives to do this, unless they are employed LMCs such as the Golden Bay midwives. 


\subsection{Location of practice}

The other major problem with classification was how respondents defined their location of practice. Only 15 respondents answered this question, and three of them classified themselves as both rural and urban midwives (Table 3). Again, this made it impossible to make any meaningful analysis. As a result I was unable to clearly differentiate between how rural midwives used the Internet compared to urban midwives. My belief was that rural midwives relied more heavily on Internet resources because of their physical and professional isolation. There is evidence that isolation may be a barrier to GPs using the Internet, and GPs with a solo practice are less likely to use the Internet (Kerse et al 2001). What is needed is further research is see if the same applies to midwives.

\subsection{Age}

Respondents were significantly most likely to be in the 40-44 age range (Table 4). This reflects the national midwifery population (NZHIS, 2001) This is slightly older than the average population of Internet users in New Zealand, which is 35 years of age (Infotech, 1998). This echos the research carried out by Sinclair (2001) and contradicts Scott's (1998) contention that people in the over 40-age group do not relate to computers.

\subsection{Years of qualification}

There did not appear to be a relationship between years of qualification and use of the Internet (Table 4). This was contrary to my expectations that newly qualified midwives would be more familiar with the Internet because they had just completed tertiary 
education, than the midwives who had been qualified for a longer period of time. The assumption that newly qualified midwives would be younger and more familiar with the Internet does follow either because women of all ages graduate from the under-graduate midwifery programs (Pairman, 2000).

\subsection{Education}

There was a high level of educational uptake amongst respondents, with 61 per cent having completed, or were currently enrolled in tertiary education (Table 5). This level of education reflects the general Internet population (Infotech, 1998). Statistics from the 2001/2002 Annual Practising Certificate survey administered by The Nursing Council of New Zealand, indicate the level of education in the general population of midwives in New Zealand (Pohatu, 2002). Of the 2264 midwives who were practising with a current Annual Practising Certificate in 2001, eight midwives had a PhD, 77 midwives had a Masters degree, 886 had a Bachelor degree and 237 had either a post-graduate certificate or diploma. I have been unable to carry out detailed comparison between the Nursing Council statistics and those generated by this study. However, one can see at a glance that the general midwifery population does not have such a high level of education as the survey population, as indicated in Table 31 . However, these general midwifery population statistics do not include midwives who are currently enrolled in a program of study. 
Table 31. Comparison of level of education between the general population of midwives and the respondents of this survey

\begin{tabular}{|c|c|c|c|}
\hline $\begin{array}{l}\text { Level of education } \\
\text { completed in general } \\
\text { population of midwives } \\
\text { (Pohatu, 2002) }\end{array}$ & Number (\%) & $\begin{array}{l}\text { Level of education } \\
\text { completed or currently } \\
\text { being und ertaken in } \\
\text { population of survey } \\
\text { respondents }\end{array}$ & $\begin{array}{l}\text { Number } \\
(\%)\end{array}$ \\
\hline Bachelor degree & $886(39.2 \%)$ & Bachelor degree & $7(13.0 \%)$ \\
\hline $\begin{array}{l}\text { Postgraduate certificate or } \\
\text { diploma }\end{array}$ & $237(10.5 \%)$ & $\begin{array}{l}\text { Postgraduate certificate or } \\
\text { diploma }\end{array}$ & $6(10.5 \%)$ \\
\hline Masters & $77(3.4 \%)$ & Masters & $18(33.8 \%)$ \\
\hline $\mathrm{PhD}$ & $8(0.4 \%)$ & $\mathrm{PhD}$ & $2(3.0 \%)$ \\
\hline
\end{tabular}

\subsection{Use of Internet}

\subsection{Location for Internet use}

Respondents were most likely to use the Internet at home (Table 6). The only respondent, who did not have access to the Internet at home, had access at work. This respondent planned to become connected to the Internet at home in the next year or two. Loy (2001a) found that 95 per cent of midwifery respondents had access to the Internet at home, whereas 55 per cent of GPs in one New Zealand study had home Internet access (Eberhart-Phillips et al, 2000). One could say this shows that this particular group of midwives have embraced the Internet enthusiastically. However, just because the Internet is accessible at home does not necessarily mean the midwife uses it. Indeed, I failed to ask midwives how accessible the Internet was at home. Judging by my experience despite having a computer with Internet connection it is not always easy to obtain access to the computer, because of competition with other members of the family. Seven respondents identified barriers to use of the Internet at home other than those listed. I can only surmise that battling other members of the family for the computer is one such barrier. 


\subsection{Definition of 'place of work'}

Respondents who identified as solely self-employed LMC midwives were most likely to use the Internet at home. This result was expected because one could anticipate that many self-employed midwives would define their place of work as their home, and thus use the Internet for work purposes at home. However, the questionnaire did not provide a means for self-employed midwives to clarify what their place of work was, so this made it difficult to say anything about the way respondents used the Internet at work.

There were more respondents with access to the Internet at work than I expected $(58.8 \%$ respondents) (Table 11). But then, I had mistakenly thought of 'work' as meaning an institution such as a hospital or university/polytechnic. I had completely forgotten about the self-employed midwives. However when one broke down the categories of respondents to hospital and employed midwives as well as midwifery managers, 61 per cent $(n=18)$ respondents had work access. This is a favourable result compared to the NZ GPs of whom only 36 per cent had access to the Internet at work (Eberhart-Phillips, 2000), and slightly better than UK midwives, of whom 55 per cent had work access.

\subsection{Use of Internet at work}

Respondents who used the Internet at work were most likely to find it reasonably easy to search for information (Table 14), and more likely to integrate information found on the Internet into their practice (Table 17). These results lose impact when one remembers that some respondents would be defining their place of work as home. 
If I had been able to access a greater population of midwives, the results may have been different. The very method of recruitment excluded midwives who did not have access to the Internet. Forty eight per cent of respondents had a work e-mail address (Table 9). However, this may have included lecturers who are all likely to have work e-mail addresses.

\subsection{Frequency of Internet use}

Respondents were more likely to access the Internet daily (Table 7). This is more frequent than the general Internet population of New Zealand, of which 79 per cent use the Internet once or twice weekly (Statistics New Zealand, 2000). This frequency of use also appears to be more frequent than the UK midwives, of whom 22 per cent use the Internet on a daily basis (Loy, 2001a). It is also more frequent than the NZ GPs, of whom only 30 per cent accessed the Internet at least weekly for work purposes (Eberhart et al, 2000).

\subsection{Reasons for use of Internet}

I found it very interesting that respondents were more likely to use the Internet for an equal combination of work, study and personal reasons (Table 8). I somehow imagined that work would be the greatest reason for Internet use, however this reflects that the Internet is becoming more a part of every day life. Loy (2001a) found that the UK midwives who participated in his study mainly used the Internet for work purposes. It has been my personal impression that the Internet is used more widely in New Zealand 
compared to the UK. Maybe that is because of New Zealand's comparative isolation in the world?

Over the three locations of work, institution of study and home, the three main reasons for using the Internet were about finding information (Table 15): satisfying a specific information need $(n=29.3,54.25 \%)$; keeping up to date $(n=20.3,37.59 \%)$; satisfying a specific information need for a woman $(\mathrm{n}=16.3,30.18 \%)$, which corresponds to Loy's (2001) findings. I imagined that one main reason would be for communication, however overall it was the fourth major reason for using the Internet. Maybe midwives are not familiar enough with the Internet as a vehicle for communication and collaboration, and need to explore this facility further. Maybe, they are quite content with traditional methods of communication.

Loy (2001a) writes that very few respondents in his study used the Internet to supply information to clients. This was not the case with respondents in this study because over half of the respondents searched for information for women at home (see Table 15). The difference between British midwives and midwives in New Zealand may be explained by the fact that midwives in New Zealand are LMC midwives. This involves providing information for clients which is an integral part of midwifery practice. Again, it may be a different story if a larger population of midwives is surveyed. 


\subsection{Barriers to use of the Internet}

As expected, the main barriers to use of the Internet were time and training (Table 16). Time is always an issue for midwives what with managing work demands; professional development obligations including the development of a professional portfolio, Midwifery Standards Review and further education; as well as personal and family commitments.

I was surprised to see that training was only identified as a barrier by 18.51 per cent of the respondents. I expected to see that percentage to be higher. But then again, this population is heavily involved in tertiary education and motivated to use the Internet, so this may explain their level of skill. I suspect this result would be much higher if a greater population of midwives were accessed, especially midwives who do not regularly use the Internet. Increasing Internet training for midwives and health professionals remains a constant theme in literature (Loy, 2001a; Sinclair, 2001; Jadad, 1999). Meanwhile, few respondents had been offered training at work or their institution of study. This is a concern because no doubt there are midwives who would benefit from training, and for Internet resources to be effectively employed, midwives need to be skilled. Thus, I would concur with Loy (2001a) who calls for employers and training providers to improve opportunities for midwives to explore Internet resources. NZCOM is providing an Internet workshop for midwives at the next Bi-anneal NZCOM conference in July 2002. 
One must remember that these respondents had 100 per cent access to the Internet so data collected about barriers may be different when a larger population of midwives is surveyed, including those midwives who do not have access to the Internet.

\subsection{Online education}

There appears to be little online midwifery education, either being offered or taken up. Only three (5.5\%) respondents have enrolled in an online program, and eight $(14.9 \%)$ respondents used the Internet to deliver lecturers, tutorials, or counselling. I believe in New Zealand that there is a real need for online post-graduate education. Admittedly, one of the big advantages of post-graduate education is the face-to-face networking midwives do when they meet up for class. However, I consider that they can still benefit from email and synchronous networking.

Online education would be particularly beneficial to rural midwives who live some distance from education providers. The extra cost of flights and accommodation are all factors that midwives have to carefully consider before they embark on a postgraduate program of study, as well as time away from their practice may mean they lose revenue from missing a birth.

\subsection{Information found on the Internet}

The information found on the Internet at work, institution of study and home was mostly clinical. It was used mostly for teaching and learning. This is not unexpected as 16 respondents were lecturers, and 33 respondents were enrolled in a program of study. 
However, it suggests that these midwives are very enthusiastic about furthering their own level of knowledge and sharing it with students and colleagues.

\subsection{Consumers and the Internet}

\subsection{Use of the Internet by consumers}

Over half $(n=38,70.4 \%)$ the respondents were aware of an increase in use of Internet by women, and had talked to women about information found on the Internet (see Table 19). This result contributes to the evidence that the Internet is being utilised by an increasing number of consumers. This compares to 65 per cent and 50 per cent respectively, in the study of UK midwives (Loy, 2001a). The NZ study of GPs (Eberhart-Phillips et al, 2001) found similar results: 71 per cent of GPs had patients who had sought medical information from the Internet, and 56 per cent GPs spoke to at least two to five patients per month about the Internet.

\subsection{Quality of information found on the Internet}

The issue of quality of information found on the Internet continues to be debated. In this study (Table 20), the greatest number of respondents $(n=33,61.2 \%)$ felt that information was of good to average quality. Concern about quality of information found on the Internet is shared by NZ GPs, of 45 per cent of whom were anxious about incorrect or inadequate online information.

Just under half ( $\mathrm{n}=23,42.7 \%$ ) of the respondents were able to critique information found of the Internet reasonably well (Table 23), which invites the questions about how they do 
that. What training have midwives had to enable them to critique information found on the Internet? This population may be able to critique information, but what about those midwives (37.1\%) who cannot critique information given that the Internet is used widely for work. This may be problematic. What are the implications for the profession if midwives are acting on inaccurate information found on the Internet, or are analysing the information inappropriately? Should consideration be given to what resources/training can be provided to help midwives who are not able to critique information found on the Internet? Maybe, the likes of NZCOM should think about providing links to quality web sites from its web page.

\subsection{Impact of consumers accessing information on the Internet}

Consumers accessing Internet information appears to be having an effect on the practice of health professionals (Table 24$)$. In this study, $32(65.3 \%)$ respondents indicated that consumers accessing information on the Internet has had an impact on midwifery practice, although $17(37.0 \%)$ felt it had had an effect on their own personal practice.

There was some ambivalence about the effect of consumers accessing information on the Internet (Table 24). Three (6.4\%) respondents were concerned about the impact on midwifery practice and $21(44.7 \%)$ were unsure about the impact. Nevertheless, there were respondents who were positive about the impact ( $\mathrm{n}=23,44.7 \%)$ It is difficult to place too much credence on these results because only $22(40.74 \%)$ participants answered this question. 
In a similar study, 25 per cent New Zealand GPs said that the Internet had already changed the way they practised medicine, and nearly two-thirds of the respondents were positive about these changes (Eberhart-Phillips et al, 2001). The GPs who voiced concerns about the effect of consumers accessing information on the Internet identified their concerns as being the effect on the patient-doctor relationship; incorrect or inadequate information, resource implications and undermining of trust between patient and doctor (Eberhart-Phillips et al, 2001). This study did not ask midwives to identify exactly what their concerns may be.

On the whole, there is not a feeling of respondents feeling threatened by consumers accessing information on the Internet (Table 24). One respondent in the New Zealand GP's study stressed that a 'highly informed patient is only a threat if the doctor-patient relationship is based on the biomedical model and is not patient-centred'. I would hope that midwives welcomed the opportunity to source another avenue of providing information to women, as midwifery practice in New Zealand is based on the premise of informed choice and consent for each woman and partnership (NZCOM, 1993).

The wording of the survey may have been ambiguous. I asked the question 'how did you feel about the impact of consumers accessing health information on the Internet has on midwifery practice'. One answer could have been that the respondent was 'concerned' about the impact. I could have used 'negative' instead because the respondent may have been concerned that women were not using the Internet enough, rather than being concerned about the effect on midwifery practice. 


\subsection{Advertising services on the Internet}

Respondents were unlikely to gain clients through the Internet (Table 25). Of the respondents who had gained clients through the Internet $(n=10,20.9 \%)$, it was most likely to be via the NZCOM 'Search for a midwife' web site $(n=9,47.4 \%)$. Indeed, 20 $(38.46 \%)$ respondents had their details posted on the web site (Table 29). This finding should be of interest to NZCOM, but as yet I am unaware of an evaluation of the effectiveness of this facility. Just as exciting is the finding that eight midwives (15.1\%) have their own web sites (Table 29), and half $(\mathrm{n}=4)$ of these respondents have gained clients through their web site (Table 25). This is quite an achievement for midwives considering the time, financial and computer 'savvy' that is required to produce and maintain a web site. This compares favourably with the NZ GPs, nine per cent of which were involved with their own web site (Eberhart-Phillips et al, 2001). As midwives see that utilising the Internet for advertising and marketing is feasible and that colleagues are acquiring clients through this avenue, then more midwives will adopt the Internet for this purpose (Rogers, 1995).

\subsection{Midwifery care delivered through the Internet}

The majority of respondents did not deliver midwifery 'care' via the Internet (Table 26). Advice $(n=6)$ was delivered mostly two to three times per year $(n=4)$. The recipients were mostly clients of the respondents $(n=6)$. However, there were four instances of recipients giving advice to unknown women who had approached them via the Internet and e-mail. Three respondents indicated they gave other forms of care, however invalid 
data was generated by the web survey. This was disappointing because it would have been interesting to find out what other form of 'care' was given. It will be worth repeating this question in a few years time to see if the instances of 'care' given via the Internet have increased. This method of communicating and practice may increase in its appeal to both women and midwives; especially to women who are isolated in rural and remote areas, and midwives who use up a lot of time and financial resources to provide a service to these women. Nevertheless, the ethical and legal issues involved with providing care via the Internet need to be thoroughly explored, so that midwives can be confident that this area of their practice meets required standards.

\subsection{E-mail discussion lists}

Just over $28(50.0 \%))$ respondents have experienced e-mail discussion lists (Table 27). This is an encouraging result but again has to be viewed with caution because of the nature of this population of midwives. It is a higher percentage than found by Loy (2001). Respondents mostly experienced the New Zealand Midwives List. The advantages and disadvantages identified by respondents mirror those of Internet scholars (Murray, 1997; Rojo, 1995). Some of these disadvantages just go to show that 'you cannot please all of the people all of the time'. However, in my view e-mail discussion lists have a part to play in midwifery practice, which is substantiated by eight $(28.57 \%)$ respondents who indicated that their practice had changed as a result of e-mail discussion. 


\subsection{Internet resources}

\subsection{Uptake of Internet resources}

There was a high level of uptake of Internet resources (Table 28). The least utilised were support groups $(n=7,13 \%)$ and online tutorials $(n=7,13 \%)$. As for resources that would be useful to access in the future, the respondents were overwhelmingly enthusiastic about being able to access a wide range of resources, including education forums, E conferences and 'the more the better'. Electronic claiming $(n=31,30.32 \%)$ was perceived to be a useful resource for the future. I would not expect that result to be much higher than it was because it would only be LMC midwives who would be interested in electronic claiming. There was no mention of wanting other Internet capabilities such as being able to access laboratory reports via the Internet or increasing women's access to midwives via web sites. A future survey or interview could investigate this further to ascertain how much knowledge midwives have about these potential functions, and whether they seen to be desirable resources.

\subsection{Online databases}

The large majority of respondents had accessed online databases $(n=48,88.9 \%)$ (Table 30). The most commonly used databases were Cochrane $(n=43,81.2 \%)$; Medline $(n=42,79.25 \%)$ and CINAHL $(n=36,66.6 \%)$. The least likely database to be used was ERIC $(n=8,15.1 \%)$. This response compares very favourably with a group of GPs in New Zealand who were surveyed in 1999. Just under half of the GPs ( 42\%) knew about the Cochrane database, but only 15 per cent of the GPs had used it (Kerse et al, 2001). 
The majority of respondents found the databases easy to use $(n=40,80 \%)$ although there were some who did not find them easy $(n=10,20 \%)$. There were a surprising number of respondents interested in the MIDIRS database, which is a midwifery-specific database. Twenty-one (36.63\%) respondents had experience of the database, and $25(83.3 \%)$ were likely to use it in the future. I believe this shows real commitment to providing evidencebased care because it is expensive for New Zealand midwives to sign up for this resource, over NZ\$200 per year. That commitment is further displayed by respondents who use databases such as Cochrane, that are considered to provide high standard evidence and information (Dickson, 2000).

\subsection{Suggestions for future online resources}

Respondents cited a number of favourite web sites from databases such as CINAHL to web sites belonging to organisations such as Midwifery Today and La Leche League. As for resources they would like to see made available, respondents made quite a few suggestions that would be useful for professional bodies for instance NZCOM and providers of education, to consider further. Respondents wanted networking resources to be made available, including hospital midwives to be able to network with other hospitals and a network for rural midwives. Respondents also wanted professional resources made available such as free Cochrane database access and access to other databases; online newsletter, both local and national from NZCOM; up to date midwifery text book, and publications focusing on topics relevant to midwives; British Journal of Midwifery. Educational resources were requested including an online mentoring system; interactive 
clinical scenario; New Zealand midwifery educators' forum; midwifery management of specific aspects of care; online education sessions that can be used for portfolio, especially for rural midwives. Specific information was requested to be online such as drug information; interactive clinical scenarios, and the ability to order equipment from suppliers in NZ. One midwife was aiming to develop her web site so that it would be more comprehensive on breech birth. Another respondent wanted to be able to access the Internet from work.

\subsection{Conclusion}

This chapter has discussed the results of a pilot study that has explored the use of the Internet by midwives in New Zealand. Several issues have been explored including results and problems with recruitment, sampling and response rates. Also discussed has been respondents' use of the Internet, as well as the effect on midwifery practice of consumers accessing the Internet. Finally, the chapter has explored the respondents' use of Internet resources.

This discussion has led to a number of recommendations that can be accessed in the next chapter. The following chapter will deal with issues that have arisen from the results of the study, and make recommendation for further research. The chapter will also make recommendations for the provision of Internet resources by leaders of the midwifery profession, employers of midwives as well as providers of midwifery education. 


\section{Chapter Six}

\section{Issues for further consideration}

\subsection{Introduction}

This chapter considers the issues raised by the results of this pilot study. It will discuss the limitations of this study and outline the requirements for a larger national study to clarify issues such as the difference in Internet use according to the midwifery role. Recommendations regarding the provision of Internet resources will be made for leaders of the midwifery profession in New Zealand, as well as midwife employers and providers of education. Finally, suggestions will be made for further research.

\subsection{Pilot study}

\subsection{Need for national study}

This pilot study has shown that there is a small population of midwives in New Zealand who regularly use the Internet for searching information, which they utilise in their professional practice, and pass onto colleagues and midwifery clients. Midwives in this study are utilising Internet resources such as e-mail discussion lists, personal web sites and online newsletters. They are also very enthusiastic for as many resources as possible to be made available on the Internet such as electronic claiming, midwifery education programs and online mentoring. 
Unfortunately, I did not obtain the response to this study that I expected, so to attain a clearer picture of how the general population of midwives is using the Internet, a national survey needs to be carried out. This pilot study cannot be relied on to give an accurate picture because it attracted such a small sample. The sample was made up of midwives who used the Internet, and did not include those who did not use the Internet so this does not provide a true picture of what is happening in New Zealand. It is important that information is obtained from midwives who do not use the Internet, because only then can one develop a strategy for encouraging and aiding midwives to adopt the Internet.

In order to capture data from midwives who do not use the Internet as well as those who do, a paper survey would need to be administered, as opposed to a web-based survey. The most effective way of reaching all practising midwives would be through the Nursing Council of New Zealand. The Council gathers contact details from midwives when they apply for their annual practising certificates.

\subsection{Level of education and the use of the Internet}

One potential bias in this study was the group who were sent the original e-mail information letter. The information e-mail was sent to a large proportion of midwives who were either colleagues working in educational institutions, or involved in postgraduate education like myself. Thus, the limitation of the recruitment method to this study was the level of educational attainment of the respondents. Over half of the respondents had some kind of post-graduate qualification, including $18(33.33 \%)$ at Masters level. 


\subsection{Topics of information found on the Internet by midwives}

The information found on the Internet at work, institution of study and home was mostly clinical. The implication for the leaders of the profession is to look carefully at the topics of information that midwives are researching. This data can be utilised as a framework for information and links provided on their web site. It also provides a structure for me as writer of the column about Internet resources, to focus on web sites that deal with these topics.

I believe that developments of Internet resources need to come from NZCOM because it is at the heart of the midwifery profession in New Zealand. It has a pivotal role in the development of midwifery practice, education and standards of practice, and is one of the major leaders of the profession. Any development of Internet resources would benefit the profession because a large number of midwives, approximately 2000, belong to NZCOM (Anderson, 2002). NZCOM is currently considering a proposal from MIDIRS about access to MIDIRS online resources (Campbell, 2002). In return for a one-off payment, MIDIRS will provide NZCOM members with access to all its online resources. This would allow midwives to access the MIDIRS database and professional portfolio. Currently the quarterly digest is only available by post but there are plans to make it accessible online (Fisher, 2002). The provision of these resources would be very important in view of the way midwives use the Internet, and the resources they want made available. 
It would not be too costly to administer a simple survey to midwives via the NZCOM newsletter. Another way to obtain information about members' access to the Internet would be to ask for their e-mail address when they renew their yearly membership fees. NZCOM are weighing up the advantages of access to the MIDIRS resources, which would be particularly attractive to midwives who practise in rural and remote areas, compared to the disadvantages which is mainly the financial cost. There are indications that the Internet is being employed by an increasing number of midwives, such as the midwives enrolled in post-graduate programs, who would have access to the Internet provided by an educational institution. It has been my personal observation as a member of the 2002 NZCOM Conference Committee, that nearly all the midwives registering to attend have an e-mail address. NZCOM are questioning whether it is financially viable to spend such a large amount of money when it is possible only a few midwives use the Internet. My recommendation to NZCOM will be to purchase the MIDIRS contract as an investment for the future to encourage more midwives to use the Internet, and maybe even attract midwives to become members of NZCOM.

\subsection{Time-saving strategies}

Time is the greatest barrier to the use of the Internet. It will take creative thinking by employers, institutions of education and professional bodies such as NZCOM, to either free up time for midwives to develop Internet-searching skills or look at alternative ideas for timesaving. Disseminating details of useful web sites, such as the column I write in the twice-yearly NZCOM Journal is a useful timesaving strategy. Links to further web

sites is another useful strategy (Stewart, 1998a; Stewart, 1998b; Stewart, 1999a; Stewart, 
1999b; Stewart 2000b; Stewart, 2001; Stewart 2002a). NZCOM could look at providing access to useful sites on its own web site. Thus, midwives will know that if they go to the NZCOM web site they'll be able to access information which saves them valuable time searching for the information. Not only will NZCOM be saving midwives time, it will also ensure that it is providing its members with quality information, thus increasing the quality of care provided by midwives to women.

Training has not been an issue for the midwives who responded to this survey. However, my experience as an educator has indicated there is a need for training in the use of the Internet. Thus, employers and institutions of education need to look at how they can provide training for those midwives who require it.

\subsection{Provision of evidence-based information}

\subsection{Recognition of the importance of evidence-based practice}

It was not the remit of the study to investigate what midwives thought about evidencebased practice, however it is interesting to note that few respondents made mention of evidence-based practice although they did talk a lot about keeping up to date. I believe that in a future study it would be important to pay more attention to evidence-based practice because of the growing role the Internet is playing in providing access to evidence-based information and guidelines. It may be that as part of a national study a subset of those surveyed could be interviewed on a one-to-one basis or in a focus group. One would then be able to investigate midwives' attitudes and understanding in greater depth than one can in a 'do you, don't you' survey approach. 


\subsection{Access to sources of evidence-based information}

In this day and age when there is a large emphasis on evidence-based practice, I believe it is vital that midwives are provided with easy access to sources of evidence such as the Cochrane database. Indeed, one respondent commented that she would like free access to the Cochrane database. NZCOM have already recognised the importance of this in its Quality Development and Maintenance Plan 2001-2003 (Guilliland, 2001b). The Plan incorporates the objective of developing 'efficient electronic search capability to support the promotion of best practice/evidence based practice, particularly for self-employed midwives without a practice base'. I would suggest that the funding for professional development provided by the Ministry of Health via the new contract with NZCOM (Guilliland, 2001b) could be exploited for this purpose.

Information about where to look for evidence-based information and guidelines on the Internet needs to be disseminated to midwives, especially those who are not familiar with the Internet. This is my aim in writing the regular Internet column in the NZCOM Journal. Training will also need to be provided for midwives in the use of databases, especially if they are linked to the NZCOM web site.

\subsection{Networking}

\subsection{Communication and collaboration}

One of the main uses of the Internet is for communication and collaboration, although not to the extent I had expected. Midwives in this study are requesting further networking opportunities. Respondents in this study have identified the need for an educators' forum; 
a network for rural/remote midwives; and connection between hospitals for the hospitalemployed midwives. The potential is for a number of small networks to develop. I feel it is important that these networks are national and coordinated from one source. NZCOM is in an ideal position to be able to do this. Specific networks via e-mail discussion groups, bulletin boards or even a synchronous chat facility can be made available from the NZCOM web site. However, I believe that it would be vital that someone was given the job of overseeing these facilities, so that they could be properly marketed and advertised, regularly monitored and evaluated. What needs to be avoided is the situation I encountered undertaking this research with the 'search for a midwife' facility in which the e-mail details had not been updated.

\subsection{Online mentoring}

One respondent mentioned that she wanted online mentoring to be made available as a resource. The requirements for a mentor are that she "listens, challenges, supports and guides another midwife's work" (NZCOM, 2000). There are those who would argue that this is definitely possible via e-mail and the Internet. Indeed, this was how the relationship worked between my research supervisor and myself whilst I was undertaking this study. Another point of view is that a mentor should be physically close by, especially to support the mentoree when she is caring for a woman in labour. Maybe the answer is for the mentoree to have several mentor relationships: one with a midwife who is able to support her with her physical presence, and another with an experienced midwife by e-mail and the Internet. Thus, the mentoree would be able to have a mentor 
relationship with an experienced midwife anywhere in the country. This is an issue that I suggest needs to be discussed in a national forum.

\subsection{E-mail discussion lists}

Although e-mail discussion lists are being utilised, in particular the New Zealand Midwives e-mail List, half the respondents in this research did not belong to a discussion list. Midwives are either unaware of e-mail discussion lists and their advantages, or have chosen not to join a discussion list. Further research is required to find out why midwives are joining or not joining discussion lists; what they perceive to be the advantages and disadvantages; how they use the discussion lists; and what are the themes in discussion.

\subsection{NZCOM Newsletter and Journal}

Further practical implications for NZCOM are to make local and national newsletters and journals available via the Internet and e-mail. This would reduce the costs incurred by printing paper copies. The Otago region has just released its first local newsletter by e-mail (Thomson, 2002). Another important implication is that electronic availability will increase NZCOM's international profile. Most likely it is difficult to access the NZCOM journal and newsletter overseas, so having it made available via the web site would allow the international midwifery community to keep in touch with midwifery developments in New Zealand. It would also give New Zealand midwives the opportunity to disseminate their work further a field. 


\subsection{Electronic claiming}

Electronic claiming is being developed which is encouraging, although it appears to be a slow process. It is important that the political will is behind electronic claiming because midwives have identified that they want it to happen.

\subsection{Online midwifery education}

Education providers are facing the challenge of how they can provide post-graduate education or professional education via the Internet. Rural midwives especially have indicated they want online education sessions and networking. This may include interactive clinical scenarios, which can be used as evidence of professional development in portfolios as part of the process of acquiring a competency-based practising certificate. Whilst the advantages of face-to-face contact will be lost, midwives can utilise all the facilities of the Internet including e-mail, bulletin boards and synchronous chat. The conversations I have had with rural midwives have indicated that there is a great need for educational institutions to take this approach to post-graduate education. I believe that even urban midwives will favour this approach. Even if the midwife is physically close to an educational institution, work commitments may preclude her from attending classroom sessions. The Internet allows flexible education that can be utilised at the midwife's convenience. 


\subsection{Critiquing information found on the Internet}

Nearly half the survey respondents felt they could not critique information very well, which suggests some lack of skill was being acknowledged. Further research is required to find out what training if any, midwives have received and what guidelines they follow. For those midwives who are unsure about their ability to critique Internet information, training and guidelines need to be provided. This is very important if midwives are incorporating information found on the Internet into their every day practice. This is a service that NZCOM or educational institutions should provide, as should employers as part of Internet training programs for employees.

\subsection{Consumers and the Internet}

\subsection{Midwives' feelings about consumers accessing information on the Internet} There were mixed feelings about the impact of consumers accessing information on the Internet. Further detailed questioning is required to find out exactly the concerns and doubts midwives have about the impact of Internet on their midwifery practice. Why do they have concerns and what are they? The same applies to those midwives who are positive about the impact on practice. Why do they feel so positive and what do they regard as the positive effects of women obtaining information from the Internet?

\subsection{Growth of e-health and midwives' response}

The survey did not tackle in any depth how midwives feel about the growth of e-health, other than asking their attitudes to consumers accessing information on the Internet. The 
next step is to find out what midwives understand by e-health and how they see their role if any, in providing e-health. Do midwives even recognise that e-health is a growing phenomenon? I believe the midwifery profession must make sure other health professions, and consumers for that matter do not leave it behind. Therefore, I believe the midwifery profession in New Zealand must openly debate what it is doing about e-health; how can the midwifery profession exploit e-health to its advantage, and that of women and their families.

\subsection{Online midwifery care}

As yet, few midwives are providing midwifery 'care' via the Internet. It would be interesting to repeat the survey in a few years to see if this proportion has increased. Meanwhile, more in-depth questions need to be asked about what exactly constitutes online midwifery care and how it is given. Probably the best way of acquiring these answers is by follow-up interviews of midwives who have been involved in giving online midwifery care. What about the more visible applications of the Internet such as online consultation, blood pressure monitoring and so on. How soon will it be before these innovations are a feature of every day life? How do midwives feel about these innovations and would they make use of them if and when they become available for use? These questions can be explored in future research.

\subsection{Online question/answer service}

NZCOM may need to consider whether it is desirable or practical to offer an information service for consumers, where women can ask online questions pertaining to pregnancy 
and childbirth. This particular service would have resource, legal and ethical implications but I believe it should be considered. It would be another way of ensuring that women are receiving information that they utilise in the process of making informed choices about their care. I must acknowledge that little work has been carried out regarding the legal and ethical issues of providing advice via the Internet, which must be taken into consideration when thinking about providing such as service.

\subsection{Advertising and marketing}

\subsection{NZCOM 'Search for a midwife'}

Another area for discussion is advertising and marketing by midwives on the Internet. Clearly the Internet plays a part in this process because midwives are gaining clients via this avenue. The NZCOM 'search for a midwife' is providing midwives with clients although as far as I am aware there has been no review of exactly how successful the site has been with regards to providing midwives with clients. A nation-wide survey would help to provide answers to this question. Another approach could be an audit of the midwives who are registered to the sites.

It is my belief that the 'search for a midwife' site has been 'sitting' on the Internet with little attention being paid to it, and I believe it is time that the site was reviewed. When the site was originally developed, midwives were told that they would have to pay yearly amounts to keep their details on the site. However, I for one have never heard about the site since. Midwives must be asked what information needs to be updated. I would recommend that a campaign promoting the site to midwives should to be carried out because there are a large number of midwives who do not have their details advertised on 
the site. Even if midwives had to pay yearly, it works out to be an easier way of advertising on the Internet than having ones own web page. It would also provide midwives with another way of being able to contact each other.

Having said that, it may well be midwives' opinion that they do not need to advertise on the Internet - conventional methods of advertising are perfectly adequate. Do midwives have the business sense to utilise the Internet for marketing and advertising? Do they see advertising and marketing in the broader sense as a requirement, in particular selfemployed practice? Perhaps they see the need but do not know how to go about it and require guidance and training? These questions provide the basis for further research in the future.

\subsection{Midwives who do not use the Internet}

I believe it is important to find out why midwives are not using the Internet. Using the information gathered from those midwives, and Rogers' (1995) theory of 'diffusion of innovations', one could then develop a strategy that would encourage midwives to adopt the Internet. Rogers writes that adoption of innovations is a social process and that midwives will adopt the Internet if they see their colleagues having positive experiences with the Internet. One strategy would be for NZCOM to raise the profile of their web site and increase the amount of Internet facilities available. That would have the effect of persuading midwives to adopt the Internet themselves, because they see that NZCOM has embraced the Internet and displays a positive attitude toward it. Rogers (1995) also maintains that midwives will adopt the Internet more rapidly if they perceive the Internet 
as easy to learn and are given the opportunity to experiment with using it. The strategy here could be for employers of midwives, and educational institutions to offer computer facilities to midwives so that they could learn how to use the Internet and experiment with its use. NZCOM is doing exactly that during its biennial conference being held in Dunedin, during July 2002. I am facilitating a half-day Internet workshop on behalf of NZCOM, which will allow midwives access to a computer laboratory in Otago Polytechnic where they can spend several hours exploring resources on the Internet.

\subsection{Conclusion}

This chapter has dealt with issues that have arisen from this pilot study and made recommendations for further research, in particular a national survey of midwives in New Zealand and their use of the Internet. The chapter has also made recommendations for the provision of Internet resources for midwives. The second part of this thesis will address issues that have arisen from the research process, especially issues around the use of the Internet as a research tool. In the next chapter I reflect on the learning I have obtained during this project. 


\section{Part Two}

\section{Chapter Seven}

\section{Reflections}

\subsection{Introduction}

The process of carrying out a pilot study of a web survey has been very interesting and worthwhile in terms of learning. I believe it is just as important to reflect on the process of the research, as it is the results, especially as this method of research is new to midwives. This chapter will describe some issues that midwives need to consider when planning to use the Internet as a tool for survey research, as well as some of the lessons I have learnt whilst carrying out this pilot study.

\subsection{Web design}

\subsection{Web designer/programmer}

The first problem I encountered was the setting up of the web site and process of data collection. My knowledge of computer programming was minimal and I relied heavily on the expertise of the web designer/programmer. I am left with the feeling that this is reasonable as long as the web designer is proficient and understands what the researcher is trying to achieve. However, it is important that the researcher has an understanding of the principles of Internet survey research because these principles do impact on how one 
designs the web survey. I knew what I wanted to achieve even though I did not know how to achieve it.

\subsection{Financial issues}

When employing a web designer it is vital to ensure he/she is expert in Internet programming and is familiar with the methods you are suggesting. My experience has reiterated that 'you get what you pay for'. It is more cost effective to employ a professional Internet programmer who knows what he/she is doing rather than waste money and valuable research time with someone who is not so expert. In particular, it is better to over estimate your costs when applying for a research grant than under estimate because the initial set up costs can be expensive. The professional web designer that I employed cost $\$ 45 \mathrm{NZ}$ per hour. At that rate it is imperative that he/she gives you a quote so you know exactly how much the job is going to cost rather than the job costing more and more money as time goes on. The other issue is intellectual property. It is important that you work out with the web designer whose intellectual property the web site is. In my experience, the web designer considered the web site to be his intellectual property until I fully paid his bill. He also registered the domain under his name instead of mine, which theoretically meant he could do what he wanted with the web site. Another piece of advice would be to ensure the researcher signs a contract with the web designer so there is evidence of exactly what has been planned and agreed to. 


\subsection{Web technology}

From a technological point of view, the survey worked very well. There were no problems with transferral of information from the web site and as far as I am aware, there were no problems with accessing the web site. What few comments I received were favourable. I was very pleased with its appearance and the ease with which respondents were able to operate the site. I think the key is to keep the site as simple with minimal graphics and 'whiz bang' technology.

\subsection{Data transfer}

As for data transfer, the process set up worked well. However, if this were repeated on a larger scale I would ensure that the site was programmed using CGI script so that data would be electronically transferred into a database rather than being entered by human hand. This would be less time consuming and more accurate.

\subsection{Technological problems}

The only problem appeared to be that midwives could not work out what the password was - seven midwives e-mailed me because they did not know the password. I am unsure why that was a problem because the e-mail information clearly contained the password. My thoughts are that the e-mail letter was not forwarded in its entirety, or that midwives did not realise the password was in the e-mail. One could argue that a password was unnecessary on this occasion. Nevertheless, I do believe that some sort of safeguarding is 
necessary for bigger surveys, especially if the web is available in the wider public domain.

\subsection{Recruitment}

\subsection{Response rate}

The survey response rate was disappointing. This does not necessarily mean that the Internet is not a useful research tool, but rather that this method is not the best way of establishing how many midwives use the Internet. I took a purist approach to recruitment and made no effort to recruit subjects other than by the official e-mail letter. I did not even make verbal reminders to colleagues who I knew had not completed the questionnaire. Quite possibly I would have recruited more subjects if I had advertised more widely. I could have advertised in midwifery and nursing periodicals such as the NZCOM Journal, as well as with conventional advertisements posted to hospitals, group midwifery practices and individual midwives.

I was overly optimistic about the effectiveness of the electronic network for recruiting respondents to the study. I suspect there are small electronic networks throughout the country, the New Zealand Midwives' List being one of them. As yet, this form of recruitment is not effective by itself. As more midwives become connected to e-mail, the networks will become larger and maybe this form of recruitment will turn out to be more effective in a few years' time. In the meantime, some sort of centralisation of e-mail addresses such as an e-mail directory or database would be useful. Midwives would know they could find particular e-mail addresses at a certain point, although issues of confidentiality may need to be considered. 
I had always had my doubts about asking midwives to inform me when they had passed on the e-mail information letter. I have always been conscious that I was asking a lot for midwives to pass the information e-mail, let alone ask them to e-mail me a conformation letter as well. I would still employ this chain letter/snowball approach to recruitment of participants, but in conjunction with conventional methods.

The method of recruiting respondents prevented me from being able to send out reminders, despite knowing that reminders increases response rate. Several colleagues whom I sent the survey to commented that they had not 'got around to completing the survey' and I feel that people like that would have benefited from reminders. I am not sure how I would manage that issue with a larger web survey. However, with a paper survey, it is possible to code the questionnaires so that reminders can be sent to those who had not completed them. It may be equally effective to carry out a telephone survey of those who did not return their questionnaires to find out the reasons for their nonresponse.

\subsection{Web survey}

The web survey has been effective because of the lessons I have learnt. I remain committed to the idea of web survey because it makes data handling so much easier than with paper questionnaires. Nevertheless, I have accepted that it may not be the appropriate method of survey at this current time when there are still midwives who have little access to the Internet, and the electronic network of midwives is fragmented. I 
would concur with Dillman (2000) who maintains that a mixed method approach consisting of web and paper survey as well as interviews is by far the most effective means of gathering data. Web and paper survey can produce relatively superficial data so that an interview either face to face or by telephone, would aim to further develop the issues raised in a survey.

\subsection{Questionnaire development}

Utilising John Loy's questionnaire as a framework for developing my own survey was helpful because it gave me ideas about areas and issues to approach. However, at times I fell into the trap of letting the questionnaire set boundaries, and restrict me in my thinking. I had the research tool all ready to run, but I could not see the whys and wherefores of the research. I felt at times as if I was 'putting the cart before the horse'. It has been a very beneficial exercise to critique Loy's questionnaire. I have learnt how to format a questionnaire and how not to ask questions. I believe that on the whole the modifications I made to the survey worked well and I acquired the data that I was seeking.

I often became sidetracked into Internet issues such as cyberfeminsim and had to keep reminding myself that this pilot study was midwifery research, and had to be of relevance to the midwifery profession. However, this is where the pilot study has been valuable for me because it has provided me the opportunity to explore the wider issues so that now I am very clear about where I want to go in the future with further research. 
Another way I could have approached the development of the questionnaire might have been to have interviewed a cross section of midwives, or carried out a focus group. I could then have developed a questionnaire from the issues that arose from these sessions. This may have led to a questionnaire asking different questions from those that I did ask. But then again, that is the function of a pilot study - to show up weaknesses of a survey and allow an opportunity to improve the data gathering tool, in this case a questionnaire.

\subsection{Conclusion}

The Internet is a valuable tool for survey research. However, there are issues that the midwife has to consider before utilising this particular method such as design of the web site, recruitment of participants and development of questionnaire and research question. In the next chapter I will discuss the recommendations I make with regards to a national study of midwives' utilisation of Internet resources in New Zealand. I will also describe the changes I would make to a future questionnaire. 


\section{Chapter Eight}

\section{Recommendations for future research}

\subsection{Introduction}

This pilot study has enabled me to test a questionnaire designed to find out how midwives use Internet resources in New Zealand. In this chapter I will make recommendations for further research, which include changes to the original questionnaire. The original questionnaire is attached in Appendix Four.

\subsection{Method of research}

Mixed methods including paper and web survey plus interview should capture all the elements and issues that one is seeking. Interview could incorporate Internet facilities such as e-mail, bulletin board, synchronous chat or even video conferencing. I believe that interview would be a better method to use to capture data on the more complex issues of how midwives feel about advertising and marketing; the effect of consumers' use of the Internet and the effect on their midwifery practice; what 'care' midwives give over the Internet, as well as legal and professional implications of this. An illustration of the inadequacy of questionnaire is that seven respondents indicated there were other barriers to their use of the Internet at home despite having access at home. It would have been interesting to know what other barriers exist to use of the Internet at home. I have no way of knowing because I did not ask the respondents to specify the reason, which may have become evident in an interview. The same applies to the question I asked about 
forms of midwifery care given via the Internet. Three respondents replied that they gave other forms of care via the Internet. I have no way of knowing what form that 'care' takes which quite intrigues me because I cannot think what it could be. In another survey, I would make sure I asked the respondents to describe other forms of 'care' given.

\subsection{Categorisations}

\subsection{Categorisation of midwifery roles}

The more complex questions relating to midwives' roles and their use of the Internet, such as the difference in the use of the Internet by hospital midwives compared to that of the self-employed midwife, remain unanswered. The major recommendation I would make for a national survey would be to ensure that midwives are only allowed to choose one main category of employment. As a result one would then be able to explore use of the Internet according to midwives' definition of role. One would then be able to analyse use of the Internet according to midwifery role. Consequently one would be able to say that self-employed midwives 'do this' with the Internet compared to hospital midwives who 'do that' with the Internet.

As for the multi-tasking that midwives carry out, further audit and research is required to find out if this is a trend throughout New Zealand or just for the midwives in this pilot study. As a midwifery lecturer, I am very interested to see that colleagues also carry out clinical practice in a variety of areas. I believe additional exploration into how midwifery lecturers practice in New Zealand would be most valuable. To further extend this would 
be to contrast how midwifery lecturers in New Zealand practice compared to lecturers in other countries such as Australia, UK and USA.

\subsection{Categorisation of location of employment}

The other major change I would make to a national survey is to make certain the question about rural and urban practice is a separate question from that of midwifery role. I would also make sure midwives are only able to answer to one option. I would also consider adding categories such as 'provincial' and 'remote'. One of themes of this research is how rural midwives use the Internet, and this pilot study was unable to adequately answer this question because midwives were allowed to categorise themselves as both rural and urban midwives.

\subsection{Categorisation of information found on the Internet and how that information was used}

A further strategy I would employ in the future is to give midwives categories into which the information they find on the Internet could be placed, as well as how it is used. This would make analysis of this information easier. As it was, I was able to place the results into four categories - clinical practice, professional practice, information to women, teaching and learning. In order to develop the categories before the survey was carried out, I would aim to ask midwives in some form of pre-test such as a focus group. The categories I have developed may be adequate, or they may need adjusting slightly. 


\subsection{Definition of place of work}

It is vital that one clearly defines terminology when one is developing a questionnaire. When I was developing questions about 'place of work', I did not consider the issue of place of work for self-employed midwives. This was one of the problems with using Loy's questionnaire as a framework, and illustrates how important it is to check someone else's instrument for applicability in the New Zealand setting. Midwives in the UK are mostly hospital-employed so their place of work is chiefly the hospital. I did not differentiate in the questionnaire between midwives working in a hospital, at home or at 'rooms'. I also did not consider the issues of 'employed' LMCs. I automatically thought of employed LMCs as being employed by a hospital. Nevertheless, other employers such as community groups also employ LMCs. So the midwife's place of work may be a community health centre. In a future questionnaire, I would ensure that respondents specify what they define as their 'place of work' and exactly what is their status of employment.

\subsection{Institution of study}

Another area of confusion that even affected me at times was the section about study. I feel that it was easy for respondents to become confused between 'place of study' and 'for study'. The confusion had the potential to be further increased for lecturers whose place of work was an institution of study. In a future questionnaire, I consider it important for questions to be more specific so one could make conclusions about use of the Internet for study as well as at the institution of study. 


\subsection{Teaching via the Internet}

Few midwifery lecturers appear to be utilising the Internet in their teaching role. However, the wording of the question was difficult because the three elements I asked about are different activities - lectures, tutorials and counselling. For example, how would one define 'counselling'? This is a very different activity to providing a lecture. Further research will be required in order to explore this in more depth and gain a more accurate picture of how lecturers are using the Internet nationally.

\subsection{Conclusion}

There is no doubt that the Internet is an innovation whose influence is growing steadily in our every day lives, especially those of us who live in the 'developed world'. In particular, there has been an acceleration of e-health that includes provision and sharing of information. Health professionals and consumers alike are taking advantage of this capability of the Internet. The growth of health consumers utilising the Internet for obtaining information and support from fellow health consumers has been exceptional. Health professionals are becoming aware of this phenomenon and are beginning to explore how they can make use of it. There are other aspects of e-health being developed, for instance online patient notes, interactive consultations and physical monitoring of health including blood pressure checks.

The Internet has a role to play in the provision of evidence-based practice, which is currently driving health care. Health professionals and consumers are able to access 
resources on the Internet, including databases that provide evidence-based information and evidence-based clinical guidelines.

This is the background to my interest in how midwives in New Zealand use the Internet. Midwives are beginning to recognise the potential of the Internet for communication and collaboration, support and sharing information with colleagues and clients, as well development of every day practice such as marketing and advertising. I believe it is essential that midwives fully explore how they can exploit the facilities of the Internet so that the midwifery profession is not left behind by other health professions such as medicine, who are already proactively developing its resources.

In order to establish the degree of use of the Internet by midwives in New Zealand, a pilot study was carried out to survey midwives. This pilot study tested a questionnaire and also the use of the Internet as a tool for research. The questionnaire was based on one developed in the UK and was modified for use in the New Zealand context. The survey was posted on a web site on the Internet. Midwives were invited by e-mail to complete the questionnaire in a snowball method of recruitment. The data gathered was nominal and descriptive statistics were used to analyse the data.

The survey only attracted 54 respondents, nevertheless that is likely to be because of the e-mail snowballing method of recruiting midwives to the survey. This does not necessarily mean the Internet is inappropriate as a tool for research, but in this case it would have been more effective to gather information using traditional methods of 
recruitment and survey. The Internet will become increasingly effective as a tool for research as more people become familiar with it. In the meantime, it is recommended that the Internet is part of a mixed methods approach, for example used in conjunction with face-to-face interview.

This pilot study has shown that there is a population of midwives in New Zealand who regularly use the Internet for searching information, which they utilise in their professional practice, and pass onto colleagues and midwifery clients. Midwives in this study are utilising Internet resources such as e-mail discussion lists, personal web sites and online newsletters. They are also enthusiastic for as many resources as possible to be made available on the Internet such as electronic claiming, midwifery education programs and online mentoring. However, because of the nature of convenience sampling and the study being so small, it has been impossible to make any generalisations about the general midwifery population.

A national survey is required to provide a more detailed picture of midwives' use of the Internet in New Zealand. A national survey will show if the results of this study are biased, in particular because the respondents had a high level of education. It is also necessary to gather data from midwives who do not use the Internet, which is an area this study did not address. It is important to ascertain the national usage of the Internet amongst midwives because the information will help the leaders of the profession such as the NZCOM, employers of midwives, and providers of midwifery education programs to decide what Internet resources are appropriate and cost-effective to provide midwives. 
The main barrier to the use of the Internet is lack of time. The challenge for leaders of the profession is to look at ways of either freeing up time for midwives to build up their Internet skills or of developing timesaving strategies. Training also needs to be provided for midwives who need to become familiar with the Internet, although this was not an issue for midwives in this study. A national study would determine the scale of training required for midwives.

The midwives in this study have identified a number of resources that they feel would benefit their practice, especially those midwives who live in rural and remote areas. NZCOM and other organisations such as education providers would do well to take heed, especially when it comes to providing resources that disseminate evidence-based information that midwives can pass onto their clients and integrate into their practice. Midwives are aware that consumers are utilising information on the Internet, and are keen to access the same information to disseminate to their clients. Training may need to be provided so that midwives are very confident about their ability to critique information found on the Internet.

Midwives are becoming aware of the potential of the Internet in their midwifery practice. However, there are opportunities that midwives can continue to explore. One potential that midwives could exploit to a much greater extent is advertising and marketing of their services. As e-health grows in popularity, midwives need to keep up with the latest 
advances in Internet technology so as not to be left behind by other health professionals and consumers.

In many ways this study has produced more questions than answers. However, I am convinced that the Internet will continue to expand and progress, and midwives will find it plays an invaluable role in their every day practice. I am also certain that increasingly midwives will recognise the potential of the Internet as a tool and source of research. If I have generated information that has either gone some small way to assist midwives in their use of the Internet, or make use of the Internet as a tool for research, then I will be happy that this study has been a success. For my part, I believe this study is just the beginning of my research journey that will continue to investigate how midwives can exploit the Internet to both their advantage and that of the women they care for. 


\section{References}

Agnew, T. (1995). Nurses' net assets. Nursing Times, 91 (40), 20-21.

Anderson, Judy (NZCOM@clear.net.nz). (2002, April 23). Membership. E-mail to Sarah Stewart (sarahs@tekotago.ac.nz).

Anthony, D. (1996). Midwives on the Internet. British Journal of Midwifery, 4 (12), 645-648.

Bachman, J. \& Panzarine, S. (1998). Enabling student nurses to use the information superhighway. Journal of Nursing Education, 37 (4), 155-161.

Baron, J., \& Siepmann, M. (1999). Techniques in creating and using web questionnaires in research and teaching [online]. Available: http://www.psych.upenn.edu/ baron/examples/baron4.htm [9/7/01]

Barrie, J., \& Presti, D. (2000). Digital plagiarism - the web giveth and the web shall taketh. Journal of Medical Internet Research, 2 (1), 7 pages [online]. Available: http://www.jmir.org/2000/1/e6/index.htm [5/9/01]

Batagelj, Z., Lozar, K., \& Vehovar, V. (1998). Who are non-respondents in web surveys? [online]. Available: http://www.websm.org/lit_response.html [8/7/01]

Beanland, C., \& Schneider, Z. (1999). Nursing research: methods, critical appraisal and utilisation. Artarmon: Mosby.

Berge, Z. (2000). Electronic discussion groups [online]. Available: http://www.emoderators.com/papers/bcommed.html [29/8/01]

Bowers, D. (1998). The new research tool. Marketing research, 10 (3), 34-35.

Bowles, N. (1996). Using the Internet to support midwifery practice. British Journal of Midwifery, 4 (12), 649-652.

Brampton, M. (2000). Hospital partnership for midwifery education. University of Southern Queensland News, 31 May, 8 pages, [online]. Available: http://www.usq.edu.au/marketng/usqnews/archive/2000/31may.pdf [15/1/02]

Brennan, M., Rae, N., \& Parackal, M. (1999). Survey-based experimental research via the web: some observations. Marketing Bulletin, 10, 8 pages, [online]. Available: http://marketing-bulletin.massey.ac.nz/article10/article9b.asp [8/7/01]

Brown, S.J. (1999). Knowledge and health care practice. Philadelphia: W.B. Saunders Company. 
Burns, N., \& Grove, S. (1993). The practice of nursing research. Philadelphia: W.B. Saunders Company.

Burns, R. (2001, February 4). Legal trouble with the IRB. Association of Internet Researchers List [online]. Available: E-mail: air-1@info.comm.uic.edu [2001, February 4]

Bush, N., Wooldridge, J., Foster, V., Shaw, K., \& Brown, P. (1999). Web site design and development issues: the Washington state breast and cervical health program web site demonstration project. Oncology Nursing Forum, 26 (5), 857-865.

Calvert, I. (1998). Birth in focus. Palmerston North: Dunmore Press.

Campbell, Norma (midwiferyadvisor@clear.net.nz). (2002, March 12). Joint venture. E-mail to Sarah Stewart (sarahs@tekotago.ac.nz).

Chandler, D. (2000). Personal home pages and the construction of identities on the web [online]. Available:http://www.aber.ac.uk/media/Documents/short/webident.html $[5 / 9 / 01]$

Clegg, F. (1992). Simple statistics. A course book for the social sciences. Cambridge: Cambridge University Press.

Cluett, E. (2000). An introduction to statistics in midwifery research. In E, Cluett \& R, Bluff (Eds.), Principles and practice of research in midwifery (pp 79-112). London: Bailliere Tindall.

Collins, M. (1992). Flaming: The relationship between social context cues and uninhibited verbal behaviour in computer-mediated communications [online]. Available: http://www.emoderators.com/papers/flames.html [6/7/01]

Comley, P. (no date). The use of the Internet as a data collection method [online]. Available: http://www.sga.co.uk/esomar.html [29/5/00]

Coomber, R. (1997). Using the Internet for survey research. Sociological Research Online [online], 2 (2), 13 pages. Available: http://www.socresonline.org.uk/2/2/2.html $[2 / 7 / 01]$

Costigan, J. (1999). Forests, trees and Internet research. In S. Jones (Ed.), Doing Internet Research (pp xvii-xxiv). Thousand Oaks: Sage.

Daly, J. (1999). Measuring impacts of the Internet in the Developing World. Information Impacts Magazine [online], May 21, 9 pages. Available: http://www.cisp.org/imp/may_99/daly/05 99daly.htm [6/7/01] 
Desborough, K. (1999). Nursing on the Net. The Canadian Nurse, March, 30-32.

Dickson, R. (2000). Systematic reviews. In S. Hamer \& G. Collinson (Eds.), Achieving evidence-based practice: a handbook for practitioners ( $\mathrm{pp}, 41-60)$. London: Bailliere Tindall.

Dillman, D., Tortora, R., \& Bowker, D. (1998). Principles for constructing web surveys [online]. Available: http://www.websm.org/topics.html [8/7/01]

Dillman, D. (2000). Mail and Internet surveys: the tailored design method. New York: John Wiley \& Sons.

Doctor Global. (2001). Doctor Global for individuals [online]. Available: http://www.doctorglobal.com/brochure/fs-indiv.asp?browser=IE [11/7/01]

Drake, E. (1999). Internet technology: resources for perinatal nurses. Journal of Obstetric, Gynaecologic and Neonatal Nursing, 28 (1), 11-14.

Eberhart-Phillips, J., Hall, K., Herbison, G., Jenkins, S., Lambert, J., Ng, R., Nicholson, M., \& Rankin, L. (2000). Internet use amonst New Zealand general practitioners. New Zealand Medical Journal, 28 April, 135-137.

Eastin, M. (2001). Credibility assessments of online health information: the effects of sources expertise and knowledge of content. Journal of Computer-Mediated Communication [online], July, 6 (4), 14 pages. Available: http://www.ascusc.org/jcmc/vol16/issues4/eastin.html [14/8/01]

Ehrenberger, H., \& Murray, P. (1998). Issues in the use of communications technologies in nursing research. Oncology Nursing Forum, 25 (10), supplement, 11-15.

Ellrodt, G., \& Keckley, P. (2001). Where medicine and technology meet. Health Management Technology, August, 44-46.

eMarketer. (2001). The net in India: a luxury few can afford [online]. Available: http://www.nua.ie/surveys/index.cgi?f=VS\&art id=905356319\&rel=true [6/7/01]

Eysenbach, G., Ryoung Sa, E., \& Diepgen, T. (1999). Shopping around the Internet today and tomorrow: towards the millennium of cybermedicine. British Medical Journal, 319 , 1294.

Eysenbach, G., \& Kohler, C. (2002). How do consumers search for and appraise health information on the world wide web? Qualitative study using focus groups, usability tests, ansd in-depth interviews. British Medical Journal, 324, 573-577.

Fahy, K. (2000). Midwives you've got m@,il! Australian College of Midwives Incorporated Journal, June, 20-21. 
Fahy, K., Evans, P., \& McDonald, J. (1999). Flexible, situated learning for midwifery: the best of both worlds. Biennial Aus tralian College of Midwives Inc National Conference. Tasmania. September 1999.

Farmer, T. (no date). Using the Internet for primary research data collection [online]. Available: http://www.researchinfo.com/library/infotek/index.shtml [25/9/00]

Farmer, J., Richardson, A., \& Lawton, S. (1999). Improving access to information for nursing staff in remote areas: the potential of the Internet and other networked information resources. International Journal of Information Management, 19, 49-62.

Fielden, N., \& Garrido, M. (1998). Internet research: theory and practice. Jefferson: McFarland and Company.

Fisher, Andy (afisher@midirs.org). (2002, March 21). Trial access to database. E-mail to Sarah Stewart (sarahs@tekotago.ac.nz).

Fleck, E., \& Levy, S. (1999). Internet support for nurses and midwives. Professional Nurse, 14 (4), 280-282.

Gagliardi, A., \& Jahad, A. (2002). Examination of instruments used to rate quality of health information on the Internet: chronicle of a voyage with an unclear destination.

British Medical Journal, 324, 569-573.

George, N., \& Hughes, D. (no date). Cyber-studies: using the Internet to do research [online]. Available: http://medsocbsa.swan.ac.uk/MSN/msn001F/msn001IT.htm [7/7/01]

Glanville, J., Haines, M., \& Auston, I. (1998). Finding information on clinical effectiveness. British Medical Journal, 317, 200-203.

Gomez, E., DuBois, K., \& King, C. (1998). Improving oncology nursing practice through understanding and exploring the Internet. Oncology Nursing Forum, 25 (10), supplement, 4-10.

Guilliland, K. (2001a). NZCOM CEO forum. New Zealand College of Midwives' Midwifery News, 23, 5-7.

Guilliland, K. (2001b). Midwifery autonomy in New Zealand: how has it influenced the birth outcomes of New Zealand women? New Zealand College of Midwives' Journal, $23,6-11$.

Gulliland, K., \& Pairman, S. (1995). The midwifery partnership. A model for practice. Wellington: Department of Nursing and Midwifery, Victoria University of Wellington.

Hamilton, J. (1999). The ethics of conducting social-science research on the Internet. The Chronicle of Higher Education, 46 (15), B6-B7. 
Hardey, M. (1996). Research, innovation and practice: the role of the World Wide Web. Nursing Standard Online [online], 11 (11), 6 pages. Available: http://www.nursingstandard.co.uk/vol11-11/ol-art.htm [9/9/99]

Harding, D. (2000). Making choices in childbirth. In, The New Midwifery: science and sensitivity in practice (pp 71-85). Edinburgh: Churchill Livingstone.

Hawthorne, S., \& Klein, R. (Eds.). (2000). CyberFeminism. North Melbourne: Spinifex.

Health Benefits Limited (no date). Online maternity claiming. Available:

http://www.hbl.co.nz/hbweb.nsf/fbf92f6846c3c1d6cc256a7b003776a7/6b64a121928823f 2cc256a7b0037aee8?OpenDocument [11/7/01]

Healthvision. (no date). Healthvision - a patient's perspective [online]. Available: http://www.healthvision.com [7/7/01]

Hine, C. (2000). Virtual ethnography. London: Sage.

Houstan, S. (1996). Designing a questionnaire for a midwifery research project. British Journal of Midwifery, 4 (12), 629-632.

Huntley, A. (1999). Midwives in cyberspace. Midwifery Today, Spring, 20-21.

Infotech. (1998). New Zealand netizen mirrors global netizen [online]. Available: http:/www.nua.ie/surveys/?f=VS\&art id=897410429\&rel=true

Internet Magazine NZ. (2001). Internet service providers' directory. Internet Magazine NZ, 5, June, 98-103.

Jadad, A. (1999). Promoting partnerships: challenges for the Internet age. British Medical Journal, 319, 761-764.

Jean Camp, L. (1996). We are geeks, and we are not guys: the systers mailing list. In L, Cherney \& E, Reba Weise (Eds.), Wired women: gender and new realities in cyberspace (pp114-125). Washington, Seal Press.

Johns, M. (2001, February 4). Legal trouble with the IRB. Association of Internet Researchers List [online]. Available: E-mail: air-1@,info.comm.uic.edu [2001, February 4]

Jones, S. (Ed.). (1999). Doing Internet research: critical issues and methods for examining the Net. Thousand Oaks: Sage.

Jordan, B. (1997). Authoritative knowledge and its construction. In R. Davis-Floyd \& C. Sargent (Eds.), Childbirth and authoritative knowledge (pp 54-79). London: Sage. 
Jordan, T. (1999). Cyberpower: the culture and politics of cyberspace and the Internet. London: Routledge.

Kassirer, J. (2000). Patients, physicians and the Internet. Health Affairs, 19 (6), 115-123.

Kent, J. (2000). Social perspectives on pregnancy and childbirth for midwives, nurses and the caring professions. Buckingham: Open University Press.

Kerse, N., Arroll, B., Lloyd, T., Young, J., \& Ward, J. (2001). Evidence databases, the Internet and general practitioners: the New Zealand story. New Zealand Medical Journal, 9 March, 114(1127), 89-91.

Kinniburgh, J. (2001). Using the Internet to support evidence-based practice. Journal of Community Nursing, 15 (8), 4, 6, 8.

Kirk, E. (2001). Evaluating information found on the Internet [online]. Available: http://milton.mse.jhu.edu:8001/research/education/net.html [29/8/01]

Kleist, J. (1996). Midwives go online. Nursing Standard Online [online], 11 (1), 3 pages. Available: http://www.nursing-standard.co.uk/voll1-5/ol-art.htm [9/9/99]

Korenman, J. (1999). Email forums and women's studies. In S, Hawthorne\& R, Klein (Eds.), Cyberfeminism (pp 80-97). North Melbourne, Spinifex.

Knuth, G. (1998). Web site developer and nurse: an essential business partnership. American Association of Occupational Health Nurses Journal, 46 (1), 47-50.

Larkin, M. (2001). E-health continues to make headway. The Lancet, 358 (9280), 517.

Lakeman, R. (1997). Using the Internet for data collection in nursing research.

Computers in Nursing, 15 (5), 269-275.

Loy, John (John.Loy@btinternet.com). (2000, November 15). Midwives and Internet research. E-mail to Sarah Stewart (sarahs@tekotago.ac.nz).

Loy, J. (2001a). Midwives and their use of the Internet. Midwifery Information and Resource Services Digest, 11 (1), 25-27.

Loy, J. (2001b). What's new on the Net? Midwifery Information and Resource Services Digest, 11 (1), 32.

Mann, C., \& Stewart, F. (2000). Internet communication and qualitative research. London: Sage. 
Mead, Marianne (Mmead75337@cs.com). (2001, February 27). Internet research.

E-mail to Sarah Stewart (sarahs@tekotago.ac.nz).

Medlin, C., Roy, S., \& Ham Chai, T. (1999). World Wide Web versus mail surveys: a comparison and report [online]. Available http://www.melbpc.org.au/pcupdate/2009/2009article6.htm [17/12/01]

Merkes, M. (2000a). Electronic health records - your health online. PC Update [online], September, 3 pages. Available:

http://www.anzmac99.unsw.edu.au/anzmacfiles/M/Medlin.pdf [5/4/01]

Merkes, M. (2000b). Health information on the Internet. PC Update [online], October, 3 pages. Available: http://www.melbpc.org.au/pcupdate/2010/2010article7.htm [5/4/01]

Miller, S., King, T., Lurie, P., \& Choitz, P. (1997). Certified nurse-midwife and physician collaborative practice. Journal of Nurse-Midwifery, 42 (4), 308-315.

Montecino, V. (2001). Criteria to evaluate the credibility of World Wide Web resources [online]. Available: http://mason.gmu.edu/ montecin/web-eval-sites.htm $[29 / 8 / 01]$

Muir Gray, J.A. (1999). Evidence-based healthcare. How to make health policy and managements. London: Churchill Livingstone.

Munro, B. (2002). Cvber café nets praise. The Star, Thursday 7 March, 1.

Murray, P. (1996). Research and the Internet: some practical and ethical issues. Nursing Standard Online [online], 10 (28), 4 pages. Available: http://www.nursingstandard.co.uk/week28/ol-art.htm [9/9/99]

Murray, P. (1997). Nursing the Internet: a case study of nurses' use of computermediated communications [online]. Available:

http://www.lemmusu.demon.co.uk/dissch1.html [29/8/01]

Musker, M. (1997). Demystifying the Internet: a guide for nurses. Nursing Standard, 3 (12), 44-47.

Neilson NetRatings. (2000). More women than men online in US [online]. Available: http://www.nua.ie/surveys/?f=VS\&art id=905355902\&rel=true $[2 / 7 / 01]$

Neilson NetRatings. (2001). Internet usage statistics for the month of May 2001 [online]. Available: http://209.249.142.57/nz/web/Nrpublicreports.useagemonthly $[2 / 7 / 01]$

New Zealand College of Midwives. (1993). Midwives handbook for practice. Christchurch: New Zealand College of Midwives. 
New Zealand College of Midwives. (2000). NZCOM Consensus Statement:

Mentoring [online]. Available:

http://www.midwife.org.nz/index.cfm/Policies/Consensus [14/3/02]

New Zealand Health Information Service. (2001). New Zealand workforce statistics 1999: nurses and midwives [online]. Available: http://www.nzhis.govt.nz/stats/nursestatsp.html [6/7/01]

Oldershaw, H. (2000, October 15). Evidence practice and the Internet. Wisdom-Nurse online]. Available: e-mail: wisdom-nurse@mailbase.ac.uk [23/8/01]

Oppenhein, A.N. (1992). Questionnaire design, interviewing and attitude measurement. London: Pinter Publishers.

Orsen, J. (2000). Using the Internet to enhance evidence-based practice. British Journal of Perioperative Nursing, 10 (8), 421-427.

Page, L. (2000). Using evidence to inform practice. In L. Page (Ed.), The New Midwifery: science and sensitivity in practice (pp 45-70). Edinburgh: Churchill Livingstone.

Pairman, S. (2000). Education framework November 1999. New Zealand College of Midwives' Journal, 22, 5-14.

Pairman, S., \& Guililland, K. (2001). Midwifery Standards Review: a strategy for credentialing. New Zealand College of Midwives Journal, 25, 23-28.

Pattanaik, B. (1999). Home and the World: The Internet as a personal and political tool. In S. Hawthorne \& R. Klein (Eds.), Cyberfeminism (pp.19-32). North Melbourne, Spinifex.

Patterson, J. (2000). Rural midwifery: challenges of the last decade, and where to from here? Midwifery News, 20,1-6.

Pemberton, P., \& Goldblatt, J. (1998). The Internet and the changing roles of doctors, patients and families. Medical Journal of Australia, 169, 594-595.

Penn, S. (1997). The women's guide to the wired world. New York: The Feminist Press, City University of New York.

Peters, S. (1998). What does electronic publishing mean to an academic? An examination of the processes and skills involved with electronic journal publishing [online]. Available: http://www.sosig.ac.uk/iriss/papers/paper26.htm [5/9/01] 
Pew Internet and American Life Project. (2000). The online healthcare revolution: how the web helps Americans take better care of themselves [online].

http://www.pewinternet.org/reports/reports.asp?Report=26\&Section=ReportLevel1\&Fiel $\underline{\mathrm{d}=\text { Level1ID\&ID }=88}[23 / 12 / 01]$

Pohatu, Jo (Joanna@nursingcouncil.org.nz). (2002, March 19). Midwifery qual info.

E-mail to Sarah Stewart (sarahs@tekotago.ac.nz).

Pretlow, R. (2000). eHealth International: a cutting health edge company for a new age in health care. Available: http://www.ehealthnurse.com/ehealthi.html [11/7/01]

Renfrew, M. (1997a). The development of evidence-based practice. British Journal of Midwifery, 5 (2), 100-104.

Renfrew, M. (1997b). Influencing the development of evidence-based practice. British Journal of Midwifery, 5 (3), 131-134.

Rogers, E.M. (1995). Diffusion of Innovations. New York: The Free Press.

Rojo, A. (1995). Participation in scholarly electronic forums [online]. Available: http://www.digitaltempo.com/e-forums/thindex.html [29/8/01]

Sackett, D., Rosenberg, W.M.C., Gray, J.A. M., Haynes, R.B., \& Richardson, W.S. (1996). Evidence-based medicine: what it is and what it isn't. British Medical Journal, $312,71-72$.

Sanborn, G. (2000). Online health information seekers growing twice as fast as online population [online]. Available: http://www.cyberdialogue.com/news/releases/2000/0523-cch-future.html [11/7/01]

Sandall, J. (1998). Bridging the gap between evidence and practice. British Journal of Midwifery, 6 (10), 624-625.

Sandall, J. (1999). Finding the evidence: using the Internet. British Journal of Midwifery, 7 (7), 440-446.

Schaefer, D., \& Dillman, D. (1998). Development of a standard e-mail methodology: results of an experiment [online]. Available:

http://survey.sesrc.wsu.edu/dillman/papers/E-Mailppr.pdf [10/7/01]

Schneider, Patricia (p.schneider@maculey.acu.edu.au). (2000, May 30). Internet research. E-mail to Sarah Stewart (sarahs@tekotago.ac.nz). 
Schuessler, H. (2001, February 22). Social class finds how far e-mail travels. New York Times [online], 3 pages. Available:

http://www.nytimes.com/auth/login?URI=http://www.nytimes.com/2001/02/22/technolo gy/22CARO.html\&OQ=exQ7E3862450Q26eiQ3Denu500http [9/7/01]

Scott, K. (1998). Girls need modems! Cyberculture and women's ezines [online]. Available: http://krista.tico.com/mrp.html [7/7/01]

Selwyn, N., \& Robson, K. (1998). Using e-mail as a research tool. Social Research Update 21 [online], 6 pages. Available: http:/www.soc.surrey.ac.uk/sru/SRU21.html $[8 / 7 / 01]$

Sheehan, Kim (ksheehan@ballmer.uoregan.edu). (2001, February 28). Your post to AOIR. E-mail to Sarah Stewart (sarahs@tekotago.ac.nz).

Shellenbarger, T., \& Thomas, S. (1996). Creating a nursing home page on the world Wide Web. Computers in Nursing, 14 (4), 239-245.

Sinclair, M. (1997). Midwives, midwifery and the Internet. Modern Midwife, 7 (9), 11 14.

Sinclair, M. (2001). Information technology skills of midwives in Northern Ireland. Modern Midwife, 4 (1), 23-28.

Slevin, J. (2000). The Internet and society. Cambridge: Polity Press.

Smith, C. (1997). Casting the Net: surveying an Internet population. Journal of Computer Mediated Communication [online], 3 (1), 14 pages. Available: http://www.ascusc.org/jemc/vol3/issue1/smith.html [9/7/01]

Smith, R. (2001). Almost no evidence exists that the Internet harms health. British Medical Journal, 323, 651.

Sparks, S. (1999). Electronic publishing and nursing research. Nursing Research, 48 (1), $50-54$.

Spender, D. (1995). Nattering on the Net. North Melbourne: Spinifex.

Statistics New Zealand. (2000). Personal use of information technology [online]. Available:

http://www.med.govt.nz/pbt/infotech/itstats2000/itstats2000-04.html [6/7/01]

Stensland Kurokawa, J. (1996). Rural midwifery and electronic communications. Journal of Nurse-Midwifery, 41 (3), 263-264. 
Stewart, S. (1998a). Surfing in Gisborne. New Zealand College of Midwives' Journal, 18,9 .

Stewart, S. (1998b). Surfing in Gisborne. New Zealand College of Midwives' Journal, 19,33 .

Stewart, S. (1999a). Surfing the Net. New Zealand College of Midwives' Journal, 20, 24.

Stewart, S. (1999b). Surfing the Net. New Zealand College of Midwives' Journal, 21, 33.

Stewart, S. (2000a). The New Zealand Midwives' E-mail List: an exploration of e-mail communication and how it can be an invaluable resource for midwives. Biennial New Zealand College of Midwives National Conference. Hamilton. 27- 30 September 2000 .

Stewart, S. (2000b). Surfing the Net. New Zealand College of Midwives' Journal, 22, 25-26.

Stewart, S. (2001). Surfing the Net. New Zealand College of Midwives' Journal, 25, 28.

Stewart, S. (2002a). Surfing the Net. New Zealand College of Midwives' Journal, 26, 24.

Stewart, S. (2002b). Internet research. The Practising Midwife, 5 (4), 42.

Sudweeks, F., \& Simoff, S. (1999). Complementary explorative data analysis: the reconciliation of quantitative and qualitative principles. In S.Jones (Ed.), Doing Internet Research (pp 29-53). Thousand Oaks: Sage.

Te Puni Kokiri/Ministry of Maori Development. (2001). Maori access to information technology. Wellington: Te Puni Kokiri/Ministry of Maori Development.

Thomas, B., Leeseberg Stamler, L., Lafreiere, K, \& Dumala, R. (2000). The Internet: an effective tool for nursing research with women. Computers in Nursing, 18 (1), 13-18.

Thomson, Pru (ph.thomson@xtra.co.nz). (2002, January 8). January newsletter. E-mail to Sarah Stewart (sarahs@tekotago.ac.nz).

Van Carrapiett, D. (1999). Creating Internet web site for nurses. Nursing Standard Online [online], 13 (22), 4 pages. Available: http://www.nursing-standard.co.uk/voll322/ol-art.htm [9/9/99] 
Wagstaff, P. (2000). Surveys. In E, Cluett \& R, Bluff (Eds.), Principles and practice of research in midwifery (pp 57-78). London: Bailliere Tindall.

Ward, R. (2001). Internet skills for nurses. Nursing Standard, 15 (21), 47-53.

Wallace, P. (2001). The Psychology of the Internet. Cambridge: Cambridge University Press.

Walsh, D. (1996). Evidence-based care series: an introduction. British Journal of Midwifery, May, 8 (5), 274-275.

Whitten, P., Steinfield, C., \& Hellmich, S. (2001). E-health: market potential and market strategies. Journal of Computer Mediated Communication [online], 6(4), 23 pages. Available: http://www.ascusc.org/jcmc/vol6/issue4/whitten.html [3/3/02]

Wickham, S. (1999). Post-natal anti-D: exploring midwifery evidence. Midwifery Information and Resource Services Digest, 9 (4), 520-524.

Wickham, S., \& Stewart, S. (2001). Web research - the final frontier? Midwifery Information and Resource Services Digest, 11 (1), 28-31.

Witmer, D., Colman, R., \& Katzman, S.L. (1999). From paper-and-pencil to screen-andkeyboard: toward a methodology for survey research on the Internet. In S.Jones (Ed.), Doing Internet Research. Thousand Oaks: Sage.

Woodlock, D. (1999). Cyberfeminism: Pre-theories [online]. Available: http://www.suite101.com/article.cfm/cyberfeminism/19027 [7/7/01]

Woong Yun, G., \& Trumbo, C. (2000). Comparative response to a survey executed by post, e-mail, \& web form. Journal of Computer Mediated Communication [online], 6 (1), 19 pages. Available: http://www.ascusc.org/jcmc/vol6/issue1/yun.html [8/7/01]

Wyatt, J. (1997). Commentary: measuring quality and the impact of the World Wide Web. British Medical Journal, 314, 1879.

Yellowlees, P. (2000). Healthcare on the Internet: buyers beware. Medical Journal of Australia, 173, 629-630. 


\section{Appendices}

\section{Appendix One}

New Zealand College of Midwives' 'Search for a midwife' (

http://www.midwife.org.nz) 


\section{Appendix Two}

National Institute for Clinical Guidelines web site (http://www.nice.org.uk) 


\section{Appendix Three}

New Zealand College of Midwives' web site 


\section{Appendix Four}

\section{Questionnaire that was developed into web survey}

\section{Section One - Information about your use of the Internet.}

1. Where do you usually use the Internet?

Mainly at home $\quad O$

Mainly at work $\quad O$

Mainly for study at university/polytechnic $\quad \mathrm{O}$

An equal combination of work, recreation and

university/polytechnic $\quad \mathrm{O}$

Cybercafe/library $\quad \mathrm{O}$

Friend/family $\quad \mathrm{O}$

Other $\quad \mathrm{O}$

2. How often do you access the Internet?

Daily $\quad \mathrm{O}$

Once a week $\quad$ O

2-3 times per week $\quad \mathrm{O}$

Once a month $\quad \mathrm{O}$

2-3 times per month $\quad \mathrm{O}$

2-3 times per year $\quad \mathrm{O}$

3. How would you describe your use of the Internet?

Mainly personal (e-mailing friends, banking etc) $\quad \mathrm{O}$

Mainly work (discussion lists, databases etc) $\quad \mathrm{O}$

Mainly study (accessing journals etc) $\quad \mathrm{O}$

An equal combination of personal, work and study $\quad \mathrm{O}$

4. Do you have your own personal e-mail address at (mark as many as you feel apply):

Home

$\mathrm{O}$

Work

$\mathrm{O}$

Institution in which you study 
5. When using the Internet, how do you get help if you need it? (Please mark as many as you feel apply).

Colleagues

Family

Friends

On-line help

Information technology (IT) support at work

IT support at university/polytechnic

Books

Newspapers

Other
$\mathrm{O}$

$\mathrm{O}$

$\mathrm{O}$

Thank you for completing this section. Please go onto the next section

\section{Section Two - Information about your use of the Internet at work.}

1. Do you have access to the Internet at work?

If no, go onto section three. Yes / No

2. If yes, is it easily accessible to you? If no, go to Q. 4 Yes / No

3. What are the main reasons you have used the Internet for work? (Please mark as many as you feel apply).

To keep up to date generally

$\mathrm{O}$

To satisfy a specific information need for yourself

$\mathrm{O}$

To satisfy a specific information need for a colleague

To satisfy a specific information need for a woman in your care

Other

4. Are there barriers to your use of the Internet at work?

If no, go onto Q 6.

Yes / No

5. If there are barriers to your use of the Internet, what are they? (Please mark as many as you feel apply).

Cost of computers

$\mathrm{O}$

Insufficient training

$\mathrm{O}$

Speed of computer/modem

$\mathrm{O}$

Cost of Internet on-line time

$\mathrm{O}$

Insufficient time

$\mathrm{O}$

Other 
6. Have you ever been offered Internet training from your employer?

7. Have you used the Internet to search for midwifery information?

If no, go onto Q 9. Yes / No

8. If yes, how would you describe your experience of finding what you want?

\section{Easy}

Reasonably easy

$\mathrm{O}$

Difficult

$\mathrm{O}$

Impossible

$\mathrm{O}$

9. Have you ever incorporated information found on the Internet into your midwifery practice? If no, please go onto next section Yes/No

10. Please give an example of what information you found on the Internet.

11. Please explain how you made use of that information.

12. Have you ever used the Internet to deliver lectures, tutorials or counselling to under-graduate or post-graduate midwifery students?

Yes / No

Thank you for completing this section. Please go onto the next section 


\section{Section Three - Information about your use of the Internet for study.}

1. Do you have access to the Internet at the institution at which you study? If no, go onto Section Four.

2. If yes, is it easily accessible to you?

3. What are the main reasons you have used the Internet at the institution at which you study? (Please mark as many as you feel apply).

To keep up to date generally

To satisfy a specific information need for yourself

$\mathrm{O}$

To satisfy a specific information need for a colleague

$\mathrm{O}$

To satisfy a specific information need for a woman in your care

Never used the Internet for study

Other
$\mathrm{O}$

$\mathrm{O}$

$\mathrm{O}$

$\mathrm{O}$

4. Are there barriers to your use of the Internet at the institution at which you study?

If no, go onto Q 6.

Yes /

No

5. If there are barriers to your use of the Internet at the institution at which you study, what are they? (Please mark as many as you feel apply).

$\begin{array}{ll}\text { Cost of computers } & \mathrm{O} \\ \text { Insufficient training } & \mathrm{O} \\ \text { Speed of computer/modem } & \mathrm{O} \\ \text { Cost of Internet on-line time } & \mathrm{O} \\ \text { Insufficient time } & \mathrm{O} \\ \text { Other } & \mathrm{O}\end{array}$

6. Have you ever been offered Internet training at the institute at which you study?

7. Have you used the Internet to search for midwifery information at the institution at which you study? If no, go onto Q 9.

Yes /

No 
8. If yes, how would you describe your experience of finding what you want?

Easy

Reasonably easy

Difficult

Impossible
$\mathrm{O}$

$\mathrm{O}$

$\mathrm{O}$

$\mathrm{O}$

9. Have you ever incorporated information found on the Internet into your study? If no, please go onto next section

10. Please give an example of what information you found on the Internet.

11. Please explain how you made use of that information.

12. Have you ever been enrolled on a midwifery or related program of study that has been delivered via the Internet?

Yes / No

Thank you for completing this section. Please go onto the next section

\section{Section Four - Information about your use of the Internet at home.}

1. Do you have access to the Internet at home?

If yes, go onto Q 5.

Yes / No

2. Are you likely to be on-line in the future? If yes, go onto Q3.

If no, go onto Q4.

Yes/No 
3. When are you likely to become connected to the Internet?

Within 6 months

$\mathrm{O}$

Within a year

$\mathrm{O}$

In a year or two

$\mathrm{O}$

\section{Please go onto Section Five}

4. What are the barriers to your use of the Internet at home?

(Please mark as many as you feel apply).

Cost of computers

$\mathrm{O}$

Insufficient training

$\mathrm{O}$

Speed of computer/modem

$\mathrm{O}$

Cost of Internet on-line time

$\mathrm{O}$

Insufficient time

$\mathrm{O}$

Other

$\mathrm{O}$

\section{Please go onto Section Five}

5. What are the main reasons you have used the Internet at home?

(Please mark as many as you feel apply).

To keep up to date generally

To satisfy a specific information need for yourself

$\mathrm{O}$

To satisfy a specific information need for a colleague

$\mathrm{O}$

To satisfy a specific information need for a woman in your care

$\mathrm{O}$

Other

$\mathrm{O}$

$\mathrm{O}$

6. Have you used the Internet to search for midwifery information at home?

If no, go onto next section.

Yes / No

7. If yes, how would you describe your experience of finding what you want?

Easy

$\mathrm{O}$

Reasonably easy

$\mathrm{O}$

Difficult

$\mathrm{O}$

Impossible

$\mathrm{O}$

8. Please give an example of the information you found on the Internet. 
9. Please explain how you made use of that information.

Thank you for completing this section. Please go onto the next section.

\section{Section Five - Information about the use of the Internet by consumers.}

1. Are you aware of an increase in the use of the Internet by women in your care?

2. Has a woman in your care ever shown you information found on the Internet?

3. Has a woman in your care ever talked to you about the information found on the Internet? If no, go onto Q 5.

No

4. If yes, what was your overall impression of the information being accessed?

Very good

Good

Average

Poor

Very poor
$\mathrm{O}$

$\mathrm{O}$

$\mathrm{O}$

$\mathrm{O}$

$\mathrm{O}$

5. Would you be able to critique information found on the Internet? Yes/No

6. Do you think that consumers accessing medical information on the Internet has had an impact on midwifery practice? If no, go onto Q $8 . \quad$ Yes/No 
7. How do you feel about this?

Positive about the impact $\quad \mathrm{O}$

Unsure about the impact $\quad \mathrm{O}$

Concerned about the impact $\quad \mathrm{O}$

Very worried about the impact $\quad \mathrm{O}$

8. Have you ever gained a client because of the Internet?

If no, go onto Section Six. $\quad$ Yes / No

9. If yes, through which avenue?

E-mail communication $\quad \mathrm{O}$

New Zealand College of Midwives 'Search for a midwife' $\quad \mathrm{O}$

Midwifery Today 'Search for a midwife'

Personal web site $\quad \mathrm{O}$

Other $\quad \mathrm{O}$

10. Do you deliver midwifery 'care' via the Internet and e-mail. If yes, go onto next question. If no, go onto next section. Yes / No

11. What form does this care take?

Advice $\quad \mathrm{O}$

Diagnosis $\quad \mathrm{O}$

Prescription of treatment $\mathrm{O}$

Other (Please give examples)

12. What is the frequency you use the Internet or e-mail to deliver midwifery care.

Daily

Once a week

$\mathrm{O}$

2-3 times per week $\quad \mathrm{O}$

Once a month $\mathrm{O}$

2-3 times per month $\quad \mathrm{O}$

2-3 times per year $\mathrm{O}$ 
13. Into which category do these consumers fall (Please mark as many as are appropriate).

A woman in my care.

Casual aquaintance who has approached you because you are known to be a midwife.

$\mathrm{O}$

Unknown person who has contacted you through the Internet.

$\mathrm{O}$

Friend or member of family.

$\mathrm{O}$

Other.

$\mathrm{O}$

Thank you for completing this section. Please go onto the next section.

\section{Section Six - Information about E-mail discussion lists/groups}

1. Do you have experience of e-mail discussion lists for midwives?

If no, go onto Section Seven.

Yes/No

2. If yes, which ones? (Please mark as many as you feel apply).

New Zealand Midwives List (http://www.yahoo.egroups.com) O

Midwifery Research (http://www.jiscmail.ac.uk O

Alaska (http://www.alaska.net/ zeldacrm) O

Oz midwifery (http://www.acegraphics.com.au ) O

Fensende (Swnymph@fensende.com) O

Other $\mathrm{O}$

3. What have you found the advantages to be? (Please mark as many as you feel apply).

Good means of networking

$\mathrm{O}$

Great for tracking down information $\quad \mathrm{O}$

Stimulating discussion $\quad \mathrm{O}$

Invaluable way of keeping up to date $\mathrm{O}$

Facilitates reflection of practice $\quad \mathrm{O}$

Provides collegial support $\quad \mathrm{O}$

Facilitates collegial collaboration $\quad \mathrm{O}$ 
4. What have you found the disadvantages to be?

Too much social chitchat $\quad \mathrm{O}$

Too many messages posted $\quad \mathrm{O}$

Not enough messages posted $\quad \mathrm{O}$

Needs some sort of editorial control $\quad \mathrm{O}$

Lazy way of doing research $\quad \mathrm{O}$

Too much conflict $\quad \mathrm{O}$

Discussion has no relevance to my own professional needs $\quad \mathrm{O}$

5. Have you ever changed your practice as a result of

e-mail discussion?

Yes / No

Thank you for completing this section. Please go onto the next section.

\section{Section Seven - Information about Internet resources available to midwives}

1. Which resources have you made use of? (Please mark as many as are applicable).

Electronic journals $\quad \mathrm{O}$

Job advertisements $\quad \mathrm{O}$

Bibliographic databases eg Medline $\quad \mathrm{O}$

Statutory bodies eg Nursing Council of New Zealand

Midwifery book/video/resource shop eg Ace Graphics, MIDIRS

On-line tutorials

Reports and research papers

E-mailed newsletter/updates eg Midwifery Today newsletter $\quad \mathrm{O}$

Support groups

$\mathrm{O}$

Conference and Course details

$\mathrm{O}$

Professional bodies eg New Zealand College of Midwives

$\mathrm{O}$

Other (Please specify) 
2. What resources do you think will be useful to access in the future? (Please mark as many as are applicable).

Electronic journals $\quad \mathrm{O}$

Job adverts $\quad \mathrm{O}$

Bibliographic databases eg Medline $\quad O$

Statutory bodies eg Nursing Council of New Zealand O

Midwifery book/video/resource shop eg Ace Graphics, MIDIRS O

On-line tutorials $\quad \mathrm{O}$

Reports and research papers $\mathrm{O}$

E-mailed newsletter/updates eg Midwifery Today newsletter $\quad \mathrm{O}$

Support groups $\quad \mathrm{O}$

Conference and Course details $\quad \mathrm{O}$

Professional bodies eg New Zealand College of Midwives $\quad \mathrm{O}$

Other (Please specify)

3. Do you have your details on the New Zealand

College of Midwives web sites? $\quad$ Yes / No

4. Do you have your own web site? Yes / No

5. Have you ever used any medical databases via the Internet?

If no, go onto Q 7.

Yes / No

6. If yes, which ones? (Please mark as many as you feel apply).

Medline $\quad \mathrm{O}$

Cochrane $\quad$ O

CINHAL $\quad$ O

ERIC

Other $\quad \mathrm{O}$

7. Generally, how did you find the databases to use?

Easy to use $\quad \mathrm{O}$

Not very easy $\quad \mathrm{O}$

Not at all easy $\quad \mathrm{O}$

8. The MIDIRS Midwifery Database is available on the Internet.

Do you use it on the Internet? Yes / No

10. If no, are you likely to use it in the future? Yes / No 
11. If you have a favourite web site which is very useful in your midwifery practice, what is it?

12. If there was a resource for midwives you would like made available on the Internet, what would it be?

Thank you for completing this section. Please go onto the next section.

Section Eight - This section will ask for your personal information in order for statistical classifications and comparisons to be made.

1. Which best describes your job? Mark as many as are applicable.

Hospital midwife

LMC midwife - employed

LMC midwife - self-employed

Research midwife

Midwifery lecturer

Midwifery manager

Urban midwife

$\mathrm{O}$

Rural midwife

$\mathrm{O}$

Not practicing at the moment

$\mathrm{O}$

Other (Please specify)

2. Which age group are you?

Under 25

$\mathrm{O}$

25-34

$\mathrm{O}$

$35-44$

$\mathrm{O}$

$35-45$

$\mathrm{O}$

45-54

$\mathrm{O}$

55 and over 


\section{Employment status}

Full-time $\quad$ O

Part-time $\quad$ O

Not working $\quad$ O

Student $\quad$ O

4. How many years have you been qualified?

Less than one year $\quad \mathrm{O}$

$1-4$ years $\quad O$

5 - 9 years $\quad O$

$10-14$ years $\quad O$

$15-19$ years $\quad \mathrm{O}$

20 - 24 years $\quad \mathrm{O}$

25 - 29 years $\quad \mathrm{O}$

30 - 34 years $\quad \mathrm{O}$

35 years and over $\mathrm{O}$

5. If you are currently a post-graduate student, or have completed formal education within the last three years, please give details of the course. 


\section{Appendix Five}

Web survey 


\section{Appendix Six}

Web site 


\title{
Appendix Seven
}

\section{E-mail information letter}

\author{
Dear Colleague
}

My name is Sarah Stewart and I am a registered midwife and midwifery lecturer at Otago Polytechnic, Dunedin. I am currently enrolled in the MA (Applied) Midwifery at the Victoria University of Wellington. I am very interested in how midwives use the Internet, and aim to survey as many registered midwives who use the Internet in New Zealand as possible.

I would be really grateful if you would take the time and fill in the questionnaire that I have developed. The questionnaire can be accessed at:

\section{http://www.midwifesurvey.co.nz}

All you need to do is click once on the above web site address, if your computer software allows. You can also open the address through a browser such as Microsoft Internet Explorer or Netscape.

To access the questionnaire you will need to fill in the following password.

\section{VERTEX}

This is to protect the questionnaire from being accessed by unauthorised people. You will also be asked to fill in your name and e-mail address. This is to provide a way of screening for bogus surveys. Your name and e-mail address will not be recorded. Check out the web site for further information.

I would be very grateful if you would take the time and complete the survey, which shouldn't take any longer than $10-15$ minutes.

In order for this questionnaire to reach as many midwives as possible, I would very much appreciate your help by sending on this e-mail to five or more midwifery colleagues. It would also be very valuable for this project if you would confirm you received this information by e-mailing me a short note of confirmation. I will then be able to use the information to track how far the electronic network extends in New Zealand. The e-mail addresses will stay completely confidential. I will not be publishing any details of e-mail addresses. The questionnaire itself will be anonymous so I will not know who has actually completed the survey. 
For further information about the research, access the above web site or e-mail me at:

\section{sarahs@tekotago.ac.nz}

I would like to take the opportunity to thank you for taking part in this research. I would also like to thank you for taking the time to post on the details of this research to other midwives, and confirm you received this e-mail.

I hope you enjoy completing the questionnaire.

\section{Sarah Stewart}




\title{
Appendix Eight
}

Consent forms for computer programmer and statistician

\author{
SCHOOL OF MIDWIFERY \\ FACULTY OF HEALTH AND COMMUNITY \\ Forth Street, Private Bag 1910 \\ Dunedin, New Zealand \\ Direct Dial Phone +64 34793642 \\ Facsimile +6434741957 \\ Email SARAHS@tekotago.ac.nz \\ Homepage http://www.tekotago.ac.nz
}

$3^{\text {rd }}$ May 2001

I, Gareth Bowen, of (address)

am the computer programmer who is working with Sarah Stewart to develop and maintain the Internet World Wide Web survey that she is using as a research tool for her MA (Applied) Midwifery. I am responsible for the technical support of this survey.

I agree to maintain the anonymity of all participants, and destroy any evidence of e-mail addresses when data collection is complete.

I also agree to treat all information in the strictest of confidence.

Signature

Date.

Witness

Date 


\section{SCHOOL OF MIDWIFERY \\ FACULTY OF HEALTH AND COMMUNITY \\ Forth Street, Private Bag 1910 \\ Dunedin, New Zealand \\ Direct Dial Phone +64 34793642 \\ Facsimile +6434741957 \\ Email SARAHS@tekotago.ac.nz \\ Homepage http://www.tekotago.ac.nz}

$3^{\text {rd }}$ May 2001

I, Sheridan Massey, of (address)

am the statistician working with Sarah Stewart to analyse the data generated by the Internet World Wide Web survey that she is using in her research for her MA (Applied) Midwifery.

I agree to maintain the anonymity of all participants.

I also agree to treat all information in the strictest of confidence.

Signature

Date.

Witness

Date 